Prepared in cooperation with the U.S. Department of Agriculture, Office of Environmental Markets

\title{
Biodiversity and Habitat Markets-Policy, Economic, and Ecological Implications of Market-Based Conservation
}

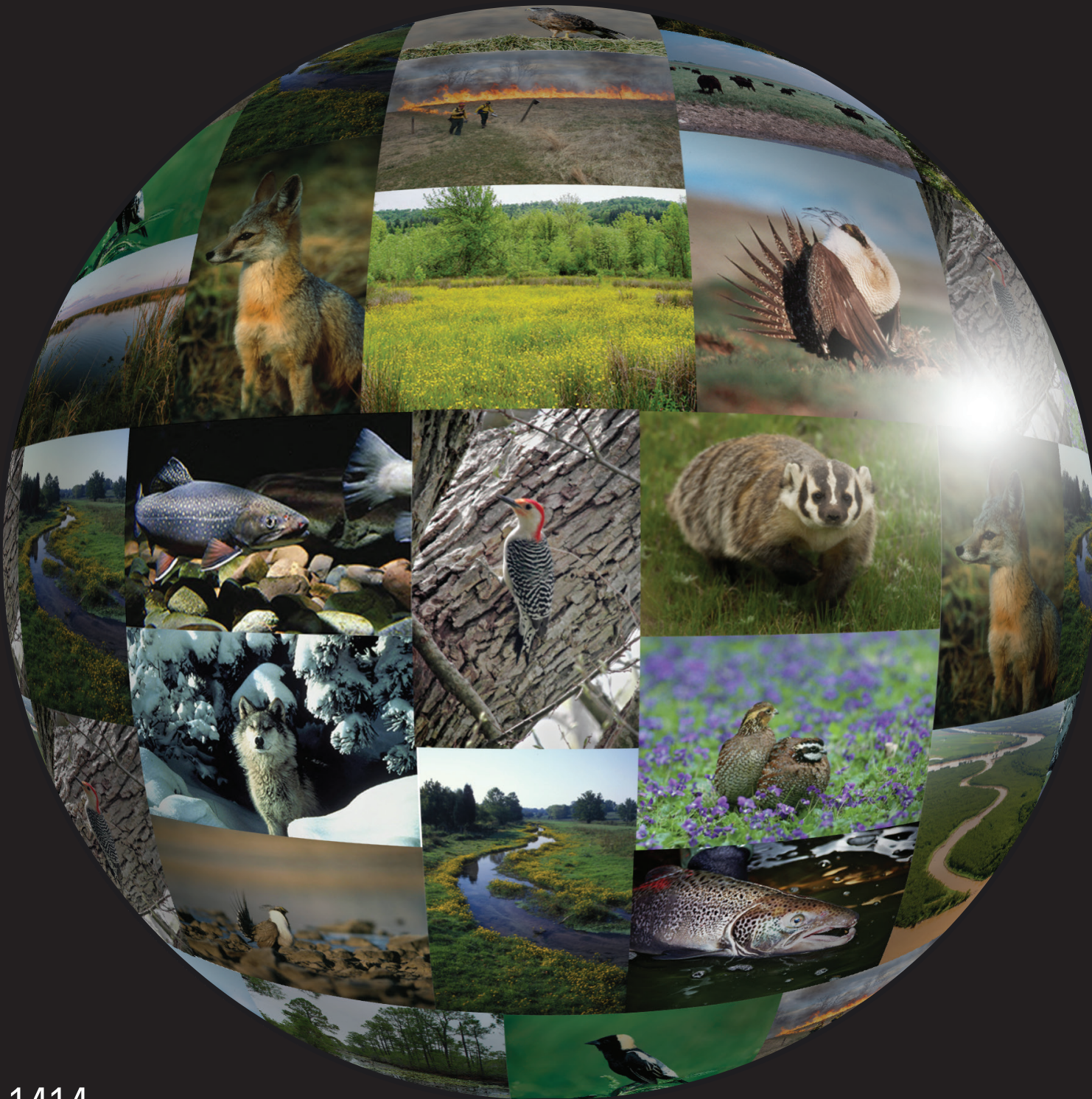

Circular 1414

U.S. Department of the Interior

U.S. Geological Survey 
Cover. Compilation of wildlife and habitat photographs found in the report. Original design by Shonté Jenkins, U.S. Geological Survey. 


\section{Biodiversity and Habitat Markets-Policy, Economic, and Ecological Implications of Market-Based Conservation}

By Emily Pindilli and Frank Casey

Prepared in cooperation with the U.S. Department of Agriculture, Office of Environmental Markets

Circular 1414 


\title{
U.S. Department of the Interior SALLY JEWELL, Secretary
}

\section{U.S. Geological Survey \\ Suzette M. Kimball, Acting Director}

\author{
U.S. Geological Survey, Reston, Virginia: 2015
}

For more information on the USGS - the Federal source for science about the Earth, its natural and living resources, natural hazards, and the environment—visit http://www.usgs.gov or call 1-888-ASK-USGS.

For an overview of USGS information products, including maps, imagery, and publications, visit http://www.usgs.gov/pubprod/.

Any use of trade, firm, or product names is for descriptive purposes only and does not imply endorsement by the U.S. Government.

Although this information product, for the most part, is in the public domain, it also may contain copyrighted materials as noted in the text. Permission to reproduce copyrighted items must be secured from the copyright owner.

Suggested citation:

Pindilli, Emily, and Casey, Frank, 2015, Biodiversity and habitat markets-Policy, economic, and ecological implications of market-based conservation: U.S. Geological Survey Circular 1414, 60 p., http://dx.doi.org/10.3133/cir1414.

ISSN 1067-084X (print)

ISSN 2330-5703 (online)

ISBN 978-1-4113-3977-4 


\section{Acknowledgments}

The authors would like to thank Dr. Chris Hartley and Ms. Kathryn Zook of the U.S. Department of Agriculture Office of Environmental Markets for the ongoing support and guidance in developing this circular. The authors would also like to acknowledge the thoughtful review and insights provided by Dr. Carl Shapiro and the research support provided by Mr. Patrick Prendergast of the U.S. Geological Survey Science and Decisions Center. The authors are especially grateful to Sarah Cline (Department of the Interior, Office of Policy Analysis), Marc Ribaudo (Department of Agriculture, Economic Research Service), and Sara Vickerman (formerly of Defenders of Wildlife) for their technical review of the circular. Finally, the development of this circular relied on input from experts and practitioners in biodiversity and habitat markets. The authors would like to thank the following people for contributing their time and sharing their knowledge on the topic: Jim Caudill (U.S. Fish and Wildlife Service (FWS)), Deblyn Mead (FWS), Ted Maillet (FWS), Susan Culliney (Lewis and Clark Law School), Ted Toombs (Environmental Defense Fund), Patrick Coady (Coady Diemar), Sara Obrien (Willamette Partnership), Bobby Cochran (Willamette Partnership), Shauna Ginger (FWS), Todd Gartner (World Resources Institute), Kevin Halsey (Ecometrix Solutions), Josh Donlan (Advanced Conservation), Eric Sprague (Alliance for the Chesapeake Bay), and Doug Bruggeman (Ecological Services and Markets). 


\section{Contents}

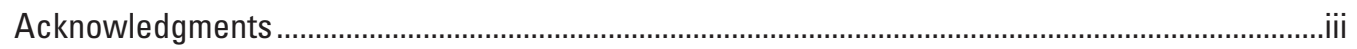

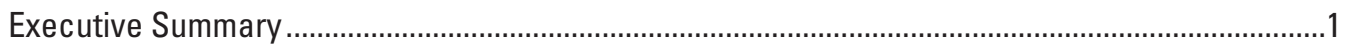

Chapter A —Introduction to Biodiversity and Habitat Markets ....................................................

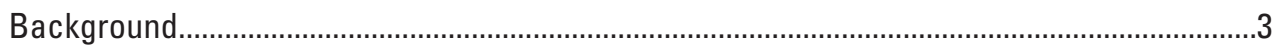

Provision of Biodiversity Benefits ......................................................................................

Introduction to Environmental Markets ...........................................................................

Introduction to Market-Based Conservation Mechanisms .......................................................

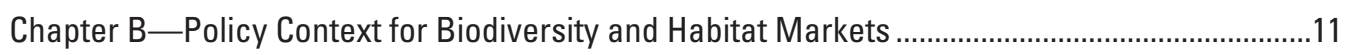

Payment for Ecosystem Services ......................................................................................11

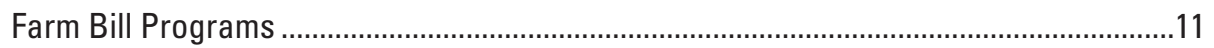

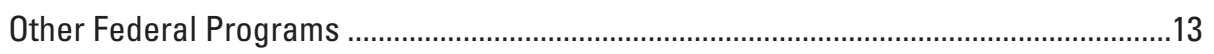

State and Local Compensation Programs .................................................................14

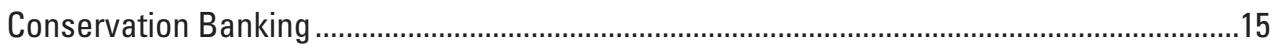

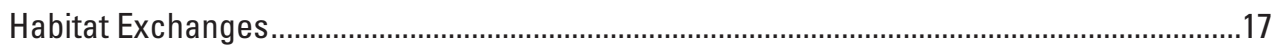

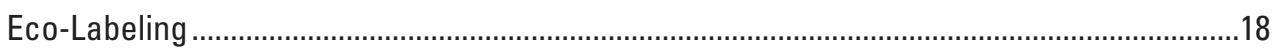

Institutional Incentives ..............................................................................................18

Summary of Biodiversity and Habitat Markets Policy Context ..............................................19

Chapter C - Structural Components of Conservation Mechanisms ................................................21

Market-Like Payments for Ecosystem Services.................................................................21

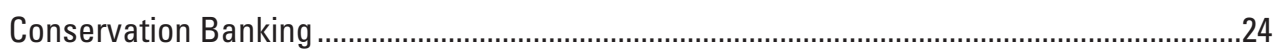

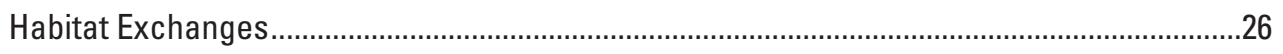

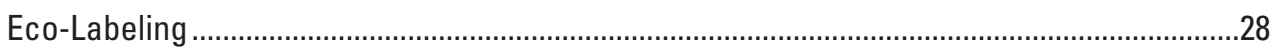

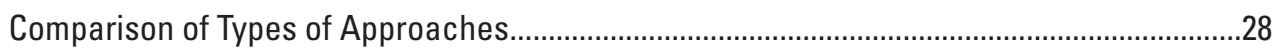

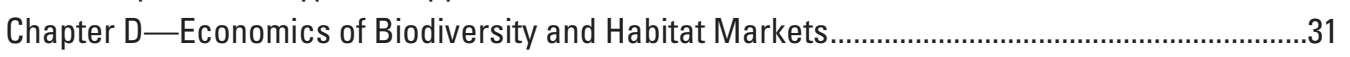

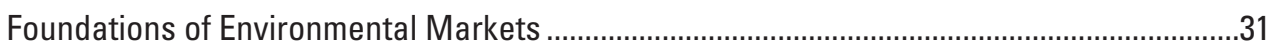

Biodiversity Specific Market Considerations ………...............................................................3

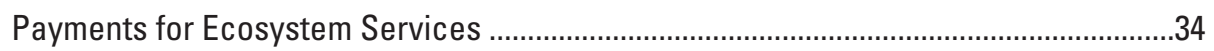

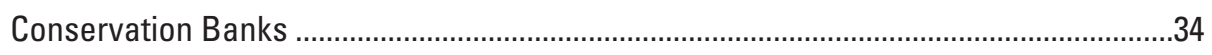

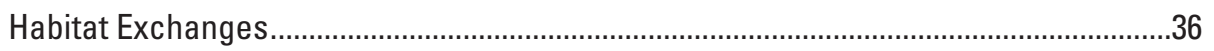

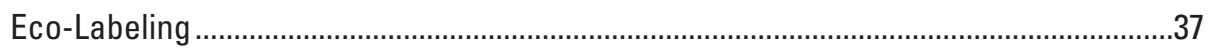

Chapter E-Performance Measurement in Biodiversity and Habitat Markets ...............................39

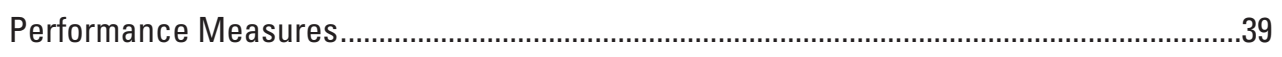

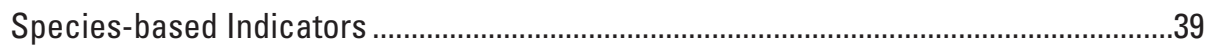

Habitat-based Indicators...........................................................................................

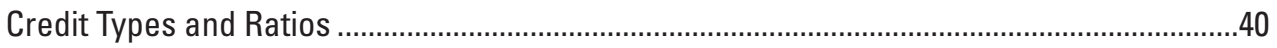

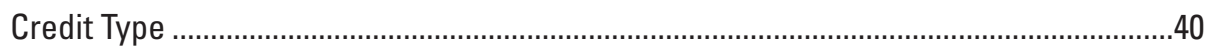

Credit Metrics and Ratios.....................................................................................

Tools to Support Biodiversity and Habitat Markets ...............................................................

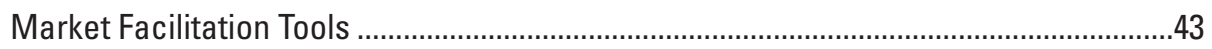

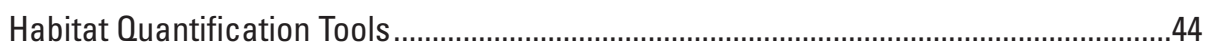

Verification and Monitoring of Conservation Benefits .................................................45

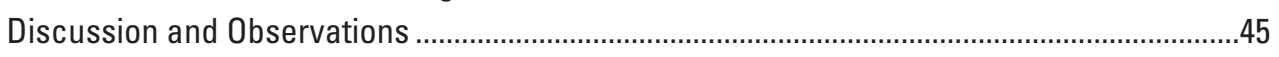




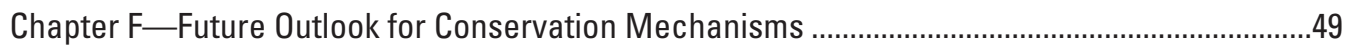

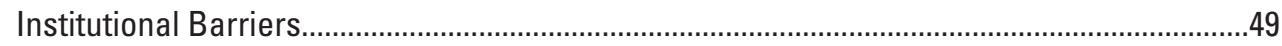

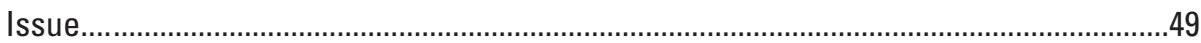

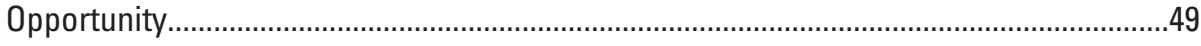

Outlook

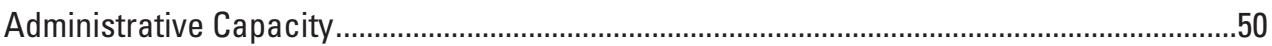

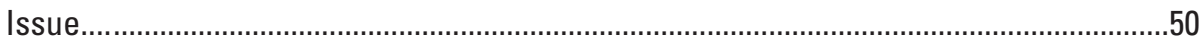

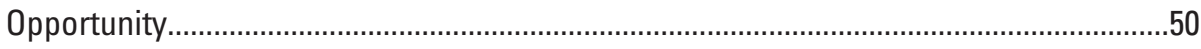

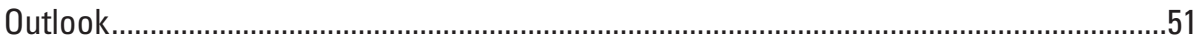

Alternative Mitigation.....................................................................................................

Issue

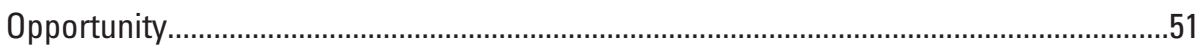

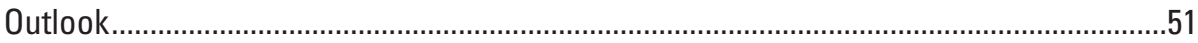

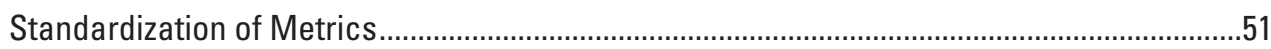

Issue

Opportunity

Outlook

Habitat Quantification Tools .......................................................................................

Issue

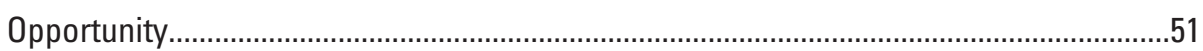

Outlook

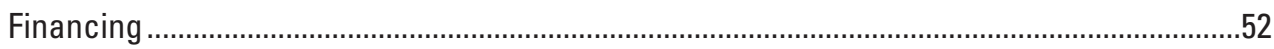

Issue

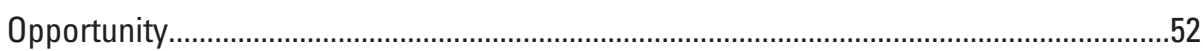

Outlook

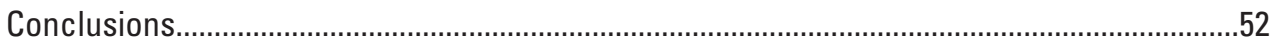

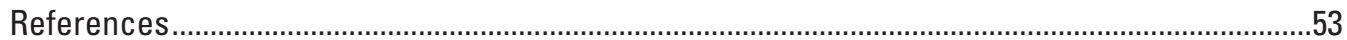




\section{Figures}

1. Diagram showing the differences between developer and societal preferences for land use defined graphically

2. Graph showing the acres of habitat that benefited annually from the Conservation Reserve Program from 1992 through 2012

\section{Tables}

1. Examples of direct, prescriptive, market-like, and market-based types of biodiversity conservation mechanisms

2. Examples of direct, prescriptive, market-like, and market-based types of biodiversity conservation mechanisms

3. Summary of the regulatory authorities (legislation) for each major program within the market-like or market-based conservation mechanism types.........................19

4. Descriptions of components of conservation mechanisms .............................................21

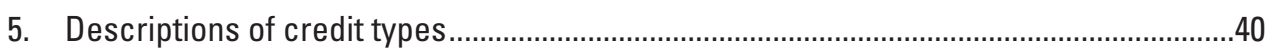

6. Sample conservation bank projects from the Army Corps of Engineer's Regulatory In-lieu fee and Bank Information Tracking System (RIBITS)

7. Summary of biodiversity and habitat market issues, opportunities, and future outlook 


\section{Abbreviations}

\begin{tabular}{ll} 
ACEP & Agricultural Conservation Easement Program \\
CFAA & Cooperative Forestry Assistance Act \\
CRP & Conservation Reserve Program \\
CSP & Conservation Stewardship Program \\
DOI PPA & U.S. Department of the Interior, Office of Policy Analysis \\
ECAS & Ecosystem Credit Accounting System \\
EDF & Environmental Defense Fund \\
EPA & U.S. Environmental Protection Agency \\
ESA & Endangered Species Act \\
FAO & Food and Agriculture Organization of the United Nations \\
FLP & Forest Legacy Program \\
FWS & U.S. Fish and Wildlife Service \\
GAO & U.S. Government Accountability Office \\
HOT & Habitat Ouantification Tools \\
IUCN & International Union for Conservation of Nature \\
NFWF & National Fish and Wildlife Program \\
NMFS & U.S. National Marine Fisheries Service \\
NOAA & National Oceanic and Atmospheric Administration \\
NRCS & U.S. Natural Resources Conservation Service \\
NWF & National Wildlife Federation \\
PES & Payments for Ecosystem Services \\
PFWP & Partners for Fish and Wildlife Program \\
RCPP & Regional Conservation Partnership Program \\
RIBITS & Regulatory In-lieu fee and Bank Information Tracking System \\
SHA & Safe Harbor Agreement \\
USACE & U.S. Army Corps of Engineers \\
USDA & U.S. Department of Agriculture \\
USFS & U.S. Forest Service (USDA) \\
WHIP & Wildlife Habitat Incentive Program \\
\hline
\end{tabular}




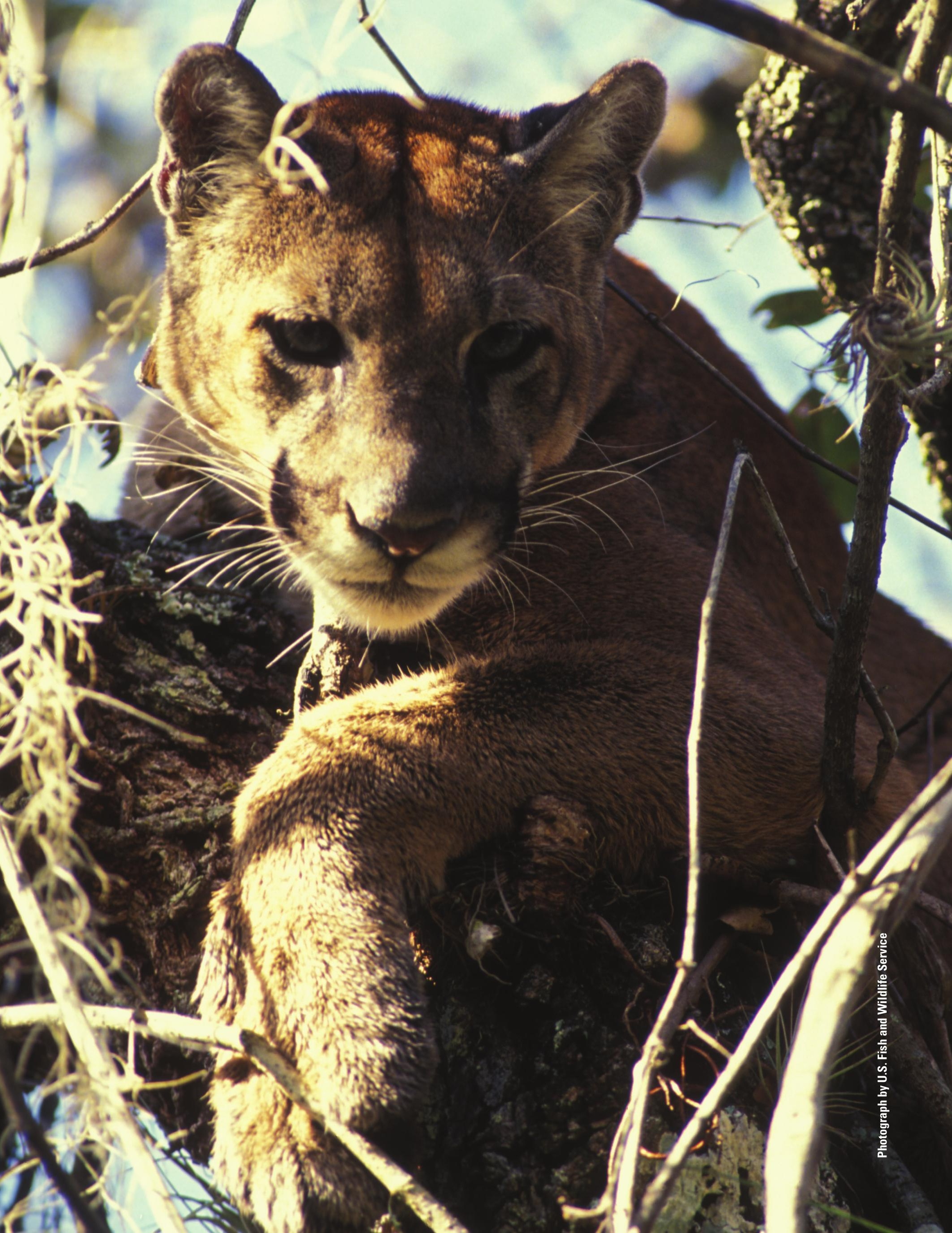




\title{
Biodiversity and Habitat Markets-Policy, Economic, and Ecological Implications of Market-Based Conservation
}

\author{
By Emily Pindilli and Frank Casey
}

\section{Executive Summary}

The United States is experiencing significant losses of biodiversity, species, and unique habitats (International Union for the Conservation of Nature (IUCN), 2014). This circular explores the policy context, structure, ecological effectiveness, and tools associated with market-based mechanisms for biodiversity and habitat conservation. The theoretical basis for applying market-based approaches and the outlook for these markets are also described. The focus of this circular is on market-like and market-based incentives for individual species conservation rather than biodiversity in the more holistic sense, although incentives for conservation of a species' habitat can have broad impacts across other species that constitute biodiversity in a given target area.

Why is there a need for market-based approaches to conserve biodiversity and habitat? The benefits of providing biodiversity - a public good — often do not accrue to the landowner. Market-based mechanisms use incentives to leverage market forces. These incentives may be driven by regulation or other forces such as consumer preferences for 'green' products. Another way to achieve conservation is via prescriptive regulation; however, economic theory lends itself to approaches that can achieve the same benefits with a more efficient and less costly allocation of resources.

What are the market-based mechanisms for biodiversity and habitat conservation? Table 1 summarizes the types of market-based conservation mechanisms. They are classified by the type of incentive they provide.

Payments for Ecosystem Services (PES) “...is... a voluntary, conditional agreement between at least one 'seller' and one 'buyer' over a well-defined environmental service..." (Wunder, 2007). PES programs may be funded by the government or other groups, such as nonprofit organizations or businesses.

Market-Based Compensatory Mitigation Programs have a regulatory requirement for one party to offset the environmental impacts of their activities. The U.S. Fish and Wildlife Service's (FWS) conservation banking program is a prime example. A conservation bank is "a site where habitat or other ecosystem resources are conserved and managed in perpetuity for listed species ..." (FWS, 2003). Conservation banks sell credits that represent an expected ecological outcome to offset impacts.

Habitat exchanges provide a marketplace platform that allow for the trade of credits from conservation banks along with credits from other market-based biodiversity conservation efforts. The exchange concept applies conservation banking more broadly to regulatory and pre-compliance markets that can address candidate species or other voluntary habitat conservation scenarios. Pre-compliance demand is based on reducing regulatory uncertainty regarding future development and land use activities by providing species conservation.

Eco-labeling is an approach to differentiate a product based on how it is produced, in this case if it supports a species, habitat, or overall biodiversity in a specific place or type of habitat. By differentiating a product, consumers may shop more selectively and be willing to pay more; in turn, this provides an incentive for landowners or producers to conduct biodiversity-enhancing activities.

What drives biodiversity and habitat conservation markets? Federal, State, and local government policies can drive market-based conservation mechanisms. The Endangered Species Act and the Farm Bill(s) provide the regulatory basis for many of the markets considered in this circular. It is important to note that although a regulation may compel mitigation, participation in a market is always voluntary.

Some mechanisms do not rely on regulation, as with eco-labeling. For this mechanism, consumer preference is the incentive. Habitat exchanges are designed to provide a platform for both compensatory and voluntary credits.

What influences the success of biodiversity and habitat markets? The biodiversity conservation mechanisms each have different specifications for their major structural components as a result of regulation, program management, or by design, to address specific issues. The structural elements considered in this circular include land eligibility, site selection, approval process, management practices, term, credit determination, trade, and other conditions. The specifications can affect landowners' willingness to participate in programs and the biodiversity outcomes that are achieved.

Ecological performance is also influenced by the design of the program: specifically the method for biodiversity or habitat measurement. Market-based mechanisms rely on an indicator that may be either performance- or practice-based. 
Practice-based measurement assumes that installation of a conservation practice will result in the desired ecological outcome. Performance-based measurement requires evidence that the intended biophysical results are being obtained.

The complexity of what constitutes biodiversity, measuring outcomes, and establishing markets is challenging. Biodiversity benefits depend on source, location, size of available habitat, ecological context, and the initial conditions of a site. Habitat quantification and monitoring tools can improve the success of markets.

There are two classes of tools that facilitate biodiversity and habitat markets: habitat quantification tools (HQTs) and market support tools. Market support tools provide protocols and platforms to assess biodiversity benefits. HQTs use ecological information about species and habitats of concern to provide improved metrics that assess biodiversity baselines and improvement.

What is the outlook for biodiversity and habitat markets? In the U.S., there are numerous threats to biodiversity and wildlife habitat: the transformation of land from habitat to agriculture; residential, commercial, and industrial development; energy and mineral production; and, climate change. This circular highlights issues that inhibit wider adoption and success of biodiversity and habitat markets. The most significant are institutional barriers, administrative capacity, alternative mitigation, standardization of metrics, lack of HQTs, and lack of financing.
There are significant challenges to extend trading programs, which have enjoyed great success curbing air emissions to biodiversity and habitat, which are localized, complex, and difficult to measure. There are also numerous opportunities to increase the adoption and success of these markets.

Although somewhat constrained, there has been marked growth in the utilization of market-based approaches for biodiversity and habitat conservation in the U.S. over the last few decades. The implementation of federal market-based mechanisms for compensatory species mitigation has largely been achieved due to the efforts of individuals in the FWS. From a nascent market in California, conservation banking has expanded to other states with a record of delivering conservation benefits for species. The potential expansion to species not yet listed represents a much broader marketplace.

PES programs have a long history. The move towards targeting high yield land, employing habitat quality metrics, and even employing performance-based metrics indicates that PES programs can adapt to address the growing awareness that biodiversity and habitat are crucial to national prosperity and well-being.

Eco-labeling markets have remained largely regional, but continued consumer preferences for 'green' products provide the opportunity for the expansion of this market approach. Addressing the challenges and taking advantage of the opportunity to promote and grow biodiversity and habitat markets can help protect the Nation's wildlife.

Table 1. Examples of direct, prescriptive, market-like, and market-based types of biodiversity conservation mechanisms.

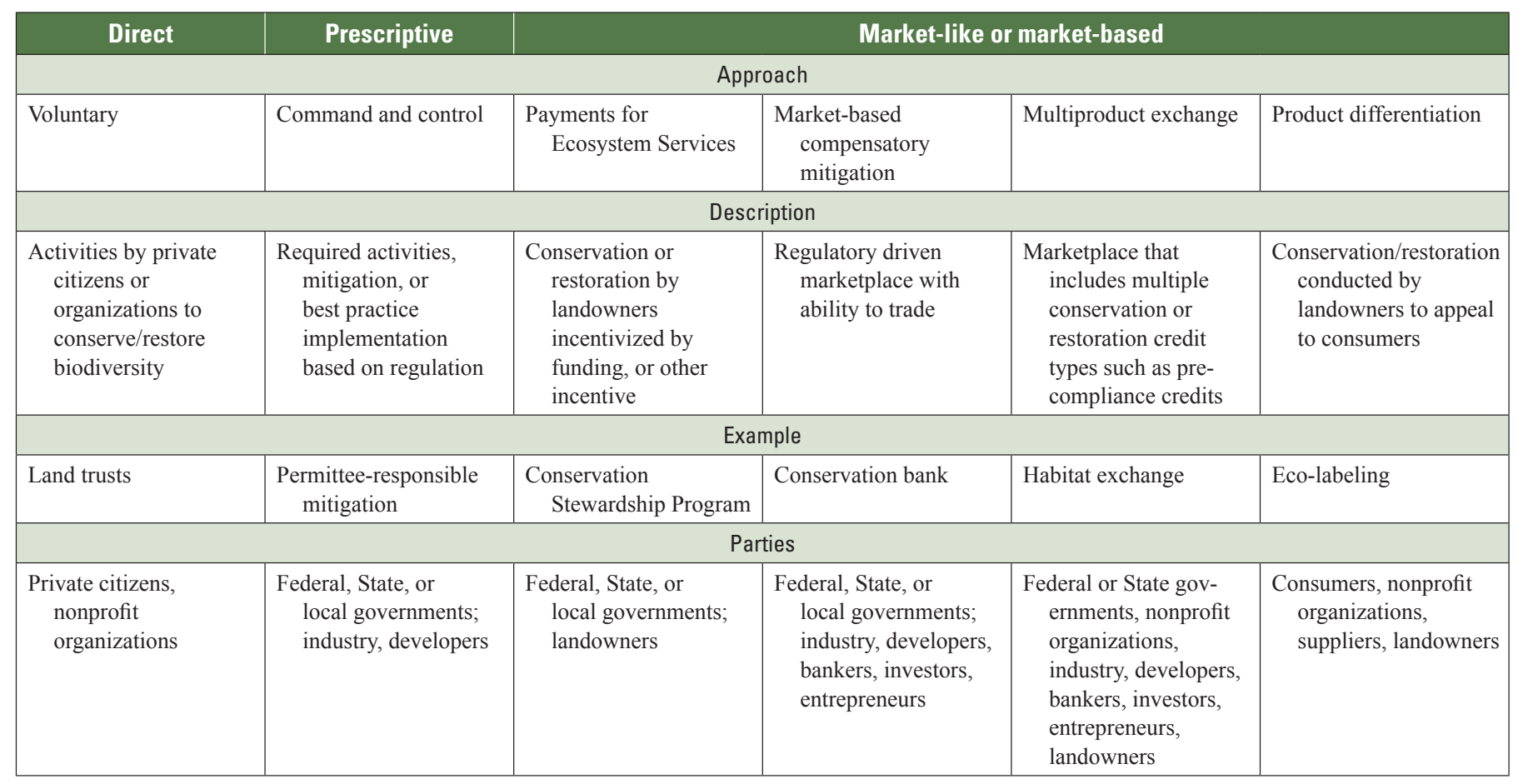




\section{Chapter A—Introduction to Biodiversity and Habitat Markets}

The United States is home to a remarkable variety of wildlife. Biological diversity (hereafter referred to as 'biodiversity') and unique habitats provide substantial benefits to humans. In the Endangered Species Act (2003), Congress states that "....species of fish, wildlife, and plants are of esthetic, ecological, educational, historical, recreational, and scientific value to the Nation and its people". The rate of loss for biodiversity, species, and unique habitats is significant (IUCN, 2014). In 2014, the International Union for Conservation of Nature (IUCN) reported that the United States had 1,006 animal species facing imminent extinction due to human activity; this represents nearly 20 percent of all animal species in the country. Numerous public and private incentive mechanisms exist to protect and conserve biodiversity and habitat (Casey and others, 2006). The Federal Government, States, localities, academia, businesses, non-governmental organizations, and individuals are engaged in some or all of these activities.

This circular is a primer on market-like and market-based mechanisms designed to conserve biodiversity and habitat. The types of markets and market-based approaches that were implemented or are emerging to benefit biodiversity and habitat in the United States are examined. The central approaches considered in this circular include payments for ecosystem services, conservation banks, habitat exchanges, and eco-labels. Based on literature reviews and input from experts and practitioners, the circular characterizes each market-based approach including policy context and structure; the theoretical basis for applying market-based approaches; the ecological effectiveness of practices and tools for measuring performance; and the future outlook for biodiversity and habitat markets. This circular draws from previous research and serves as a summary of pertinent information associated with biodiversity and habitat markets while providing references to materials that go into greater detail on specific topics. The circular is organized into the clearly defined chapters:
A. Introduction to Biodiversity and Habitat Markets
B. Policy Context for Biodiversity and Habitat Markets
C. Structural Components of Conservation Mechanisms
D. Economics of Biodiversity and Habitat Markets
E. Performance Measurement in Biodiversity and Habitat Markets

\section{F. Future Outlook for Conservation Mechanisms}

The remainder of this chapter provides additional background on biodiversity and habitat markets, discusses the provision of biodiversity benefits, introduces environmental markets, and describes market-based mechanisms. Chapter B explores the regulatory context for biodiversity markets and identifies how regulation can drive or constrain these markets. Chapter $\mathrm{C}$ delves into more detail on the conservation mechanisms' structure, provides additional examples, and highlights the components of each that help or hinder market efficiency and effectiveness. Chapter D considers the economic foundations for biodiversity markets and explores the efficiency and potential of market-like structures and processes. Chapter E describes the types of measures used to estimate effectiveness, determine credits, and develop habitat quantification tools. Finally, Chapter F draws conclusions on the current status of biodiversity and habitat markets, provides an indication of their future outlook, and identifies opportunities to overcome challenges to future development and success in these markets.

\section{Background}

In 2011, the U.S. Department of Agriculture (USDA) funded the Willamette Partnership, a nonprofit coalition dedicated to increasing the pace, scope and effectiveness of restoration, to evaluate the measures and metrics employed to assess the impact of conservation efforts on biodiversity. Building on the Willamette Partnership Study, this circular assesses how the policy context, structural design, and other factors influence the success of market-based mechanisms to provide biodiversity benefits. To consider the state of and potential for biodiversity and habitat markets, a clear definition of biodiversity and the activities that deliver positive biodiversity outcomes must first be established. "At its simplest level, biodiversity is the sum total of all the plants, animals, fungi and microorganisms in the world, or in a particular area; all of their individual variation; and all the interactions between them" (Raven, 1994).

Measuring biodiversity is a complex task: "Assessment and monitoring [of biodiversity] are only possible for specific aspects or particular, defined goals" (Food and Agriculture Organization of the United Nations (FAO), 2010). Some proxy measures have emerged to characterize biodiversity. Species 
Biodiversity and Habitat Markets: Policy, Economic, and Ecological Implications of Market-Based Conservation

richness is a measure often used to assess biodiversity in a particular area; however, this measure has weaknesses, including inconsistencies in measurement (Gotelli and Colwell, 2001). Additional indicators of biodiversity are the existence of rare or threatened species (Caro, 2010).

With threats to species driving biodiversity losses, biologists often use endangered species as an indicator of biodiversity. The loss of these species often represents a loss to an ecosystem's overall diversity. This circular discusses mechanisms focused on endangered and threatened species as well as other indicators, such as wildlife habitat.

This circular focuses on market-like and market-based incentives for individual species conservation rather than biodiversity in a holistic sense, although incentives for conservation of a species' habitat can have broad impacts across the species that make up biodiversity in a given area. An area suited for further research into market-based mechanisms is comprehensive strategies that integrate considerations about maintaining and restoring ecosystems essential to biodiversity at all scales - genetic, species, ecosystems and landscapes. One way of doing this is to apply the market concept to broader-scale planning and management that considers fish and wildlife needs alongside other ecological goals like clean water, clean air, and protection from floods, fire, and other natural and anthropogenic disturbances. An awareness of the need to address a variety of threats at appropriate scales is becoming more apparent. For example, hydrologic processes, invasive species, fire, human development, and climate change all occur on broad scales and cannot be addressed on a speciesby-species or site-by-site basis. These larger-scale assessments are critical to the identification and selection of priority sites for development and conservation, and more widely based "ecosystem service markets" may be more efficient for achieving larger-scale biodiversity conservation goals. Examples of addressing broader-scale biodiversity include Vickerman and Kagan (2014) and Culliney (2014). Research on the challenges and opportunities associated with broader-scale market mechanisms is an important need.

The Willamette Partnership defines biodiversity benefits as the "range of variables used to describe species population status and trend, habitat conditions, and ecological processes, as well as biodiversity values of a given area" (Willamette Partnership, 2011). Adopting this concept, biodiversity benefits in the context of this circular includes the protection, conservation, or restoration of biodiversity, species, or habitat and is limited to the United States.

Biodiversity benefits can be achieved on public and private land by nonprofit organizations, private citizens, Federal, State, or local government, and others. The 'place' where biodiversity benefits are received is termed the benefit site; this may be a geographic location where land is preserved, restored, or created to support biodiversity at a given level. Mitigation site is used interchangeably with benefit site. Impact sites are the geographic locations where some disturbance reduces or changes the composition of biodiversity. Within the scope of the current study, an impact site is a human-induced disturbance. Polluters is used as a general term to refer to those conducting activities that disturb, pollute, or otherwise negatively impact biodiversity. ${ }^{1}$

There are many economic and institutional mechanisms used to achieve biodiversity conservation (Casey and others, 2006). These mechanisms are identified as conservation mechanisms. Conservation mechanisms can be direct, voluntary activities; they can be prescriptive based on regulation; or they can be market-based or incentive driven. Direct, voluntary activities are actions that a private citizen or organization undertake to preserve or restore biodiversity based on their preference for biodiversity benefits. An example of this is a land trust that invests in land conservation. This circular focuses on market-based approaches and does not further consider direct, voluntary conservation mechanisms. Finally, the circular is limited to mechanisms that benefit biodiversity as a primary goal and does not include mechanisms that provide biodiversity as a co-benefit (such as wetland mitigation banks).

The implementation of regulations can take a prescriptive approach (for example, command and control) or a marketbased approach. Command and control approaches compel polluters to comply with specific parameters such as the use of best practices, use of specific technology, or the restriction of certain activities. While market-based approaches adhere to strict guidelines in the implementing of policy or programs, they provide additional flexibility for achieving biodiversity benefits in comparison to command and control methods (EPA, 2010). Command and control methods are considered to the extent that they provide a comparison with market-based alternatives to achieve biodiversity benefits. However, this circular does not include a comprehensive review of command and control approaches that benefit biodiversity.

Market-based or market-like approaches rely on incentives for biodiversity benefits. They may be voluntary or driven by regulation. Market-based approaches allow prices (or payments) to be determined through market exchange. Similar mechanisms, often considered as "market-like," rely on a fixed price that can be determined by the cost of a practice or by another approach. Market-like approaches that benefit biodiversity include payments for ecosystem services (PES). Market-based approaches include compensatory mitigation markets, habitat exchanges, and eco-labels. For simplicity, market-like approaches are referred to in the same category as market-based approaches throughout this circular. It is noteworthy that incentives are commonly monetary, but not strictly, and other types of incentives are considered. Table 2 summarizes the categories of conservation mechanisms, provides a description of each, gives an example, and indicates the parties usually involved in these types of approaches.

\footnotetext{
${ }^{1}$ For conservation banking, the term 'project proponent' is used to identify those parties proposing a project that may impact a listed species. The more general term 'polluter' is used in this circular to identify project proponents and others that affect species, biodiversity, or habitat and may be market participants.
} 


\section{Provision of Biodiversity Benefits}

All conservation market mechanisms in this circular are designed to provide biodiversity benefits. First, a market must translate biodiversity benefits into a good to be exchanged. The unit of exchange in a biodiversity or habitat market is typically a credit; in some cases it is a label that may induce a price premium. The credit represents an expected ecological outcome. A credit may have any number of specific meanings depending on the quantification methodology, but credits are a proxy representing the species, biodiversity, or habitat being considered and serve as the unit of trade exchanged. For example, in a conservation bank scenario developed for the preservation of a species, the credit may be an acre of habitat, an individual of the species, or a breeding pair. Since a credit is not a tangible good, confidence that the credit represents what it promises is an important component in a successful market.

To provide a biodiversity benefit, additionality must be present; alternatively known as uplift; above and beyond a baseline. The baseline is defined as the in-place biodiversity benefits that a site, whether a benefit or impact site, provides under current, non-improved conditions. For example, the current conditions of a habitat on a site may support 25 individuals from an endangered species. If a credit represents one individual, the site must increase to 26 individuals to provide a biodiversity benefit and to receive one credit. Uplift includes any measure that increases the long-term viability of a site to provide biodiversity benefits. In some cases, this includes protecting a previously unprotected site (as with a conservation easement), particularly if that site is at high risk for land use change.

A disturbance is also measured against the baseline. The impact is quantified as a debit. The debit represents the direct and indirect ecological damage expected to result from an activity. For example, given the baseline example of 25 individuals, if a housing development is expected to reduce habitat so that only 12 individuals are supported, the debit will be 13 individuals. Equivalent approaches to quantify credits and debits are important for trading. Quantification methods should be scientifically sound, transparent, and consistent.

Another important concept in biodiversity and habitat markets is the measurement of ecological performance and the relationship of specific measures to market effectiveness and ecological outcomes. Both credits and eco-labels are based on an indicator of ecological performance; however, performance can be either practice- or outcome-based. Practice-based measurement assumes that a particular conservation practice (for example, vegetation management through grazing) will result in the desired ecological outcome. Performance-based measurement requires evidence that the intended biophysical results are being obtained.

Practice-based measurement can be inflexible and provides uncertain outcomes. For example, the implementation of the same practice on two different plots of land may have dissimilar results due to the land itself or the installation and management practices. A practice-based credit does not provide an incentive to ensure practices are optimally implemented unless there is effective monitoring. It also does not provide an incentive to supply the best habitat for conservation

Table 2. Examples of direct, prescriptive, market-like, and market-based types of biodiversity conservation mechanisms.

\begin{tabular}{|c|c|c|c|c|c|}
\hline Direct & Prescriptive & \multicolumn{4}{|c|}{ Market-like or market-based } \\
\hline \multicolumn{6}{|c|}{ Approach } \\
\hline Voluntary & Command and control & $\begin{array}{l}\text { Payments for } \\
\text { Ecosystem Services }\end{array}$ & $\begin{array}{l}\text { Market-based } \\
\text { compensatory } \\
\text { mitigation }\end{array}$ & Multiproduct exchange & Product differentiation \\
\hline \multicolumn{6}{|c|}{ Description } \\
\hline $\begin{array}{l}\text { Activities by private } \\
\text { citizens or } \\
\text { organizations to } \\
\text { conserve/restore } \\
\text { biodiversity }\end{array}$ & $\begin{array}{l}\text { Required activities, } \\
\text { mitigation, or } \\
\text { best practice } \\
\text { implementation } \\
\text { based on regulation }\end{array}$ & $\begin{array}{l}\text { Conservation or } \\
\text { restoration by } \\
\text { landowners } \\
\text { incentivized by } \\
\text { funding, or other } \\
\text { incentive }\end{array}$ & $\begin{array}{l}\text { Regulatory driven } \\
\text { marketplace with } \\
\text { ability to trade }\end{array}$ & $\begin{array}{l}\text { Marketplace that } \\
\text { includes multiple } \\
\text { conservation or } \\
\text { restoration credit } \\
\text { types such as pre- } \\
\text { compliance credits }\end{array}$ & $\begin{array}{l}\text { Conservation/restoration } \\
\text { conducted by } \\
\text { landowners to appeal } \\
\text { to consumers }\end{array}$ \\
\hline \multicolumn{6}{|c|}{ Example } \\
\hline Land trusts & $\begin{array}{l}\text { Permittee-responsible } \\
\text { mitigation }\end{array}$ & $\begin{array}{l}\text { Conservation } \\
\text { Stewardship Program }\end{array}$ & Conservation bank & Habitat exchange & Eco-labeling \\
\hline \multicolumn{6}{|c|}{ Parties } \\
\hline
\end{tabular}


because all sites yield the same number of credits. The potential that ecological outcomes do not meet expectations is a significant risk in practice-based measurement. An important benefit, however, is that practice-based measurement is relatively simple and less expensive to implement than outcomebased approaches.

Outcome-based measurement allows flexibility for innovative conservation practices and ensures that ecological outcomes are attained before crediting. This approach is more costly to develop and monitor and puts more financial risk on the landowner or bank owner to ensure they attain outcomes regardless of the practices that they implement. When, how, and where to measure outcomes are critical questions. Chapter $\mathrm{E}$ describes ecological measurement in more detail.

The institutional design of biodiversity markets influences their overall capability to deliver conservation benefits. The terms of easements and the relative involvement of government influences landowner participation and the potential for biodiversity conservation. "There is an inherent trade-off between maximizing participation and maximizing the conservation benefits when designing a conservation incentive program" (Sorice and others, 2013). The structural components of the conservation mechanisms are discussed in Chapter C.

\section{Introduction to Environmental Markets}

Environmental markets, like traditional markets, are mechanisms used to exchange goods, in this case, environmental amenities. Environmental amenities can be cleaner air via reduced emissions, cleaner water via implementation of best management practices, or increased biodiversity via habitat creation. Environmental markets provide amenities not supplied in traditional markets due to market failure. The establishment of an environmental market typically requires some incentive to form the basis for supply and demand of an environmental amenity. Incentives are commonly monetary, but can take other forms such as legal assurances or the transfer of liability.

This circular focuses on market-based and market-like mechanisms, such as the Conservation Stewardship Program for achieving biodiversity benefits. Market-based mechanisms are instruments that influence behavior through market signals rather than explicit directives (Stavins, 2001). Market signals are prices based on demand or supply. As a price increases, suppliers become willing to increase the quantity of supply. Conversely, as a price increases, the quantity demanded will decrease. Market-based mechanisms are designed to leverage market forces to achieve conservation goals in the most efficient manner.

The benefits of providing biodiversity often do not accrue to the landowner. A landowner may, therefore, utilize the land for a competing land use (such as for crops or grazing). This lack of remuneration for providing diverse, non-use services and biodiversity creates an economic problem known as an externality. Conservation payment mechanisms incentivize landowners to maintain or manage their property to improve biodiversity and habitat for which markets do not exist.

The conservation mechanisms are classified by the type of incentive they provide. For PES programs, the incentive is a direct financial payment. In the case of market-based compensatory mitigation, requiring mitigation induces demand for biodiversity and habitat credits. And for eco-labeling, the price of products is influenced by distinguishing a given product prompting a price premium.

From an economic perspective, the goal of an environmental market is to provide the desired level of environmental amenities with the greatest efficiency. An assumption about the benefits of environmental markets over command and control type regulation is that some parties can provide environmental amenities at a lower cost than others. The heterogeneity in the cost of supply provides an opportunity to increase the economic efficiency of achieving a given environmental objective. For instance, to protect an endangered species, ranchers may already have land suitable for the species, and the cost to enhance the habitat to allow the species to thrive is relatively low compared to the cost for a land developer who must mitigate the impact of development. This heterogeneity in cost allows the buyer-the land developer-to pay the rancher to achieve the biological objective for the species or a particular habitat. This result is a win-win-win situation: the species is protected, the rancher is compensated for protecting the species by managing or improving habitat on their land, and the developer incurs a lower cost.

Theory does not always translate into practice. The impacts of development on a species and approaches to 'abate' the impact are complex. The complexity of what constitutes biodiversity, measuring outcomes, and establishing markets for trade is challenging. The ecological needs of any species will differ from another, requiring specific land management practices whose overall impacts may or may not be well understood.

The complexity of biodiversity impacts and benefits is a substantial barrier to achieving efficient and effective markets. Market-based mechanisms are most successful when marginal environmental benefits are constant (Jack and others, 2008), although marginal environmental benefits from an additional

Biodiversity Market Considerations

A traditional market is a place where buyers and sellers 'meet' and goods are offered for sale with the potential for exchange. Biodiversity benefits are not goods traditionally brought to a market. What would be the good brought to the market for exchange? Why would one want to purchase biodiversity benefits or habitat? How would a buyer verify they received what they paid for? These challenges must be resolved to set up either a public administrative or private market for biodiversity or wildlife habitat. 
unit of biodiversity conservation practices may not be constant. Instead, they depend on source, location, the size of available habitat, ecological context, and the initial conditions of any impact or benefit site.

Despite the inherent complexity, there have been some initiatives to establish biodiversity and habitat markets. Additional efforts are currently underway to develop standardized, sciencebased tools that quantify habitat quantity and quality and relate them to desired biodiversity outcomes. The metrics and tools are discussed in greater detail in Chapter E. Chapter D examines the economic foundations of environmental markets more closely.

\section{Introduction to Market-Based Conservation Mechanisms}

Referring back to table 2, the approaches are ordered from left to right as the least to most market-like. The final column is the suite of market-based mechanisms being attempted in the United States that are considered in detail in this circular. Practice-based payments for ecosystem services (PES) are commonly used by the Federal Government to provide biodiversity and other environmental benefits (including water quality and carbon sequestration). Typically, PES are market-like rather than market-based, with payments that are fixed outside of a market exchange. This approach often occurs with a contract between one buyer and one seller, rather than in a market for competitive exchange. PES are important mechanisms to encourage biodiversity conservation with the use of a price signal and are considered along with the more traditionally market-based approaches in this circular.

Conservation banks more closely mimic a marketplace than PES due to the establishment of multiple buyers and sellers (theoretically, if not in practice). Habitat exchanges are multi-credittype marketplaces. These can include credits from conservation banks, pre-compliance credits, and other types of voluntary credits. Finally, eco-labels are a mechanism used to differentiate products with practices that protect biodiversity. A brief description of each conservation mechanism is provided below.

\section{Market-Like Payments for Ecosystem Services (PES)}

“... simply stated, is defined as a voluntary, conditional agreement between at least one 'seller' and one 'buyer' over a well-defined environmental service - or a land use presumed to produce that service" (Wunder, 2007). It is important to note that this definition limits PES to voluntary agreements. Conservation mechanisms in this category rely on an incentive (monetary or otherwise) to induce action unlike the direct conservation activities previously described. There are other definitions of PES, and this term is often used to represent all types of activities in which a payment is exchanged for an ecosystem service; however, PES here references the direct, voluntary payments and agreements for biodiversity and habitat considered in this circular.

PES programs may be funded by government entities or others such as nonprofit organizations or utilities (see an example in highlight 2). There is a limited pool of buyers and sellers, and agreements are typically between one buyer and one seller. While PES are traditionally an agreement for a specific outcome, this
Natural Resources Conservation Service Sage Grouse Initiative

The U.S. Department of Agriculture Natural Resources Conservation Service (NRCS) started the Sage Grouse Initiative in 2010 to encourage partnerships within agency programs and with external partners to conserve the bird and its habitat. The sage grouse is a candidate for listing by the Fish and Wildlife Service on the Endangered Species list. Conservation investment pre-listing may prevent the need to list and the potential for recovery prior to listing may be higher.

By making the sage grouse and its habitat, sagebrush steppe, a priority, the NRCS is leveraging multiple payments for ecosystem programs including the Environmental Quality Incentives Program and the Wildlife Habitat Incentive Program to provide technical and financial assistance to encourage rangeland practices that benefit the birds. The Farm Bill provides funds, and the initiative is designed to encourage additional funding from partners. In Idaho, financial incentives for easements from the NRCS are supplemented by The Nature Conservancy, The Blaine County Land and Wildlife Program and other sources.

Since 2010, over 700 ranchers have joined in the initiative and implemented practices on 2.5 million acres of rangeland across multiple States. The Initiative has a science-based strategy that includes conservation easements on core sage grouse areas, installation of fence markers to reduce bird collisions, removal of junipers, and increased sagebrush cover.

Adapted from USDA, $2013 b$.

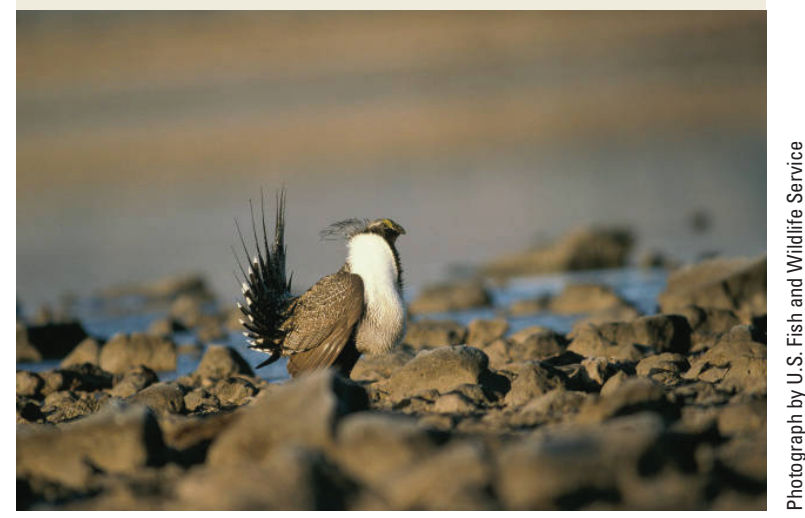


Biodiversity and Habitat Markets: Policy, Economic, and Ecological Implications of Market-Based Conservation

discussion of PES includes practice-based payments that incentivize biodiversity and habitat conservation. While outcomes may vary from field to field, best management practices have often been demonstrated to provide specific environmental benefits.

PES programs are growing internationally and vary in objective from carbon sequestration to protecting a specific species. In the United States, PES policies have been in place for a number of decades in the form of conservation programs that pay landowners to carry out conservation through specific management practices, but not necessarily for the outcomes of those practices. The USDA's Conservation Reserve Program has paid farmers to plant permanent vegetation on environmentally sensitive cropland since the mid-1980s (Sullivan and others, 2004). ${ }^{2}$ A study by Forest Trends (Mercer and others, 2011) estimated that in 2007, government PES for forestlands to benefit biodiversity totaled about $\$ 31.7$ million. The USDA and the Department of the Interior have multiple PES programs.

There are also incentive-based programs that do not provide monetary payments. Like PES, these programs leverage incentives to influence landowner behavior. Regulatory assurances, such as the Safe Harbor Program administered by the FWS, provide examples of non-monetary incentives. With Safe Harbor Agreements, the FWS or National Marine Fisheries Service (NMFS) provide assurances that no additional regulatory constraints will be placed on a landowner if the land is managed for a listed species for an agreed amount of time, providing a net conservation benefit. According to the FWS (2005b), more than 300 landowners are enrolled in Safe Harbor Agreements that protect 36 endangered or threatened species.

Fundamentally, a PES approach provides a monetary incentive to establish a benefit site, and is a formal agreement between two parties. PES approaches are considered in greater detail in the following chapters.

Market-Based Compensatory Mitigation Programs have statutory or regulatory authority driving them that requires a polluter to offset the environmental impacts of their activities. Under this approach, an impact site results from a human activity which must be mitigated via a benefit (or offset) site. Polluters are allowed to conduct the activities that create the impact site and to purchase credits from a benefit site to offset

\footnotetext{
${ }^{2}$ Marc Ribaudo (USDA Economic Research Service), written commun., December 31, 2014 argued that traditional practice-based subsidy payments are not PES, rather PES instruments are limited to mechanisms that base payments on the amount of environmental services produced. The authors adopt a broader view after Jack and others (2008) to include payment for practice mechanisms and consider those within the PES category. While payment is based on practice cost rather than environmental services, the practice is designed to achieve an environmental objective and the purpose of the payment is to incentivize behavior that results in that objective. In regards to the economic efficiency of practice-based payments versus outcome-based mechanisms, Ribaudo describes the advantages of an outcome-based payment that encourages landowners who can provide the most environmental services at the lowest cost to enter a program without the need for specific government targeting. The authors agree and compare practice- versus outcome-based mechanisms in more detail in Chapter E.
}

these activities. This provides an opportunity for the mitigation to be achieved at the lowest cost while ensuring that ecological requirements are met. In comparison to PES programs, compensatory mitigation provides an incentive for voluntary benefit site development, but the incentive comes from the polluter being required to mitigate rather than from a payment by the government. This approach has a shorter history than PES in the United States.

Similar to PES programs, compensatory mitigation can be implemented to achieve numerous objectives, including species protection, water quality, and wetland protection. For biodiversity benefits, the primary market-based compensatory mitigation program is conservation banking. A conservation bank is "a site where habitat and/or other ecosystem resources are conserved and managed in perpetuity for listed species expressly for the purpose of offsetting impacts occurring elsewhere to the same resource values" (FWS, 2003). As previously mentioned, endangered species and their habitat are common indicators for overall native biodiversity. A conservation bank is a compensatory mitigation program requiring polluters to mitigate impacts to listed species.

Individual landowners, including farmers, or in other cases professional mitigation bankers, establish conservation banks that must be approved by the FWS or NMFS, which administer conservation bank programs. There are currently 132 conservation banks in the United States (USACE, 2014). An example of a conservation bank in California which provides a benefit site for multiple species, including the San Joaquin kit fox, is featured in highlight 3 . This is one bank of many that provide benefit sites for this species, and there are multiple buyers (such as polluters) that may choose this or other banks from which to purchase credits.

In comparison to PES approaches, conservation banks more closely resemble a market, with the potential for multiple buyers and sellers to compete for the same 'product' or 'revenue'. Banks are intended to preserve large tracts of land. The Wetland Banking Program administered by the U.S. Army Corps of Engineers (USACE) has provided lessons for the development of the conservation banking program. In particular, findings by the Government Accountability Office (2005) that the wetland banking program lacked oversight and that permittee-responsible mitigation was largely unsuccessful provided motivation to develop a conservation banking program that includes strong oversight and monitoring to ensure improved biodiversity outcomes.

It is important to note that a conservation bank must maintain land for the given purpose in perpetuity, in contrast to PES, which often have annual, 5-year, or 10-15 year contracts. There are considerable implications caused by the requirement for land to be set aside in perpetuity, and the positive and negative effects are discussed in greater detail in the following chapters.

Habitat Exchanges are a platform to exchange habitat or biodiversity credits, or a marketplace. Building on the concept of conservation banks, habitat exchange developers attempt to apply the approach more broadly to regulatory or 


\section{Deadman Creek Conservation Bank}

Deadman Creek Conservation Bank is a multi-species bank in southwest California managed by Wildlands, Inc. The 684 acre bank was approved and provided 639 credits for upland habitat to offset San Joaquin kit fox habitat impacts. To date, the bank has sold 429 credits (USACE, 2014). The San Joaquin kit fox is federally listed as an endangered species and it's estimated that only a few thousand remain in its native California range (NatureServe, 2013).

One stipulation of a conservation bank is a management plan; the Deadman Creek Conservation Bank uses grazing to reduce invasive species and maintain native vegetation species (Wildlands, Inc., 2008). In coordination with a permanent easement, the management activities are designed to support the kit fox and other wildlife. The management plan also accommodates compatible activities such as bird watching and hunting. Grazing, recreation, and hunting may all be sources of additional revenue (above and beyond the sale of credits) for the owner. This revenue can help sustain the bank and incentivize investment in new bank locations.

Another stipulation of a conservation bank is that impact sites must be located within a specified service area. This condition

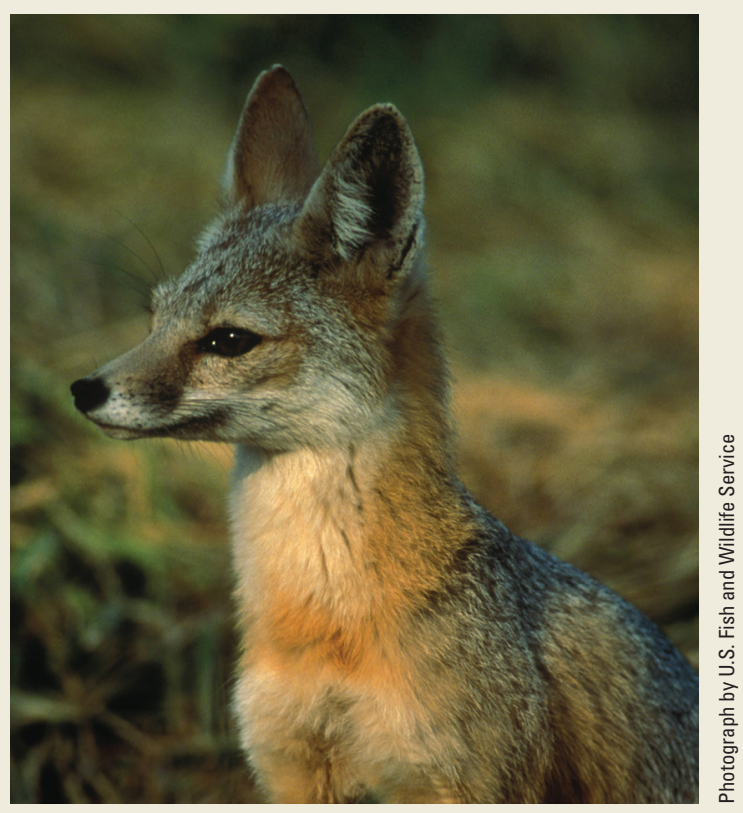
protects diverse subpopulations.

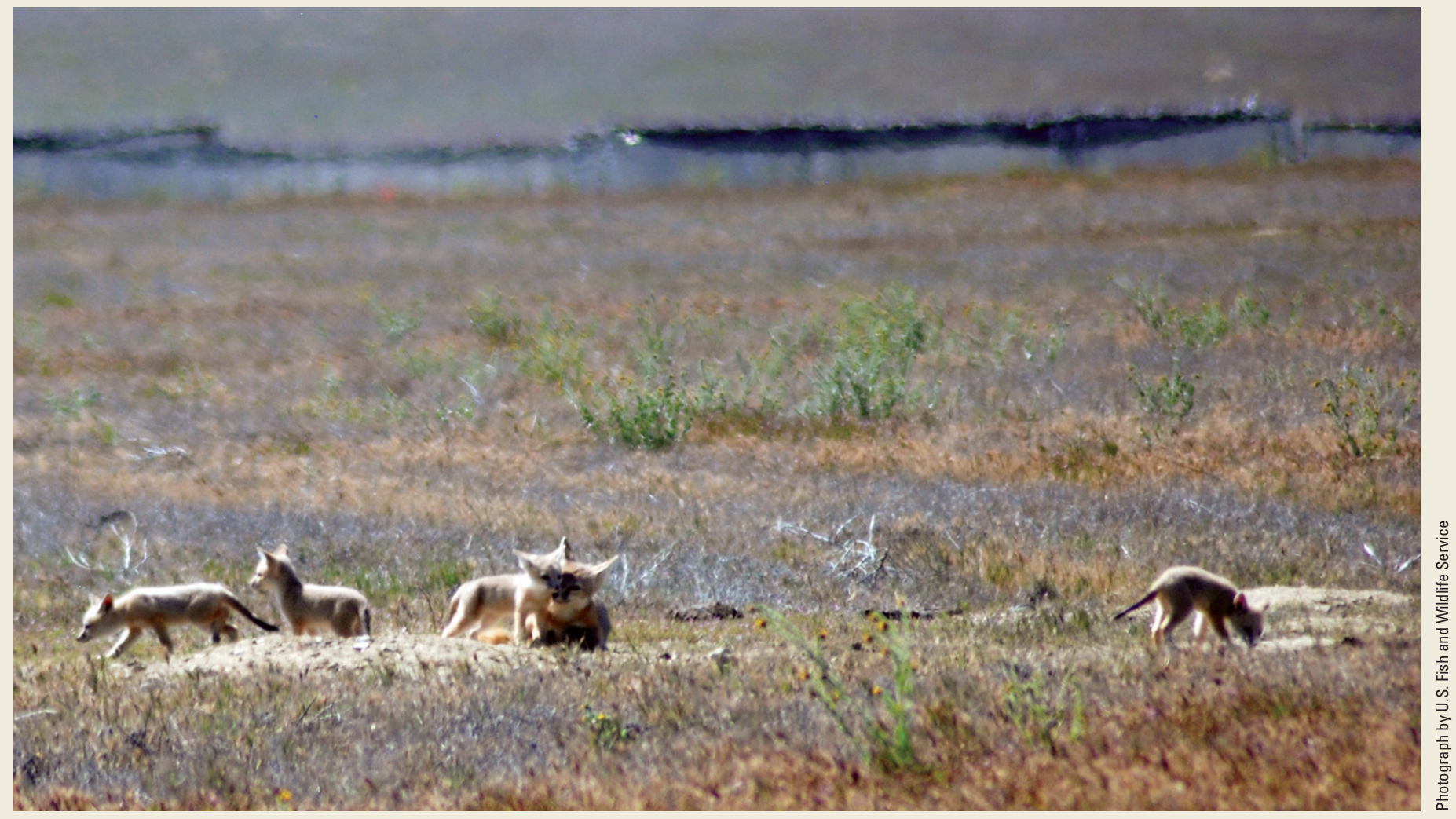


pre-compliance markets that can address candidate species or other voluntary habitat conservation scenarios in addition to listed species.

Pre-compliance demand is based on industry (including agriculture) and agency agreements to achieve conservation while reducing regulatory uncertainty about development and land-use activities. Firms and agencies are willing to pay to reduce this uncertainty and penalties associated with species impacts. For example, the Colorado Habitat Exchange is being developed by a number of parties to provide a market structure that allows ranchers who improve their land for sage-grouse to sell habitat credits to energy developers to offset their impacts on sage-grouse, pre-listing. The objective is to establish an incentive-driven market that can result in a net benefit for the species and potentially eliminate the need for a listing (Environmental Defense Fund (EDF), 2013a).

A similar example is the voluntary gopher tortoise habitat credit system, which is based on demand from an Army base in the tortoise's current range, but where the species is not currently listed. This effort is featured in highlight 4. Habitat exchanges are trying to reverse species or biodiversity loss to minimize the need for regulatory action while achieving conservation gains. By managing the habitat needs of a species of concern, the entire ecosystem benefits.
An exchange can provide the platform for voluntary and compensatory mitigation, and in the case of compulsory mitigation the polluter purchases a credit from a conservation bank via the exchange. The exchange platform theoretically brings all buyers and sellers to a single, virtual marketplace. This can make it easier for buyers to find credits and increase market transparency. Exchanges are discussed in greater detail in the following chapters.

Certification or Eco-labeling is a way to differentiate a product based on how it is produced; in this case when it supports a species, habitat, or overall biodiversity in a specific place or type of habitat. By differentiating a product, consumers may shop more selectively and may be willing to pay more, providing an incentive and competitive edge for producers who conduct biodiversity-friendly activities. An example is the Salmon-Safe eco-label available in the Pacific Northwest. The label is only given to businesses verified by Salmon-Safe as using practices that lead to better habitat quality for salmon; currently, more than 60,000 acres of farm and urban lands are certified Salmon-Safe in Oregon, Washington, California, and British Columbia (Salmon-Safe, 2014). Eco-labeling is discussed in greater detail in the following chapters. See Casey and others (2006) for more examples of eco-labeling.

\section{Voluntary Gopher Tortoise Habitat Crediting System}

The American Forest Foundation and the World Resources Institute partnered to develop a voluntary conservation banking system to protect and enhance the longleaf pine habitat that eastern gopher tortoises rely on. The tortoise is listed as threatened in its western range and is a candidate for listing in its eastern range. The partnership's goal is to encourage conservation banks to provide habitat pre-listing. A bank can generate credits based on a set of indicators of good longleaf pine habitat for tortoises. The credit itself is a tradable unit of habitat.

The gopher tortoise habitat crediting system illustrates the indicators often used to assess the biodiversity benefits of a conservation activity. For operation, indicators need to be comprised of a standard set of observable and verifiable metrics. Although the crediting system was developed, this initiative has not been implemented.

The figure below shows the relationship between the gopher tortoise and the longleaf pine forest. A potential listing of the species is the regulatory impetus for generating interest and demand for credits that will mitigate activities that would disturb the tortoise habitat.
The metric used to measure conservation is a unit of longleaf pine habitat which can be turned into a credit and traded. The ecological premise is that the habitat leads to tortoise benefits. In turn, tortoises are an indicator of ecosystem health and the other species of the longleaf pine forest can benefit as well, leading to overall biodiversity increases.

\section{Adapted from Gartner and Donlan, 2011.}

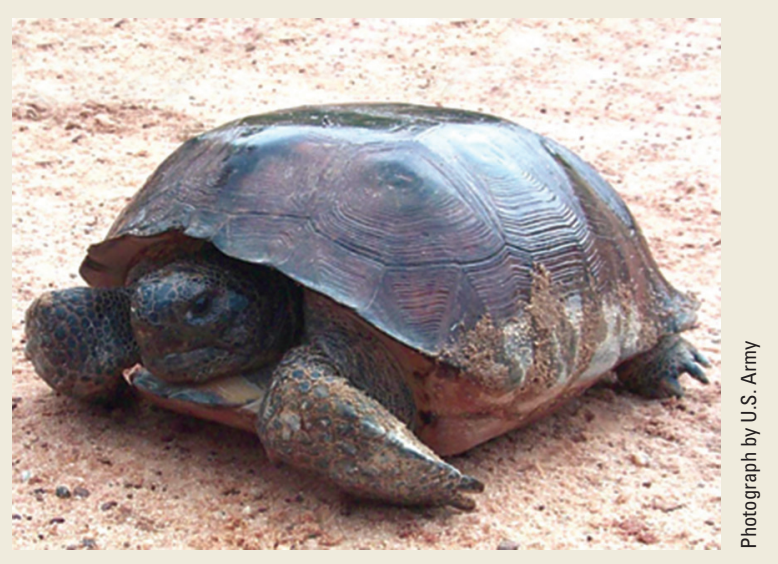




\section{Chapter B-Policy Context for Biodiversity and Habitat Markets}

To understand the market-based mechanisms considered in this circular, reviewing the regulatory context in which these market-based mechanisms evolved is important. The different approaches may or may not have a specific regulatory mandate. Additionally, the overarching policy, including guidance developed by agencies, can affect how market mechanisms are implemented programmatically and for individual projects. The regulatory and policy context that impacts biodiversity or habitat markets is explored in this chapter.

\section{Payment for Ecosystem Services}

Payment for Ecosystem Services (PES) is an incentivebased approach that promotes conservation or restoration of environmental services by private landowners through funding from the government or other sources. There are Federal, State, and local government mandates that promote the use of payments for ecosystem services. The Federal Government has provided payments to farmers for soil conservation since the 1930s (Scarlett and Boyd, 2011). This earlier process evolved into the current PES suite of programs (some of which are practice-based and payments are largely cost-based) mandated by the Food Security Act of 1985 (Public Law 99-253). Commonly known as the Farm Bill, this act has gone through multiple iterations over the years with the most recent being the Agricultural Act of 2014 (Public Law 113-79). The Farm Bill has established many conservation programs that provide private landowners with cost-share payments. The Farm Bill also provides procedural rules for the conservation programs managed by the USDA.

Current Farm Bill-based PES programs with the potential to create biodiversity benefits include the Conservation Reserve Program, the Conservation Stewardship Program, the Environmental Quality Incentives Program, the Agricultural Conservation Easement Program, the Regional Conservation Partnership Program, and the Forest Legacy Program. Other Federal Government efforts to incentivize biodiversity benefits include the Partnership for Fish and Wildlife Program. There are also PES programs supported by State or local regulations and those that have no regulatory driver. The scope of the PES programs considered in this circular includes only voluntary participation programs (as compulsory mitigation is considered separately). This section describes the major Federal efforts along with examples of State and local programs.

\section{Farm Bill Programs}

Conservation Reserve Program (CRP) is one of the longest running federally funded programs and was established in the Food Security Act of 1985. CRP is a voluntary land rental program in which private agricultural producers receive payments and cost-share assistance in return for planting vegetation cover on their land to deliver ecosystem services such as soil erosion reduction, water quality improvement, and the development of wildlife habitat (USDA, 2013a). CRP funds aimed at improving or preserving wildlife habitat are considered in this circular.

Section 1231 of the Food Security Act of 1985 provides programmatic guidance for CRP including the determination of eligible cropland, maximum enrollment in the program, contract duration, procedures for handling conservation priority areas, re-enrollment guidance, and the balance of natural resource purposes. The overall acreage covered in CRP is scheduled to decrease over the next four years from a maximum acreage of 27.5 million acres in 2014 to 24 million acres in 2018 .

Conservation Stewardship Program (CSP) was established by the Farm Security and Rural Investment Act of 2002 (United States Government, 2002). CSP is a voluntary, performance-based program in which private agricultural producers receive payments for maintaining and improving existing conservation activities and adopting additional conservationbased activities that address natural resource concerns (USDA, 2014c). The benefits of CSP include improvement in soil conditions, air and habitat quality, water quality and quantity, and energy conservation. This circular focuses on the CSP funds aimed at improving or preserving wildlife habitat. Highlight 5 describes an example of CSP in action to benefit Missouri Quail. Section 1238D of the Food Security Act of 1985, as amended through 2014, provides programmatic guidance for CSP including the establishment and purpose of the program, the determination of eligible land, stipulations of stewardship contracts, and the duties of the USDA in the program. To reach the program's conservation goals, the USDA identifies at least five priority resource concerns in a particular watershed, appropriate region, or area within a State that stewardship agreements are designed to address through performance thresholds. Unlike CRP, CSP is scheduled to increase in size; from 2014 to 2022 , the program is allowed to increase by 10 million acres a year with a national average payment of $\$ 18$ per acre. 
Scott County, Missouri, is an intensely farmed area where soybeans, corn, wheat, and cotton are produced in large fields with few environmental habitat benefits for wildlife. Bird populations such as quail have experienced population declines in this area.

Before the Conservation Stewardship Program, portions of Scott County were designated quail focus area where farmers were encouraged to convert cropland to quail habitat, but there was little progress.

In 2005 and 2006, CSP funds were made available in two watersheds covering most of the Scott County quail focus area. Missouri Department of Conservation biologists and NRCS employees worked together to incentivize the best land stewards in the area to improve their environmental performance by helping them meet wildlife enhancement criteria. These included quail-friendly wildlife practices like adding shrubby cover and diverse crop rotations, and leaving rows of unharvested grain standing in fields.
Under CSP, 3.5 percent of the county's cropland was converted to quality quail habitat, resulting in an increase of roadside quail counts of 200 percent. Quail siting reports from hunters also increased after the program's inception.

\section{Adapted from National Wildlife Federation (NWF, 2014).}

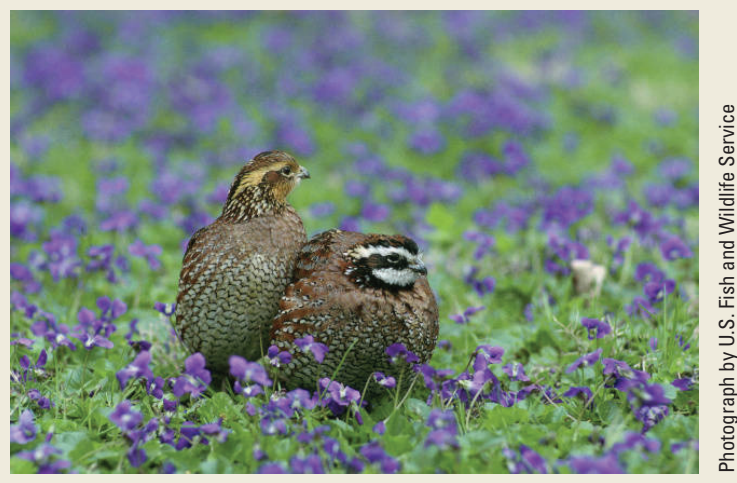

\section{Environmental Quality Incentives Program (EQIP)}

was established by the Federal Agriculture Improvement and Reform Act of 1996 (United States Government, 1996). EQIP is a voluntary program in which agricultural producers receive financial and technical assistance to implement conservation practices or conservation planning to deliver environmental benefits such as improved water and air quality, conserved ground and surface water, reduced soil erosion and sedimentation, or improved or created wildlife habitat (USDA, 2014d). The potential benefits for biodiversity and wildlife habitat generated by this program are included in this circular. Section 1240 of the Food Security Act of 1985, as amended through 2014, provides programmatic guidance for EQIP including the purpose of the program, establishment and administration, evaluation of applications, the duties of the agricultural producers, the duties of the USDA, limitations on payments, and guidance for competitive grants for innovative conservation approaches. Similar to CSP, EQIP is scheduled to increase in size. The program will receive $\$ 1.35$ billion in $2014, \$ 1.6$ billion in 2015, $\$ 1.65$ billion in 2016, $\$ 1.65$ billion in 2017 , and $\$ 1.75$ billion in 2018. Previously a standalone program, the Wildlife Habitat Incentive Program (WHIP) is now a component of EQIP. WHIP supports conservation practices that promote restoration, development, protection, and improvement of upland wildlife habitat, wetland wildlife habitat, threatened and endangered species habitat, fish habitat, field pivot corners, and other types of wildlife habitats. Each fiscal year between 2014 and 2018, WHIP is slated to receive at least five percent of appropriated EQIP funds.

Agricultural Conservation Easement Program (ACEP) was established by the 2014 Farm Bill. ACEP is a voluntary program in which agricultural producers receive financial and technical assistance to conserve agricultural lands and wetlands, and their related benefits. Benefits such as environmental quality, historic preservation, wildlife habitat, and protection of open space are managed under the Agricultural Land Easements component of ACEP. The Wetland Reserve Easements component provides assistance for the provision of habitat for fish and wildlife, improved water quality, reduced flooding, groundwater recharge, and protected biological diversity (USDA, 2014a). ACEP consolidated the three formerly independent programs: Grassland Reserve Program, Wetlands Reserve Program, and the Farm and Ranchland Protection Program into one larger easement program (NWF, 2014). Section 2301 of the Agricultural Act of 2014 provides programmatic guidance for ACEP including the establishment and purpose of the program, stipulations for Agricultural Land Easements, stipulations for Wetland Reserve Easements, and administration. Funding for ACEP increases through 2017, with the program scheduled to receive $\$ 400$ million in 2014, $\$ 425$ million in 2015, \$450 million in 2016, \$500 million in 2017, and then decreasing to $\$ 250$ million in 2018 .

\section{Regional Conservation Partnership Program (RCPP)}

was established by the 2014 Farm Bill. RCPP is a voluntary program in which NRCS coordinates with State, local, and regional partners to help agricultural producers install and maintain conservation activities in selected project areas to deliver environmental benefits such as clean and abundant water, healthy and productive soils, and enhanced wildlife and pollinator habitat (USDA, 2014e). This circular focuses on the enhanced wildlife and pollinator habitat that RCPP delivers. Section 1271 of the Agricultural Act of 2014 provides programmatic guidance for RCPP, including the establishment and purpose of the program, procedures for creating regional 
conservation partnerships, stipulations for contracts with agricultural producers, funding, administration, and the stipulations for critical conservation areas. RCPP will be appropriated $\$ 100$ million for each of the fiscal years from 2014 through 2018, with 25 percent of funds allocated to projects on the basis of a State competitive process, 40 percent of funds allocated to projects on the basis of a national competitive process, and the remaining 35 percent of funds allocated to projects for critical conservation areas.

Forest Legacy Program is a USDA program that provides financial incentives to private forest landowners to prevent forest conversion and fragmentation and ultimately protects wildlife habitat. The Cooperative Forestry Assistance Act (CFAA) of 1978, as amended, (16 U.S.C. 2101 et. seq.) authorizes the USDA to provide financial, technical, educational, and related assistance to States, communities, and private forest landowners. The USDA delegates authority of program administration to the U.S. Forest Service (USFS). The CFAA and the Farm Bill jointly provide the authority and means for the USFS to administer this PES program. The Forest Legacy Program (FLP) was established in Section 1217 of Title XII of the Food, Agriculture, Conservation, and Trade Act of 1990 (United States Government, 1990b). The mission of the program is to protect private forests nationwide and promote sustainable forest management for working forest lands (U.S. Endowment for Forestry and Communities, 2008). In 2003, the USFS published guidance for the implementation of FLP. The guidance specifies the land eligibility criteria, the process for allocating funds, cost share requirements, and required monitoring, management, record-keeping, and enforcement (USFS, 2003). The USFS works with State partners and may fund up to 75 percent of project costs to private landowners as part of conservation easement acquisition; 25 percent of the funds may come from private, State or local sources (USFS, 2013). Participants may also be eligible for tax benefits. FLP protected more than 1.5 million acres of working forests across 36 States and Puerto Rico in 2008 (U.S. Endowment for Forestry and Communities, 2008).

While the Farm Bill offers multiple PES programs, there are potential factors that could constrain biodiversity benefits. In the past, Farm Bill conservation programs have been criticized for inefficiently allocating funds to high-priority ecosystems and not using metrics related to ecosystem functionality or types of ecosystem services provided when evaluating program results (Scarlett and Boyd, 2011). It is important to note that the Farm Bill conservation programs mentioned in this section are voluntary. The success of each program is therefore highly dependent on how many private landowners are willing to participate. A number of factors influence willingness to participate in PES programs, including awareness of existing programs, knowledge of ecosystem services, willingness to enter into contracts, and willingness to work with Federal, State, or local governments (Prokopy and others, 2008).

\section{Other Federal Programs}

Partners for Fish and Wildlife Program (PFWP) is a PES program administered by the FWS (see an example in highlight 6). The program was not directly established through legislation. Rather, the Fish and Wildlife Act of 1956 and the Fish and Wildlife Coordination Act provided the authority to use Federal funds to benefit wildlife on private lands. The FWS has used this authority to provide additional
Batten Kill River Brook Trout Stream Restoration Project

Brook trout are often considered health indicators for the watersheds they inhabit. Healthy brook trout populations may indicate that a stream or river ecosystem is healthy and that water quality is good. Eastern brook trout populations have declined greatly and are now primarily found in scattered headwater streams.

Eastern brook trout habitat is threatened in many parts of the northeast United States by extensive erosion, widening, and shallowing of rivers. Eastern brook trout, alongside other native species, prefer deeper, cooler channels. To address this issue, a project on the Batten Kill River in Washington County, New York, is implementing measures to restore fish habitat.

The partnership is leveraging funds from the FWS Partners for Fish and Wildlife Program, along with the Batten Kill Watershed Alliance of New York, Vermont Trout Unlimited, and the Washington County Soil and Water Conservation District. Working with local landowners, the habitat restoration includes returning this section of river to a natural channel by installing rock vanes, log vanes, and large wood debris. The channel and materials provide substrate for macro invertebrate production and cover for juvenile fish.

This project restored 17 sections of the river for a total cost of $\$ 87,000$. Not only are benefits expected for eastern brook trout but for many native species that occupy similar habitat and even the entire local ecosystem.

Adapted from FWS Regional Showcase Accomplishments, 2010, Available at: http:// www.fws.gov/partners/docs/PFW_Accomplishments_2010.pdf.

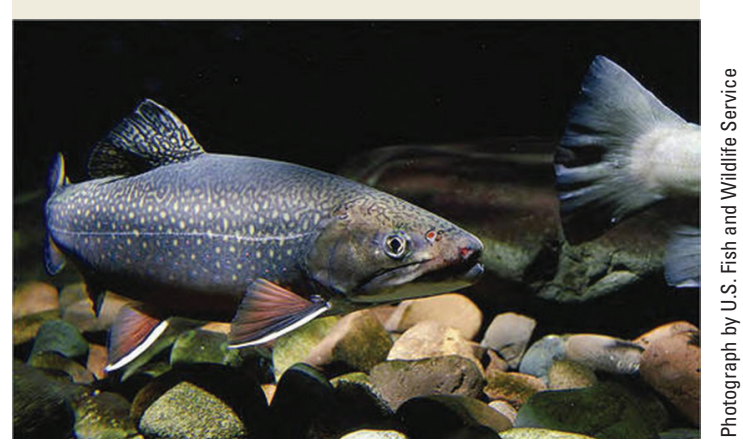


funds to CRP projects (established in the 1985 Farm Bill). Initially, the focus of the PFWP was wetland restoration, but it currently provides funding for fish habitat and endangered species habitat restoration (FWS, 2011a). The program was established in 1987 as a small collaborative effort and is considered the FWS premiere non-regulatory and voluntary habitat restoration program.

In 2006, Congress enacted the Partners for Fish and Wildlife Act (Public Law 109-294, 16 USC 3771). Nearly twenty years after its initiation, the act acknowledges that the majority of wildlife is found on private lands and that the program exemplifies cooperative conservation as an innovative, voluntary partnership with private landowners to restore wetland and other fish and wildlife habitat. The act specifies which species are considered and defines habitat enhancement, establishment, improvement, and restoration in detail. The act authorized the FWS to continue providing technical and financial assistance under this program and authorized $\$ 75$ million per year through 2011. The PFWP has restored an estimated 800,000 acres of wildlife habitat across the nation since 1987 (FWS, 2011a).

In 1984, Congress chartered the National Fish and Wildlife Foundation (NFWF) to "further the conservation and management of fish, wildlife, plants, and other natural resources" of the United States (National Fish and Wildlife Foundation Establishment Act, 16 U.S.C. $\$ 3701$ et seq.). The NFWF acts as a third party to direct funding from litigation or required for mitigation towards effective conservation programs. This approach brings funds from multiple sources together and increases the ease of administering grants to biodiversity and habitat restoration projects.

\section{State and Local Compensation Programs}

Much like the Farm Bill conservation programs, regulatory and non-regulatory programs at the State and local levels offer landowners financial incentives to offset threats to specific habitats or species. Examples of compensation programs that offer these types of incentives include reimbursements to landowners who suffer losses due to wildlife predators and payments to agricultural producers for adopting land management practices that benefit biodiversity.

As humans and predators occupy the same habitat, there is a growing risk that carnivores prey on pets or livestock which could encourage depredation by humans. Compensation programs are designed to mitigate these types of conflicts between humans and wildlife to sustain biodiversity (Casey and others, 2006). Since 1982, the State of Wisconsin has used a compensation program for livestock losses caused by wolves. Administered by the Wisconsin Department of Natural Resources and the Bureau of Endangered Resources, the Wisconsin wolf compensation program pays designated percentages of losses to all livestock, commercially raised game animals, hunting dogs, pets, and veterinary bills for injured animals (Agarwala and others, 2010). Other animals covered under compensation programs include the pronghorn antelope in Colorado, the black bear in Pennsylvania, and deer and elk in Washington (Wagner and others, 1997).

Private, often nonprofit efforts to pay for ecosystem services are not based on regulation but may provide meaningful biodiversity benefits. An example of a local program that is non-regulatory driven is the Bobolink Project in Jamestown, Rhode Island, which is discussed in highlight 7.

\section{The Bobolink Project}

The Bobolink Project was started in 2007 in Jamestown, Rhode Island, to protect the habitat of bobolinks, promote ecosystem services as a marketing opportunity for local farmers, and to encourage community members to participate in ecosystem preservation.

Bobolinks are small migratory birds that nest in open grassy fields. This makes farm hay fields a perfect breeding habitat for Bobolinks. Unfortunately, bobolink populations have declined due to loss of habitat from the reduction of the number of hayfields in North America, conversion of fields from hay to corn and soybeans, and the increased frequency and intensity of hay cutting over the past 30 years. Farmers often mow their fields before young bobolinks can fly; young that survive the mowing often fall victim to predators.

Unlike the mandate-driven PES programs of the Farm Bill and State damage compensation programs, the Bobolink Project was founded on an initiative by the University of Rhode Island (URI) and EcoAsset Markets Inc. (EAM) to gauge the willingness of Jamestown community members to pay farmers to delay mowing hayfields until after young bobolinks are ready to leave their nests.

In 2007 and 2008, residents of Jamestown preserved five fields during the bobolink breeding season via community payments to farmers, which helped hatch an estimated 40 to 60 bobolinks. Since then, the Bobolink Project has spread throughout Rhode Island and into parts of Vermont.

Adapted from Jain, 2013 and Bobolink Project Official Website, 2014

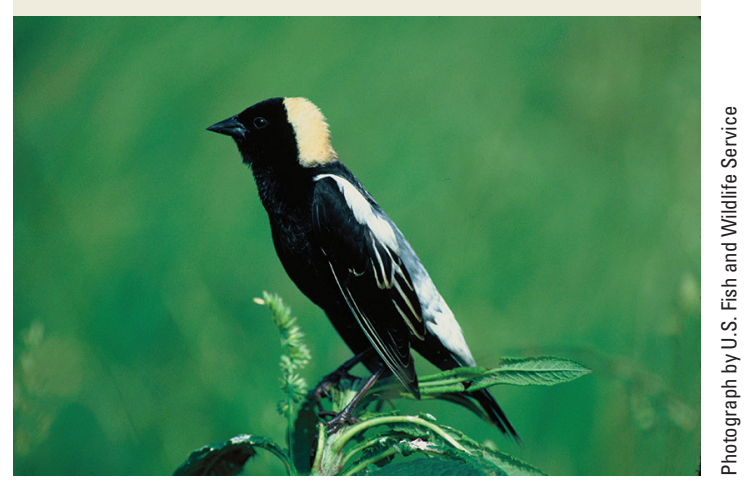




\section{Conservation Banking}

Conservation banking is a market-based approach to compensatory mitigation. A strong regulatory mandate allows for the use of conservation banks to achieve biodiversity benefits. However, under the current regulatory regime, polluters may choose an in-lieu fee option or permittee-responsible mitigation. Agency guidance provides the procedural rules for conservation banking.

Federally listed endangered or threatened species can be indicators of biodiversity, but not necessarily. ${ }^{3}$ The Endangered Species Act (ESA) (Public Law 93-205) "set the nation's biodiversity conservation policy on a path that emphasized species-based conservation and triggered action only when a species faced imminent extinction" (Davis and others, 2006). Not only does the ESA set the course for focusing on species, it also serves as the regulatory authority that enables protection of the listed species.

The purpose of the ESA is to "provide a means whereby the ecosystems upon which endangered... and threatened species depend may be conserved... [and] to provide a program for the conservation of such endangered... and threatened species..." (16 U.S. Code $\S 1531)$. The regulation prohibits 'take' of endangered or threatened species - defined as to "harass, harm, pursue, hunt, shoot, wound, kill, trap, capture, or collect, or to attempt to engage in any such conduct" (16 U.S. Code $\S 1532)$. The ESA sets out procedures for listing species as endangered or threatened and designating critical habitat. The Federal agencies responsible for regulating endangered species are the FWS for terrestrial and freshwater species and some marine mammals, and the NMFS for marine and anadromous species.

Section 4(d) of the ESA allows the FWS to establish special regulations for threatened-not endangered-species, subspecies, and Distinct Population Segments (FWS, no date). If "necessary and advisable to provide for the conservation of such species", Section 4(d) allows for special rules to take the place of normal ESA protections. The special rules allow relaxation of normal ESA restrictions if it is in the best interest of species recovery. The special rules provision allows regulatory flexibility in the ESA and allows for take of certain threatened species under well-defined circumstances (Martin and Mead, 2014).

Sections 7(a)(1) and 10(a)(1)(B) of the ESA provide additional regulatory language to govern mitigation of incidental take. Where 7(a)(1) applies to Federal agencies, 10(a)(1)(B) applies to private entities. Section 7(a)(1) requires that Federal agencies, in consultation with-and with the assistance of - the FWS, use their authority in furthering ESA purposes by carrying out programs for conservation of listed species. Impacts on listed species are minimized by including conservation measures in a Federal agency's project description.

\footnotetext{
${ }^{3}$ Vickerman ((formerly of Defenders of Wildlife), written commun., December 29,2014$)$ points out that a particular listed species may not be a good indicator of overall biodiversity.
}

Section 10(a)(1)(B) authorizes the FWS to issue a permit to non-Federal entities for the incidental take of endangered and threatened species that might occur during an otherwise legal activity. A habitat conservation plan must accompany an incidental take permit, which ensures that the effects of the permitted action on covered species are adequately minimized and mitigated, and that the action does not jeopardize the survival and recovery of a particular species.

The implementation of ESA sections 7(a)(1) and 10(a) (1)(B) create the need for mitigation to offset impacts to listed species and their habitat (Ruhl and others, 2005). Mitigation for activities that impact threatened species is compensatory or required by statute. The party responsible for impacts may choose to implement either permittee-responsible mitigation, the in-lieu fee program (where available), or purchase credits via a conservation bank (U.S. Department of the Interior (DOI), 2013b). Conservation banking is the market-based mechanism designed to meet mitigation requirements.

The in-lieu fee program provides the funds to a governmental or nonprofit natural resources management entity for restoration, establishment, enhancement, and preservation of habitat to satisfy compensatory mitigation. This option may be offered at the discretion of the FWS if no conservation banks are available for credit purchasing. In contrast, permitteeresponsible mitigation is a "do-it-yourself" offsetting conducted by a developer or subcontractor and may take place on the development site or at another location.

Additional regulatory statutes require compensatory mitigation to encourage the use of conservation banks. The Magnuson-Stevens Fishery Conservation and Management Act requires Federal agencies to consult with NMFS if they may adversely impact critical habitat (16 U.S.C. $\S \S 1801-$ 1884). The Clean Water Act, Section 404 (33 U.S. Code $\S$ 1344), provides the authority to regulate the dredge and fill of the Nation's navigable waterways. Section 404 allows the administrative authority (the USACE in coordination with EPA) to grant permits that include compensatory mitigation and may be in the form of a conservation bank.

While the management of waterways and wetlands under the Clean Water Act may be for the purpose of maintaining clean water, there can be co-benefits for biodiversity and habitat. The Code of Federal Regulations 33, Part 332, prescribes allowances for the compensatory mitigation for losses of aquatic resources; according to the code, "mitigation projects... may be designed to holistically address requirements under multiple programs and authorities for the same project." This allowance led to the establishment of several joint conservation-mitigation banks. All of the same statutory drivers from the ESA apply; however, there may be an additional impetus to establish a bank with the increased demand for wetland mitigation credits.

The seeds for conservation banking took root in the mid1990s. During that time, there was much demand for mitigation options in the State of California. In April of 1995, the Resources Agency and California Environmental Protection Agency announced the State's Official Policy on Conservation 
Banks (Ruhl and others, 2005). With a long list of endangered and threatened species, and demand for development that would require offsets, California was an early adopter of conservation banking as a mitigation tool. Shortly thereafter, the FWS included conservation banking as a mitigation option, but without official guidance (Ruhl and others, 2005). California continues to develop policy and guidance on conservation banking specific to banks in the State; see highlight 8 .

In 2003, the FWS published guidance for the establishment, use, and operation of conservation banks (FWS, 2003). Updated guidance is expected before the end of 2015. The design of conservation banks was greatly influenced by lessons from the USACE's regulation of wetlands under the Clean Water Act (Ruhl and others, 2005). In 1995, after several findings that indicated the wetland mitigation program did not maintain or improve upon environmental benefits, the USACE published guidance on mitigation banks. The USACE stated that "banks provide greater flexibility to applicants needing to comply with mitigation requirements and can have several advantages over individual mitigation projects":

- It may be more advantageous for maintaining the integrity of the aquatic ecosystem to consolidate compensatory mitigation into a single large parcel or contiguous parcels...;

- Compensatory mitigation is typically implemented and functioning in advance of project impacts, thereby reducing temporal losses of aquatic functions and uncertainty over whether the mitigation will be successful in offsetting project impacts (Federal Register, 1995).

In 2008, the USACE and the EPA published regulations that state a preference for mitigation banks for the wetland program over permittee-responsible mitigation (Federal Register, 2008).

The FWS's guidance provides procedures and standards to evaluate the effectiveness of conservation banks. The guidance does not direct field offices to prefer or use conservation banks over alternatives, and some local and regional FWS field offices may use conservation banking more than others. While the guidance provides standardized Federal regulations for the approval process for conservation banks, it is not a Federal policy to establish conservation banks. The new policy guidance may increase the use of conservation banking if it establishes a stronger preference towards banking over the in-lieu fee program and permittee-responsible mitigation.

The details of the 2003 guidance underpin the provisions of conservation banks; Chapter $\mathrm{C}$ considers these provisions in detail alongside other structural components that define conservation banking. One potential constraint on the wider application of conservation banking is the allowance of alternatives for compensatory mitigation under the ESA. The alternatives effectively compete with the establishment of conservation banks. While competition is not innately bad, it is important that alternatives have an equal basis. All of the stipulations required for a conservation bank-including financial assurances, ecological performance, and oversight—-should be the same for permitteeresponsible mitigation and the in-lieu fee program.

The obligations of the FWS and limitations on resources may be an institutional barrier to the broader adoption of conservation banking. In 2013, the Department of the Interior Office of Policy Analysis conducted a survey of FWS staff to assess the conservation banking program. Based on survey results, FWS staff identified "institutional
California Fish and Game Conservation Banking Guidance

California was an early adopter of conservation banking. The State has 129 federally listed endangered and threatened species and another 83 designated by the State (California Resources Agency, 2014). The 1995 Official Policy on Conservation Banks provided the initial guidance for conservation banking in California. A brief three pages, the document provides general guidelines such as the preference for an offsite bank for long-term preservation, a stipulation that minimum size should account for ecological viability, and basic elements that should be associated with any bank (Wheeler and Strock, 1996).

In 1996, supplemental policy was published and stated that "... agencies support the creation of conservation banks because they: (1) further the conservation of habitat; (2) help with regional open space planning; (3) help implement NCCPs; and (4) assist in endangered species issue resolution and provide a relatively simple means for landowners to obtain "value" for properties" (California Department of Fish and Game, 1996).

In 2012, the California legislature enacted the California Fish and Game Code Guidance, Chapter 7.9, Sections 1797 to 1799.1, to govern bank applications and fees (California Department of Fish and Wildlife, 2015). Unlike other States, California now requires fees from applicants such as the prospectus review fee of $\$ 10,000$ (California Fish and Game Code; Section 1797-1799.1). The code goes into greater detail on what is included in an application and the timeline for approvals.

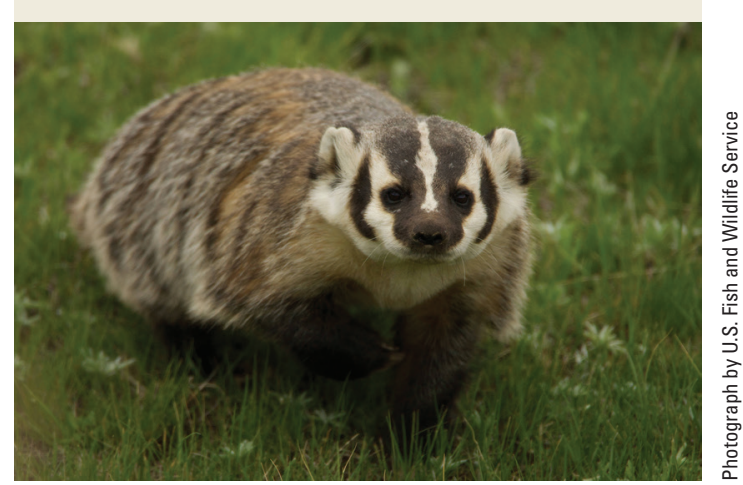


obstacles to bank creation including delays in banking document approval, which were thought to be most influenced by insufficient staffing, delays in solicitor approval, and lengthy banking documents" (DOI, 2013a).

\section{Habitat Exchanges}

A habitat exchange is a market platform for trading biodiversity and habitat credits. The current vision for habitat exchanges under development includes upfront determination of a standardized set of protocols, including a habitat quantification tool (HQT), which is used to quantify potential habitat and species' benefits from restoration activities and impacts from disturbance activities on the same basis (Environmental Defense Fund (EDF), 2013a). The HQT will be used to assess functional acres that incorporate measures of habitat quality (credit types are addressed in Chapter E). According to one of the exchange developers, the Environmental Defense Fund (2013), the exchange will establish protocols to validate projects and quantify, register, certify, and transfer associated credits within a trading platform.

In contrast to conservation banking, an exchange would not require individual banks (or landowners) to complete the entire process for FWS approval. Rather, if the landowner met the exchange protocol's requirements they could use the HQT to determine how many credits they might receive (or be debited in the case of a negative impact). The credits generated are subject to the same regulatory requirements imposed by the ESA as for conservation banks sold outside of a habitat exchange; however, the exchange streamlines the process for permitting. This concept is designed to reduce the transaction costs associated with the time and effort needed to comply with regulatory requirements and increase the participation of landowners, and to increase the recovery potential for species on the landscape. While there are many efforts to develop habitat exchanges across the country, this approach has not yet been successfully demonstrated.

In addition to designing a different approach to conservation banking, habitat exchanges are intended to advance the protection of species not listed as threatened or endangered. Termed pre-listing conservation (Donlan and others, 2013), and also known as pre-compliance, these efforts focus on benefiting at-risk species that are candidates for listing. The ESA does not provide protections for these species, nor does it require polluters that impact the species to mitigate for their actions. From the perspective of Federal law, there is no regulatory driver for protecting species in a pre-listing status.

Although at-risk candidate species are not protected by the ESA, their potential for listing creates a perceived regulatory driver that can affect behavior. The perceived threat of future regulatory restrictions on their activities is a 'soft' regulatory incentive for landowners to consider mitigation approaches. Pre-compliance approaches rely on some assurance that mitigation or credits for mitigation purchased in a pre-compliance environment will be recognized in a postlisting environment. In essence, the buyer is purchasing down the uncertainty of the future regulatory regime.

\section{Voluntary versus Regulatory Markets}

Regulatory markets for biodiversity benefits are driven by specific legislation and the requirement to mitigate. The protocols for providing and buying credits are strict and highly regulated. The U.S. Fish and Wildlife Service and the U.S. National Marine Fisheries are the predominant authorities that administer regulatory markets. In regulatory markets, demand is driven by the polluter's requirement to mitigate. Supply of conservation is not required by the legislation, but the assignment of credits is subject to regulation.

Voluntary markets encompass a number of different forms. Private, voluntary markets for eco-labels do not have a regulatory driver mandating the implementation of practices. Third party verifiers establish rules and procedures for procuring labels. Consumers have the option of buying products with these labels but there is no requirement to do so.

Habitat exchanges can have a number of voluntary credit types. Individuals, nonprofits, or businesses can purchase credits for reasons other than compensatory mitigation. For example, businesses may have sustainability objectives.
Standards for credits in voluntary markets may not be as stringent as in regulatory markets.

Alternatively, 'voluntary' markets may have credits for pre-listed species. In an effort to reduce future risk, firms may purchase offsets prior to species becoming protected. Credits for mitigation of State-listed species are often considered as a pseudo-voluntary market.

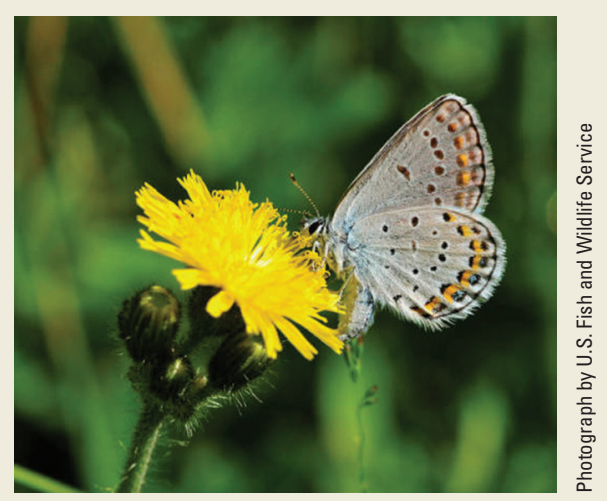


This type of advanced credit acquisition would provide the incentive to purchase credits and provide the financial incentive to landowners to provide biodiversity benefits (Ted Toombs (Environmental Defense Fund), oral commun., February 26, 2014). Since buyers are purchasing away uncertainty rather than complying with current regulations, less demand is probable for these types of credits. Lower demand is also likely to lead to decreased prices. There are some limited examples of this approach, and the potential is discussed in Chapter D.

Habitat exchanges seek a new, more streamlined approach to conservation banking and a wider concept application to provide pre-listing conservation. There are constraints to this approach within the current regulatory regime. While developers intend to design the exchanges so that biodiversity benefits and mitigation for impacts comply with the ESA, streamlining the process by developing protocols for approval is subject to approval by the FWS and may be met with resistance by the FWS. The gopher tortoise habitat crediting system attempted to secure assurances and reportedly lost momentum when the potential for receiving assurances from FWS decreased. ${ }^{4}$

\section{Eco-Labeling}

Eco-labeling is a market-based approach to differentiate products based on practices, sources of materials, or other factors that protect or enhance the environment. Biodiversity conservation through eco-labeling in the United States is not driven by regulations-regulatory agencies are involved in some types of eco-labeling such as USDA organic certification, which can be considered to promote biodiversity. Eco-labeling is an approach that targets consumers willing to pay more for products that protect species or habitat with a certified label.

\section{Institutional Incentives}

Although not a PES program, the Safe Harbor Agreement (SHA) is an important complementary policy under the Endangered Species Act established in 1999 (FWS and NOAA, 1999). The SHA creates a legal-institutional framework to remove barriers to, and facilitate the creation of, market-like structures for biodiversity conservation. The SHA is a voluntary agreement between private landowners and the FWS or the National Oceanic and Atmospheric Administration (via NMFS). Participating landowners receive formal assurances that no additional land management activities will be required of them without their consent in exchange for actions that contribute to the recovery of listed species (FWS, 2011b). Like other incentive programs, SHAs are voluntary, although landowners do not receive a financial incentive. Rather, the incentive is a regulatory assurance. Since SHAs ensure future property use limitations will not occur on participating land without the landowner's consent,

${ }^{4}$ Multiple individuals involved in program development identified this challenge.

\section{Permanent versus Term Credits}

Credits can exist for a permanent or fixed term. Permanent credits provide the most ecological benefits in terms of net present value since they continue to deliver conservation year after year. However, permanent credits can limit the number of agricultural producers willing to participate in programs. The potential ecological benefits of perpetual land protection may be outweighed by reduced program participation.

Term credits may be more suitable to mitigate impacts under certain conditions. For example, coal mining is disruptive during exploration and extraction, but there is an opportunity to reclaim the site once production is complete. Term credits could cover the period of disturbance without being cost prohibitive. The specific needs of the species and the potential for reintroduction would have to be taken into account.

In other cases, permanent credits are the only way to ensure survival or recovery of a species. Residential development is likely to be permanently transformed from a wildlife habitat. Permanent credits can provide perpetually protected habitat for those species impacted while term credits would risk the development of protected habitat once terms have expired. Especially with an increasing demand for shrinking real estate, property values are likely to increase, further incentivizing development.

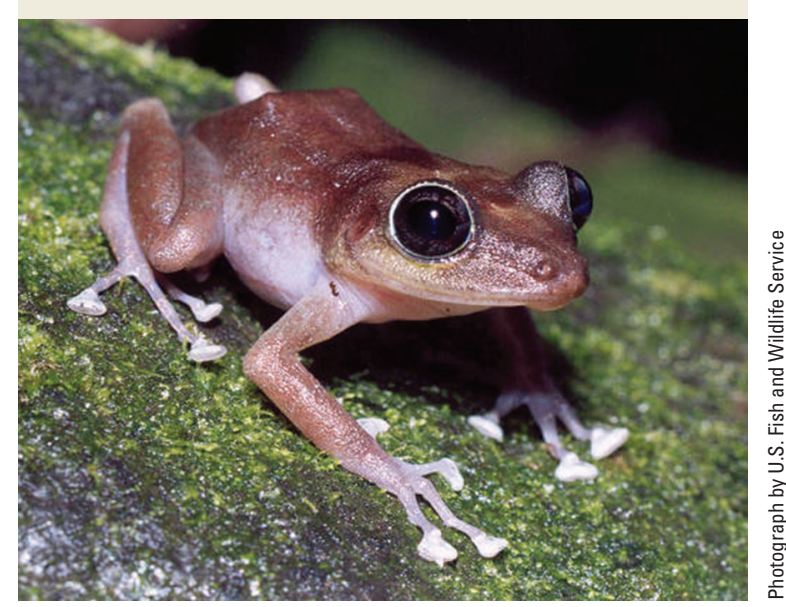


people may be more willing to undertake land management activities that support endangered species.

Section 10(a)(1)(A) of the Endangered Species Act permits the use of tools like Safe Harbor Agreements to be used as permitted exceptions to actions otherwise prohibited by the Act. The Announcement of the Final Safe Harbor Policy contains a detailed explanation of the policy including purposes, definitions, procedures for cooperation and coordination with the States and tribes, species net conservation benefit, policy standards, baseline conditions, assurances to property owners, management of non-covered or newly listed species, required monitoring, compliance with the National Environmental Policy Act, transfer of agreements, property owner discretion, management of neighboring landowners, public review, and the scope of the policy (FWS and NOAA, 1999).

\section{Summary of Biodiversity and Habitat Markets Policy Context}

The policy context for the various biodiversity and habitat market mechanisms varies widely. There are examples of efforts that were initiated with no regulatory basis and rely fully on voluntary contributions from local residents or other sources of funding to incentivize landowners to engage in management that yields biodiversity benefits. Many PES programs are based on the Farm Bill and have similar terms regarding administrator obligations, landowner obligations, and the lengths of contracts. While the funding and programmatic authority for these programs is based on regulation, PES programs rely on the voluntary participation of landowners who consider multiple factors in determining their willingness to participate.

Conservation banking is grounded in the Endangered Species Act and additional programmatic guidance. While robust regulatory authority provides incentives for polluters (in the form of compensatory mitigation), this program still relies on voluntary participation by agricultural landowners to supply habitat. The regulatory requirements associated with conservation banking may be a hurdle for individual landowners, and habitat exchanges being developed are attempting to reduce the administrative burdens on these potential suppliers. Table 3 below summarizes the regulations that form the basis for the major programs discussed in this chapter.

Legislation may provide the incentive for a biodiversity or habitat market, it may authorize funds for a PES program, or it may provide other types of non-financial incentives such as regulatory assurances. Programs developed based on regulations, and those that developed without any regulatory impetus, have stipulations that impact their ability to provide biodiversity benefits. Chapter $\mathrm{C}$ considers the structure of each conservation mechanism and how they can affect the ecological effectiveness and economic viability of each particular approach.

Table 3. Summary of the regulatory authorities (legislation) for each major program within the market-like or market-based conservation mechanism types.

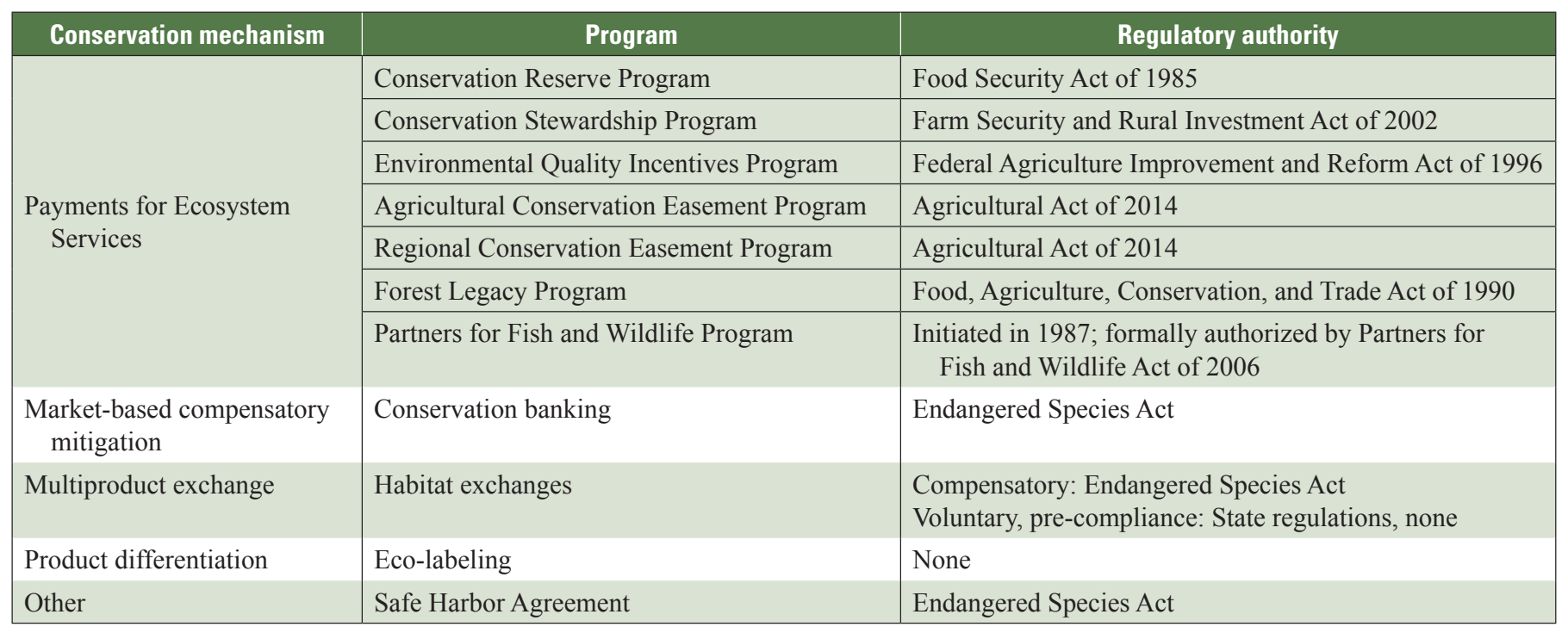




\section{Chapter C-Structural Components of Conservation Mechanisms}

The various conservation mechanisms that benefit biodiversity and habitat share common structural components based on regulatory context, programmatic management, and program design. A number of structural components common to most conservation mechanisms, including marketlike programs, exist: baseline, criteria for eligible lands, site selection, approval process, practices, term, protocols for credit determination and measurement, and trading rules. Each structural component is briefly described in table 4. Specific structural components for each of the conservation incentive mechanisms (PES, conservation banking, habitat exchanges, and eco-labeling) are then discussed.

\section{Market-Like Payments for Ecosystem Services}

Eligible Lands: For USDA Payments for Ecosystem Services (PES) programs, agricultural producers and lands that produce agricultural commodities, livestock, or forest-related products are typically eligible to receive assistance to conserve ecosystem services, excluding private industrial forestland. Significantly, only privately held lands-which include tribal lands-are eligible for participation in the program.

The Conservation Reserve Program (CRP) currently focuses on water quality and habitat and accepts applications from farmers with marginal pastureland, grassland, and

Table 4. Descriptions of components of conservation mechanisms.

\section{Component}

Baseline

Land eligibility

Site selection

Approval process

Management practices

Term

Credit determination

Trade rules

\section{Description}

The baseline represents the characteristics of a site prior to implementing biodiversity or habitat conservation. It can include conditions only or can also require a suite of practices that are already occurring on-site.

Depending on the mechanism and program, this component outlines what lands and what entities are eligible to participate.

The process for selecting a biodiversity benefit site is a component of any approach. The market-based approaches considered in this circular largely rely on private landowners to voluntarily supply land for program participation.

The approval process is a set of administrative procedures carried out by the approving authority whether it is a government program, exchange administrator, or an independent accreditor (as in eco-labeling).

The practices for each mechanism depend on the specific program. These practices can include the acquisition and protection of land for conservation, habitat restoration or creation activities, and the ongoing management approaches necessary to maintain habitat.

Contract term is the length of a contract and may be 1, 5, 10, or 15 years, or in perpetuity depending on the mechanism. Term is considered a crucial component of conservation programs because it impacts how long biodiversity benefits accrue and the willingness of agricultural producers to participate in a program.

The process for defining and determining the number of credits or level of funding for a project varies between mechanisms. Credits are the currency for market-based biodiversity mechanisms.

Trade rules in the current context are how payments for a Payments for Ecosystem Services (PES) are disbursed or how tradable credits are regulated. This element considers who the buyers are, where they purchase credits, and what, if any, approvals are needed for transactions. 
Conservation Management Practices: Predator Compensation Program

Defenders of Wildlife, a national nonprofit conservation organization, operates a Predator Compensation Program to help conserve large predators. The mechanism operates by providing financial compensation for livestock killed by predators at fair market value. The objective is to provide an incentive for ranchers not to kill the predators. The program works to reduce the view of predators as a liability or increase 'predator tolerance'.

In 1987, Defenders initiated a compensation program for wolf conservation. The compensation fund has paid out nearly $\$ 40,000$ to ranchers since that time. Ten years later, Defenders took over and expanded a program for grizzly bears that was previously administered by the Great Bear Foundation.

To be eligible for either of these programs, a landowner has to find and cover the remains of livestock suspected of predation with a tarp. The landowner then contacts State or Federal officials whom verify the loss. Upon verification, the agency contacts Defenders, who assesses the market value of the livestock and send the landowner a check. There is a limit of $\$ 2,000$ for compensation on a single animal.

The program is designed to compensate landowners in a short time - often less than two weeks - and provide a reliable, objective source of compensation. Multiple States, including Oregon and Minnesota, also have compensation programs.

Adapted from Defenders of Wildlife, 1997.

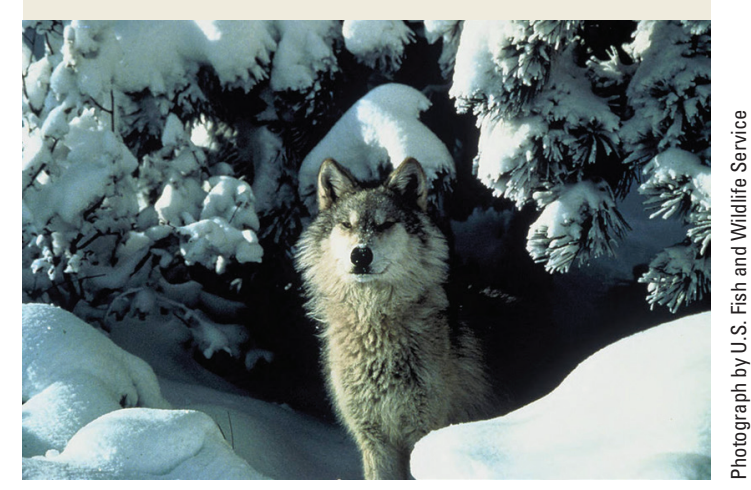

cropland. The other programs consider all lands owned or operated by agricultural producers that supply commodities, livestock, or forestrelated products, including cropland, grassland, rangeland, pastureland, and nonindustrial private forest land.

Similar to PES, another mechanism that incentivizes biodiversity is a compensation program. The Defenders of Wildlife Predator Compensation Program is featured in highlight 11. Similar to other mechanisms, these programs provide benefits to private landowners. Rather than receiving a payment for an environmental service, landowners can receive a type of 'insurance' that, if they don't kill endangered predators (and hence adversely impact an area's overall biodiversity), they will be compensated for lost livestock.

Site Selection: While USDA PES programs rely on private agricultural producers volunteering their land for programs, the Department does designate priority areas for conservation. The designation of conservation priority areas allows USDA PES conservation programs to give precedence to projects in areas of special environmental sensitivity. For example, the CRP places a priority on projects on land with actual and significant adverse water quality or habitat impacts due to agriculture production.

Approval Process: USDA PES programs are voluntary and highly competitive. The Farm Bill includes guidelines for administrators to evaluate applications from agricultural producers or eligible partners. For the CRP, applications are ranked against each other at a national level according to an Environmental Benefits Index (EBI). An applicant's EBI is dependent on factors such as wildlife habitat, water quality, erosion reduction, and air quality as well as enduring benefits beyond the project's completion.

The CSP has an 11-step enrollment process that includes a selfscreening checklist; a Conservation Management Tool (CMT) used to assess existing and proposed conservation practices and determine which conservation activities are to be added during the contract length; and verifying activities that occur on a yearly basis to enable funding (Kemp, 2009). For EQIP, the NRCS ranks applications according to local and national criteria. Local conservationists, agricultural producers, and others in the natural resources community choose what resource problems are most important at the local level; these are weighted at 25 percent while national criteria comprise the remaining 75 percent of ranking points.

ACEP has a five-step evaluation process. The ranking criteria emphasize maximizing conservation values that protect agricultural lands, rather than strictly focusing on the highest conservation value. Cost-effectiveness may be considered, but it does not increase a project's priority ranking if other criteria are not satisfied.

For RCPP, eligible partners and agricultural producers must submit a pre-proposal with basic information followed by a more detailed proposal. The application requires a description of the scope of the project; the plan for monitoring, evaluating, and reporting on progress; requested resources for the project; and the roles, responsibilities, capabilities, and financial contribution of collaborating partners. The Farm Bill outlines what applications are given a higher priority, including applications that assist producers in meeting regulatory requirements; cover multiple participating producers in the same area; utilizes significant amounts of non-Federal funds; addresses regional, State, or national conservation initiatives; and provide conservation innovations (American Farmland Trust, 2014). 
Management Practices: The specific practices allowed within any USDA PES program depends on the intent of that program. The level of specificity can impact how many farmers are willing to participate in a particular program. The CRP incentivizes several practices, with wildlife habitat buffers and wetland restoration being the most relevant to biodiversity benefits.

The CSP allows grazing management, shallow water habitat creation, patch burning, prairie restoration, and the establishment of pollinator habitat, all of which can directly or indirectly benefit biodiversity. The RCPP includes forest restoration and habitat conservation, restoration, and enhancement practices in their suite of PES activities. An example of a common practice is the riparian buffers described in highlight 12 .

For some programs, the USDA partners with an eligible entity to help producers install and maintain conservation activities. For example, under the RCPP, the USDA collaborates with local partners such as farmer cooperatives and local governments to coordinate resources and provide assistance to producers for projects (USDA, 2014e). The programs also permit certain activities or commercial land use under contract as long as they are consistent with the approved conservation plan.

Term: The Farm Bill governs the length of conservation program contracts between the USDA and agricultural producers. The CRP has contracts ranging from 10 to 15 years, while EQIP contracts are not to exceed 10 years. The CSP contracts are the shortest at five years (with renewal options). The longest USDA PES contract terms are for ACEP, which may require land to be held in permanent easements or for the maximum duration allowed under State law.

Credit Determination: In return for implementing or continuing to maintain conservation land management practices, USDA PES programs offer combinations of direct payments and project cost assistance to private landowners. Landowners don't receive tradable credits as in the conservation bank program or habitat exchanges. The approval process considers the quantity of biodiversity benefits that a particular project may yield, but payments are based on what a practice costs (though often a set payment rather than based on actual costs). A significant factor in PES programs is that funds are distributed on an annual basis.

Conservation Management Practices: Riparian Buffers

Riparian buffers are areas of trees and shrubs bordering streams, lakes, ponds, and wetlands. Riparian buffers provide thermal, nesting/fawning, and hiding cover in riparian zones, stream banks, and shorelines; diverse food sources; a steady source of leaves, brush, and small woody material for downstream aquatic food webs; root systems to enhance bank stability; and vegetation filters for surface water run-off (USDA, 2014b).

Riparian buffers are usually established as part of a conservation management system with other practices. For example, riparian buffers would have to be established concurrently with other projects, such as filter strips and critical area planting to control upslope, excessive water flows and erosion, in order to maintain proper functioning of the trees and shrubs (USDA, 1997).

In a collaborative program headed by the Leopold Center for Sustainable Agriculture at lowa State University, researchers worked with landowners in the Bear Creek watershed to install riparian buffers to mitigate erosion, reduce nitrate runoff, and improve wildlife habitat between 1990 and 2002. Over 22,500 acres of riparian buffers were installed in lowa.

Through the Leopold Center Program, researchers were able to intensively study the benefits of riparian buffers. Researchers learned that riparian buffers can reduce sediment in surface runoff by as much as 90 percent, increase soil organic compounds by 66 percent, and support five times as many bird species as row cropped or heavily grazed land (Leopold Center, 2013).

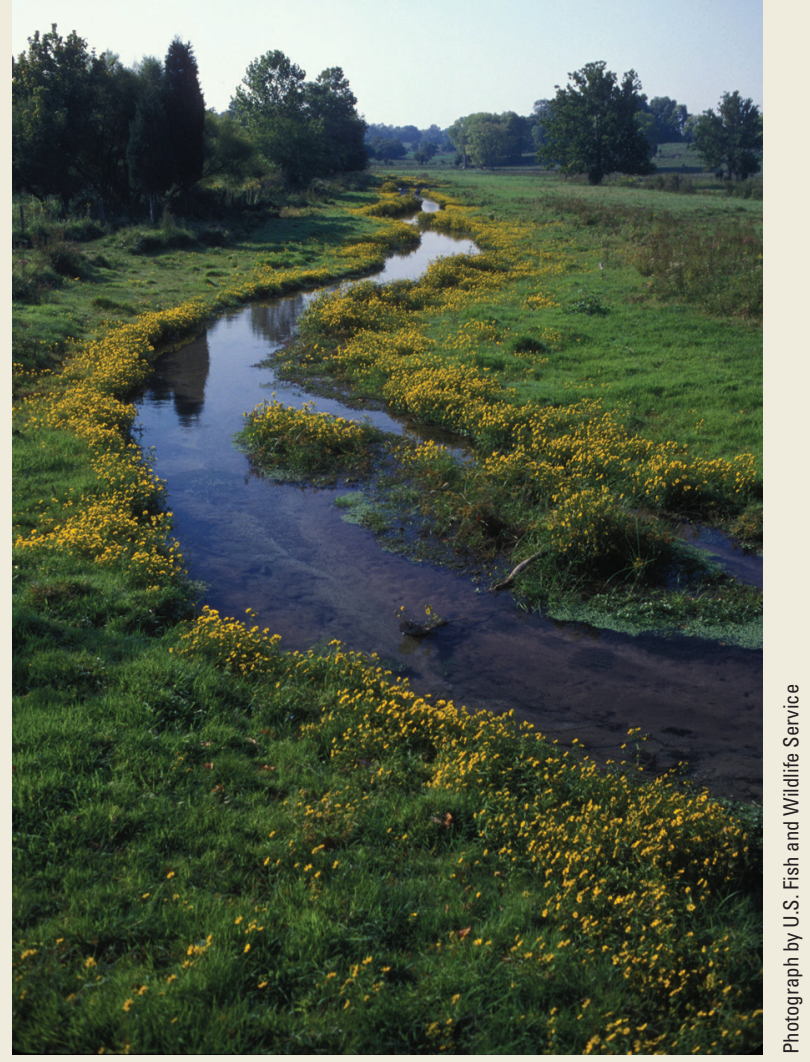


CRP payments typically include 50 percent cost-share and an annual payment intended to compensate for foregone crop production. The annual payment for each enrollment is based on a county-average survey estimate of cash rents and a soil-specific agricultural productivity index. Average CRP rental payments were $\$ 46.51$ per acre in 2010 and $\$ 55.06$ per acre in 2011 (USDA, 2011b). EQIP provides up to 75 percent of average estimated project costs associated with planning, design, materials, equipment, installation, labor, management, maintenance, or training and up to 100 percent of income forgone by the producer (Food Security Act of 1985).

ACEP offers cost-share assistance for the purchase of agricultural land easements not to exceed 50 percent of the fair market value for cropland and 75 percent of the fair market value for grasslands (Agricultural Act of 2014). ${ }^{5}$ Under the Regional Conservation Partnership Program, the USDA partners with local entities such as farmer cooperatives and local governments to help fund conservation activities such as water quality restoration and habitat conservation. Regional Conservation Partnership Program receives funding from ACEP, EQIP, CSP, and the Healthy Forests Reserve Program, and payments follow the requirements of those specific programs.

The CSP is different from other USDA PES programs as participants are paid annually based on continuous performance as opposed to a flat rental rate or cost share percentage, thus making CSP payments more "market-like" than other USDA conservation programs. Annual land use payments are calculated by multiplying the land use acres by program performance points and land use payment rate (USDA, 2014c).

Annual payments, as opposed to the one-time lump sum used in conservation banking, may be preferred by farmers. In a study conducted on government agencies working with landowners on conservation in Oregon, Washington, Idaho, and Montana, researchers found that landowners preferred program participation benefits such as tax incentives and insurance against legal liability and contract failure in addition to an appropriate annual payment amount (Gosnell and others, 2013).

Trade Rules: For the PES mechanisms considered here, the USDA, on behalf of the public, is the sole buyer. These incentive-based programs provide direct payments, cost share, or technical assistance in return for the ecosystem services derived from private landowners, whether based on environmental outcomes or the installation of best management practices and the assumed benefits derived therefrom. The Farm Bill outlines the rules for payments and assistance, which can include the availability of payments, the timing of payments, limitations on payments, activities excluded from payments, and how payments are delivered. For example, producers under EQIP are paid to implement one or more conservation practice; payments are not to exceed 75 percent of the costs associated with the planning, design, materials, equipment, installation, labor, management, maintenance, or training; and they are not to receive aggregate cost-share or incentive payments that exceed $\$ 450,000$ between 2014 and 2018 .

${ }^{5}$ The cost-share may be as high as 90 percent for historically underserved groups.
Additional Conditions: The USDA and participants in the Farm Bill conservation programs enter into contracts to define the responsibilities necessary to deliver desired ecosystem services. Requirements are included in the conservation program sections in the Farm Bill and generally include land ownership or operation requirements for entering into a contract, payment amount, producer land management requirements, provisions for the sale or transfer of lands covered in the conservation program, and provisions for the modification, termination, and violation of the contract. Conservation programs in the Farm Bill often have elements such as special programs or practices that require specialized rules and regulations in addition to the overall conservation program. The CSP offers additional supplemental payments for resource-conserving crop rotations as well as outreach and technical assistance for specialty crop and organic producers.

\section{Conservation Banking}

The design of the conservation banking program was influenced by lessons learned from the USACE regulation of wetlands under the Clean Water Act. From the finding in 1995 that the wetland mitigation program was not delivering ecological benefits, the USACE published guidance on mitigation banks (in 2008, the USACE and EPA published regulations). The USACE stated that "banks provide greater flexibility to applicants needing to comply with mitigation requirements and can have several advantages over individual mitigation projects":

- Establishment of a mitigation bank can bring together financial resources, planning and scientific expertise not practicable to many project-specific compensatory mitigation proposals. This consolidation can increase establishment and long-term management of successful mitigation that maximizes opportunities for contributing to biodiversity and (or) watershed function;

- Banks may reduce permit processing times and provide more cost-effective mitigation;

- Consolidation of compensatory mitigation within a bank increases the efficiency of limited agency resources in the review and compliance monitoring of mitigation projects, and improves the reliability of efforts to restore, create or enhance wetlands for mitigation purposes. (Federal Register, 1995).

Eligible Lands: Private, tribal, State and local government lands are eligible. The FWS (2003) guidance specifies land must be habitat acquired or further protected through a conservation easement; disturbed habitat that is restored or enhanced; or habitat that is created. All of these represent additionality for the species in the FWS view; with the minimum being to protect habitat that would not otherwise be protected. All require prescriptive management based on the species' needs. For privately held habitat without the species present, directed management is essentially for at-risk habitat and does 
not necessarily aid in the species' recovery. Habitat can be purchased outright, or it may remain in the original landowner's possession, as long as a permanent conservation easement is put in place. The additional layer of land protection and prescribed management are considered additional biodiversity benefits. In practice, conservation banks may take several different land ownership models. The typical models include a joint venture, an outright purchase of property, or a landowner managed bank. ${ }^{6}$

Site Selection: A conservation bank site is ultimately selected by the bank owner or manager, although it is often selected in coordination with the FWS. During the bank approval process, the FWS must agree that the proposed site will "fit into the overall conservation needs of the listed species the bank intends to cover" (FWS, 2003). There are currently 1,535 endangered and threatened species (FWS, 2014), each with different recovery and protection needs, which are reflected in the limited guidance on site selection. The elements that make a site suitable for one species, such as a gray bat, and another species, such as an oyster mussel, are different. The FWS guidance, therefore, encourages the use of best science and the fundamentals of recovery ecology.

Approval Process: The process of approval for a conservation bank is regimented by the 2003 FWS Conservation Banking Guidance. Initially, a landowner or banker proposes to establish a conservation bank. Depending on the State or FWS office, there might be a standard template for the initial application. The Sacramento, California, office developed a template to streamline the application process, benefitting applicants and the FWS staff.

The next step is to convene a Conservation Bank Review Team (CBRT) that includes biologists. The CBRT is an interagency group of Federal, State, tribal, and local regulatory and resource agency representatives that are signatory to the bank agreement and oversee the establishment, use, and operation of the bank. The CBRT reviews the site and a management plan on the practices that the bank will implement to benefit the species. During the approval process, the CBRT and applicant develop a banking agreement that details the responsibilities of the conservation bank manager. At this time, the easement holder must be named and funding assurances for permanent management described. The approval process for conservation banks is lengthy; it can take as little as six months or as long as five years to receive approval for a bank.

Management Practices: The specific conservation practices for a given bank may differ depending on a species' needs. Practices may be aimed at habitat preservation and management, restoration of degraded habitat, connecting separated habitats, buffering already protected areas, creating habitat, or other appropriate actions. Conservation banks will have both initial practices to preserve, restore, or create habitat, as well as ongoing management practices. One example of a management practice is grazing, which is featured in highlight 13 .

The FWS guidance allows bankers to conduct activities on conservation bank land that are compatible with conservation. Fox and NinoMurcia (2005) surveyed conservation banks and found that 66 percent allowed cattle grazing, hunting, biking, horseback riding, hiking, or fishing. In some cases, grazing or other revenue generating activities can be a part of the management plan as a component of habitat enhancement for the species.

${ }^{6}$ Patrick Coady (Coady Diemar Investment Banking), oral communication.
Conservation Management Practices: Grazing

In California and Oregon, vernal pools contain species that rely on the habitat. The vernal pool fairy shrimp is federally listed as a threatened species throughout its range. The primary threat to vernal pool fairy shrimp is the elimination and degradation of its habitat. This habitat is threatened by industrial, urban, and residential development, as well as the conversion of grasslands to agricultural fields (FWS, 2006).

Within vernal pool habitat areas, invasive nonnative plants negatively impact the vernal pool hydrology and further threaten vernal pool fairy shrimp (FWS, 2007). One way to manage protected vernal pool habitat is to reduce the invasion of nonnative vegetation via grazing. Grazing is used on conservation banks for vernal pool fairy shrimp to reduce weeds and invasive plants in California.

At the Orchard Creek conservation bank in Placer County, California, the long-term management includes weed control via grazing cattle on the pastureland. Cattle grazing is the preferred method for weed control; cattle walk through the vernal pools when they are wet and preferentially graze on invasive exotic grasses targeting a source of detriment for the vernal pool fairy shrimp (The Conservation Fund, 2010a).

Grazing must be well managed to ensure that an excess of cattle do not negatively impact the habitat and that the timing optimizes their ability to control weeds. Effective grazing can be a win-win for conservation banks by managing invasive species and providing an additional source of revenue.

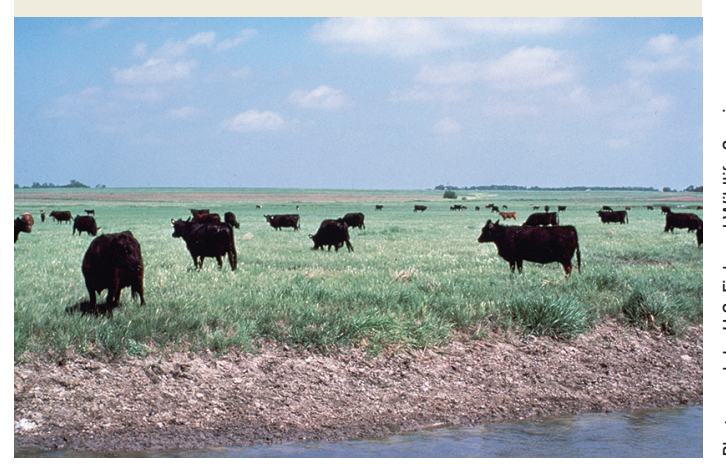


Term: Conservation banks, by definition, exist in perpetuity. The FWS guidance has two requirements to safeguard perpetuity in practice. The first is a financial assurance intended to cover all the ongoing management costs of the bank. The FWS guidance suggests a non-wasting endowment as an approach to ensure that conservation activities will be funded over time (FWS, 2003).

The second component for ensuring conservation bank perpetuity is a conservation easement. Most banks must have a conservation easement, or another fee title, that legally protects the land in perpetuity. The easement has to be in place by the time the first credit is sold. This approach ensures, at a minimum, that the land is legally protected. Permittee-responsible mitigation is also meant to protect habitat permanently, although in practice this might not be achieved because of inefficient economies of scale at the single project level (DOI, 2013b).

Credit Determination: Credits represent the biodiversity benefits that conservation banks yield. The credit is the asset for the bank owner. The FWS determines the number of credits the bank will receive based on biological criterion such as habitat quality, habitat quantity, species covered, and conservation benefits, including the contribution to regional conservation efforts, property location and configuration, and available or prospective resource values (FWS, 2003).

The methods for defining and determining credits are not specified further in the FWS guidance. For a particular species, a credit may simply represent one acre of habitat, a "functional acre", a breeding pair and their associated habitat, or other biophysical characteristics. A functional acre is a unit of measurement based on factors that include geospatial units and habitat quality indicators. A functional acre may assign a different value to a given acre of land based on how it is used by the species. For example, upland habitat may be given a score of half an acre while vernal pools are a full acre in the case of a vernal-pool-dependent species. Further consideration of the credit types and methodologies is discussed in Chapter E.

The definition of a credit for a bank is not standardized and can differ between FWS field offices. The method for assigning the number of credits a bank receives; or an impact, which would be debited; is also not standardized. A significant criticism of conservation banking is the lack of standardization in credit quantification methods. According to a 2012 survey of FWS employees, determining the number of credits was considered one of two areas needing the most improvement in the program (DOI, 2013a). In addition to the number of credits attributed to a bank, the release schedule through which bankers can offer credits for sale is determined by the FWS.

Trade Rules: For a buyer to purchase credits from a conservation bank for use in compensatory mitigation, the transaction must be approved by the FWS. There are two key components in transaction approval: (1) the impact in the service area of the conservation bank and 2) the debits for which the project proponent has to purchase credits. A service area for any conservation bank is determined in the banking agreement and is associated with the specific recovery unit, watershed, or other geospatial boundary for which the conservation bank provides biodiversity benefits (FWS, 2003). A service area may have one or more banks, and there may be one or more buyers within a service area. Impacts that occur outside the bank's service area may affect a genetically distinct subgroup of the species or otherwise affect the species in such a way that the bank would not provide sufficient mitigation.

From a banker's perspective, siting the banks in the largest possible service area broadens their potential market. Additionally, the desirability of the land in the service area, and, therefore, the number of potential developers and credit seekers, affects the size of the market for biodiversity credits.

The FWS determines the magnitude of impact, or debits, that a party has on their site. The FWS guidance calls for debits to be determined using the same method banks use with credits. A consideration for project proponents is that the purchase of a credit in a conservation bank fully transfers liability for mitigation to the banker, as opposed to the rules under permittee-responsible mitigation, where they would retain liability (DOI, 2013b). The transfer of liability may be a significant enticement for purchasing bank credits. This contrasts with other markets, such as water quality trading, where the regulated source (for example, a wastewater treatment facility) remains liable for pollution abatement; the potential failure of a project from which a buyer purchased credits then creates a disincentive for trading (Ribaudo and others, 2008).

Additional Conditions: The FWS guidance also requires conservation banks to have management plans detailed in their banking agreements, regular monitoring, and specified remedial actions.

\section{Habitat Exchanges}

Habitat exchanges are trading platforms designed to ease administrative burden and address uncertainties that arise from the structure of conservation banks. The concept is, rather than to approve banks and assign debits on a case by case basis, to use a programmatic mechanism to create credits across large areas; these credits and debits would be based on the same HQT (EDF, 2013b). HQTs and similar tools are discussed in Chapter E.

There are many efforts to develop habitat exchanges or similar market mechanisms. Some efforts are focused on pre-compliance markets (such as the gopher tortoise example), while others anticipate broader application in both pre-compliance and compensatory mitigation (such as the Greater Sage Grouse habitat exchange effort).

Eligible Lands: Similar to conservation banks, a property must be able to yield a certain amount of biodiversity benefits or uplift to qualify. Within the habitat exchange framework, the HQT is used to estimate habitat quality within a given area and considers four geographic scales: the site, the surrounding landscape, the allowable service area, and the overall range of the species (EDF, 2013b). The exact method for quantifying habitat quality differs between exchanges and depends on the 
species of concern. Habitat exchanges will likely focus on private land and specify how the baseline from which the HQT will estimate potential uplift is determined.

Site Selection: Like conservation banks, bankers or landowners ultimately determine the biodiversity benefit site. The HQT uses landscape-scale factors to create a higher value for habitat in priority areas for species of concern. Theoretically, this can encourage siting conservation in high priority areas and discourage development in areas with high-quality habitat. Priority areas and avoidance areas are determined by the exchange's science team or by adopting pre-existing areas delineated by States (as with Wyoming Core Areas), the FWS, or others (EDF, 2013b). Unlike conservation banks, which have advisory teams to approve individual banks, habitat exchanges use a science team to determine priority areas and quantification methods for a comprehensive program rather than for individual efforts.

The HQT approach may provide significant information to improve banker, landowner, and developer decisions on where to conserve and develop land. However, based on current information, a comprehensive assessment of the exchange area is not to be completed. Rather, the HQT is to be used in an on-demand approach when a banker or developer expresses interest in a site. At this time, they will use (directly or via a third party assessor) the HQT to estimate the potential of their site. A full assessment could enable the intra-regional decisions envisioned by habitat exchange developers, but this on-demand approach could limit additional siting benefits. A comprehensive assessment is not without concerns either, as landowners may be sensitive to the analysis of their private property and costs could be substantial.

Approval Process: Based on the upfront development of the HQT, the approval process could be streamlined in comparison to the approval process of conservation banks, but this would need to be tested in the field.

Management Practices: Practices for habitat exchanges are likely similar to conservation banks and aimed at habitat preservation, management, restoration of degraded habitat, connecting separated habitats, buffering already protected areas, creating habitat, and other appropriate actions. An example of a management practice is prescribed fire, which is featured in highlight 14. Habitat exchanges are designed to encourage outcome-based incentives. This encouragement could engender innovative practices beyond the scope of traditional conservation strategies. Outcome- or performance-based approaches versus practice-based incentives are discussed in Chapter E.

Term: The term for habitat exchanges varies depending on the type of mitigation. The term for compensatory mitigation is in perpetuity to comply with conservation banking regulations. Precompliance mitigation may vary. The Environmental Defense Fund (2014) has designed an innovative approach to provide credits for permanent mitigation for a lesser prairie chicken habitat exchange. The exchange allows traditional conservation banks to trade on the exchange alongside two additional categories: static permanent mitigation and dynamic permanent mitigation. For static permanent mitigation, landowners would be subject to restrictions similar to those of conservation banks, such as land being in a permanent easement prior to the sale of credits.
Conservation Management Practices: Prescribed Fire

Prescribed fire is a management approach that reduces hazardous fuels (such as undergrowth) and protects human communities from extreme fires, minimizes the spread of pest insects and disease, removes unwanted species that threaten species native to an ecosystem, provides forage for game, improves habitat for threatened and endangered species, recycles nutrients back into the soil, and promotes the growth of trees, wildflowers, and other plants (USFS, 2014).

As a conservation tool, the ecosystems in which prescribed fire is frequently practiced are loblolly, short-leaf, longleaf or slash pine forests. According to Wade and Lundsford (1986), fire tends to favor species that require open habitats that result in a mosaic of burnt and unburnt areas that maximizes the "edge effect". This type of habitat promotes a large and varied wildlife population. Deer, dove, quail and turkey all benefit from prescribed fire. Several endangered species, including Florida panthers, gopher tortoises, indigo snakes and red-cockaded woodpeckers, also benefit from fires (Wade and Lundsford, 1986).

Fires need close management to prevent outof-control burns leading to greater damage than benefits. In prescribed fire, it is important to select the appropriate size, frequency, and timing of burns.

Prescribed fire remains controversial in some ecosystems. It is used in sagebrush to provide more grasslands for ranching. Prescribed fire was once thought to improve sagebrush habitat for sage grouse, but the Sage and Columbian Sharp-tailed Grouse Technical Committee (2009) concluded that prescribed fire is detrimental to the species (which is a candidate for ESA listing).

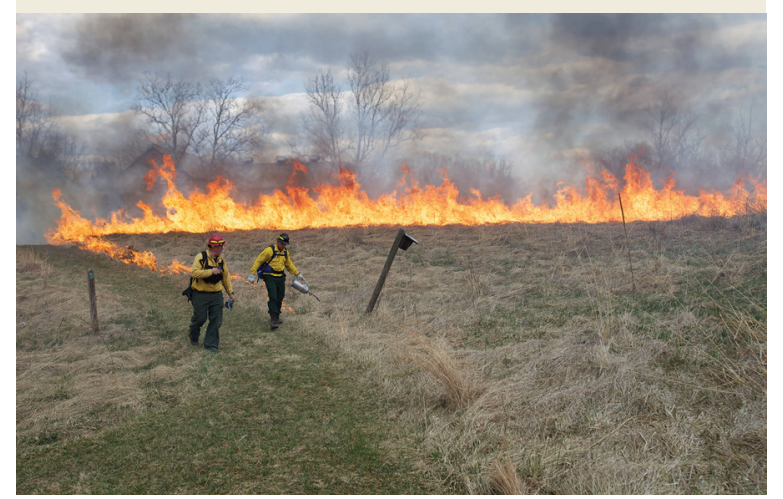


Dynamic permanent mitigation is designed to address issues caused by a lack of available credits for static permanent mitigation. Not all property owners may be willing to place a permanent easement on their land. A dynamic permanent mitigation approach allows for permanent mitigation from a debtor to be achieved through the purchase of dynamic credits from multiple landowners over a period of years. As a result, these credit types may have a limited term although they are intended to cover a permanent impact in aggregate.

The lesser prairie chicken habitat exchange design includes assurances against gaps in mitigation. One novel feature of the habitat exchange is the Reserve Account. This account is a reserve of credits; the exchange has stipulations such that purchasers and sellers must contribute a predetermined number of credits to the reserve in addition to the quantity of credits required for mitigation. The reserve account accumulates credits that can ensure there are no gaps in permanent mitigation through the use of dynamic permanent mitigation credits, as well as for other purposes (EDF, 2014).

Credit Determination: A cornerstone of habitat exchanges are the HQTs developed upfront and used to assess all proposals, assigning both credits and debits to a given project. The tools measure functional acres at a site and modify the number of credits based on site location within the landscape (EDF, 2013b). Credit determination is based on performance in habitat exchanges. Rather than awarding credits when a banker installs and manages a particular practice, the seller must perform and continue to show results to have credits verified throughout the life of each credit.

Trade Rules: Trade within habitat exchanges is when the differences from a conservation bank framework become noticeable. Rather than go through an approval process for the purchase of credits, the approval and verification of credits and debits has already occurred. The trading process can be conducted using a transparent, auction-based platform. Buyers pay a market price for credits listed for sale (EDF, 2013b).

\section{Eco-Labeling}

Eligible Lands: The eligibility of land for eco-labeling depends on the label's purpose, even though certification is probably for private landowners. For Salmon-Safe certification, multiple types of land and structures are targeted: vineyards, farms, corporate and university campuses, green infrastructure buildings, large-scale residential developments, parks, golf courses, and large-scale construction sites (SalmonSafe, 2014). Unlike many of the approaches considered, Salmon-Safe is predominantly a regional program focused on the west coast of the United States. For vineyards, the SalmonSafe certification only considers Washington and Oregon State vineyards.

Site Selection: Similar to the approaches discussed, ecolabeling is a voluntary approach and applicants choose a site to be approved by accreditors.
Approval Process: The process for receiving an accreditation depends on the program. The Salmon-Safe program has a process designed for approval for each type of land and structure verified. For farms, a documented evaluation must be conducted by an independent expert evaluator. The evaluator assesses the farm with a scoring protocol designed to protect salmon streams (Salmon-Safe, 2005).

Management Practices: The biodiversity benefit conferred to an entity through a specific label is the factor upon which eco-labeling practices depend. The Salmon-Safe certification program is designed to verify that farm management practices incorporate Best Management Practices to "avoid harm, and where appropriate, enhance and restore the health of stream ecosystems" (Salmon-Safe, 2005). Practices focus on improving riparian and wetland area management, irrigation water use and management, erosion and sediment control, fertility and pest management systems to reduce impacts on salmon ecosystems, animal management, and biological diversity conservation.

The Wildlife Friendly certification program, administered by the Wildlife Friendly Enterprise Network, is featured in highlight 15 . This mechanism requires non-lethal management activities that circumvent depredation for a landowner to receive certification. This approach is in contrast to the Defenders of Wildlife Compensation Program previously described, and landowners can seek incentives from both mechanisms to realize even greater benefits.

Term: The Salmon-Safe certification is valid for three years and subject to annual inspections (Salmon-Safe, 2005). Other eco-labels may have longer or shorter terms.

Credit Determination: Credit determination depends on the program. Some eco-labels may allow different levels of accreditation. The Salmon-Safe program requires that farms meet standards on the entire farm, not just for one area or crop. A pre-established scoring approach determines whether or not a farm meets a net positive score across all elements. If the farm passes, they receive the accreditation that theoretically differentiates their products to consumers willing to pay a higher price than they would for similar, unaccredited products.

Trade: For eco-labels, trade is not regulated. Once the accreditation is awarded, the product can be advertised (dependent on the programs parameters) as accredited and consumers can freely choose these products. Purchase of ecolabeled products is not compensatory and therefore not subject to transaction verification.

\section{Comparison of Types of Approaches}

The biodiversity conservation mechanisms discussed in this chapter have different specifications for their major structural components as a result of regulation or program management, or by design to address specific issues. A number of structural elements are considered: land eligibility, site 
The Wildlife Friendly certification program verifies farm and ranch lands that employ non-lethal predator management practices. Examples of non-lethal predator management practices are listed below.

- Adaptive Grazing Planning, in which grazing is scheduled during periods of low predatory pressure. Knowledge of dens and patterns of wildlife use is necessary to implement this strategy.

- Mixing larger animals with smaller livestock for protection.

- Adaptive Feeding Strategies, in which feeding is done when livestock are collected in a secure location at night or during other strategic periods.
- Use of protected pastures, fenced lots, or sheds to secure stock during lambing/calving and other highly vulnerable periods.

- Producers time calving, lambing, kidding, farrowing and/or hatching to reduce predation risk.

- Use of livestock guardian animals, such as dogs, llamas, and donkeys, where their presence has been shown to add to predator deterrence.

- Use of barriers, such as electric fencing and fladry (fencing with special flags), and mechanical deterrents, such as RAG (radio-activated guard) boxes, to deter predators.

Adapted from Certified Wildlife Friendly, 2013. selection, approval process, management practices, term, credit determination, trade, and other conditions. The specifications for these components can affect a landowner's willingness to participate in programs and the anticipated biodiversity outcomes.

Land eligibility ordinarily involves private property, with agricultural land, forests, and grasslands being centrally important for biodiversity and habitat conservation. Site selection is largely conducted by applicants because all of these approaches are voluntary. Different conservation mechanism programs allow varying degrees of outside input into the site selection process. For instance, with conservation banks the FWS is regularly involved to ensure potential bank sites are suitable for a specific species.

The approval process for each mechanism varies in time and administrative processing. Some programs have more rigid criteria for evaluating potential projects while others examine biodiversity benefits on a case-by-case basis. Environmental indices like the Environmental Benefits Index can increase environmental cost-effectiveness in conservation programs by ensuring projects with the highest potential environmental benefits are funded first (Claassen and others, 2008). Some programs have long administrative processes, such as the multi-stepped CSP. Cheatum and others (2011) reported that excessive paperwork or the general hassle of applying are considered major constraints by some ranchers in their decision to apply to USDA resource conservation programs.

The management practices allowed by different mechanisms depend on the biodiversity target. For example, prescribed fire and grazing may be established practices that benefit some wildlife species while these practices may be detrimental to other species. Most approaches include practices to conserve and protect habitat. Some require proactive management to retain or improve habitat.
The contract term is an important factor and varies widely across conservation mechanisms. The USDA PES programs range from 1- to 15-year contracts, while conservation banking requires a conservation easement to guarantee land is set aside in perpetuity. The lesser prairie chicken habitat exchange may have an innovative approach with dynamic permanent mitigation (DPM) credits, although the DPM approach still needs to be field tested. Optimal contract length depends on the tradeoff between the biodiversity benefits from conserved land and the number of private landowners willing to enter into the program (Chen and Ando, 2006). While longer conservation contracts maximize environmental benefits, private landowners like ranchers are more willing to enter into contracts with shorter lengths and higher payments (Cheatum and others, 2011). Cheatum and others (2011) found that California ranchers required a marginal payment increase of $\$ 0.81$ per acre for each additional contract year. In a similar study, Maryland tree farmers and agricultural landowners required an additional $\$ 2.00$ per acre for each additional contract year (Tjaden and others, 2013).

Credit determination and representation are critical components of either outcome- or practice-based conservation mechanisms. While USDA PES programs and conservation banking are largely practice-based, habitat exchanges are attempting to develop outcome-based crediting systems. Outcome-based credit assignment assures that the biodiversity benefits being sold are realized, and it allows for innovation in practices. However, there may be additional costs associated with verifying and monitoring outcome-based approaches in comparison to practice-based approaches. These methods may also require more intrusion on private land, which may discourage agricultural landowner participation.

Additional differences in credit determination occur across the programs. For PES programs, funds are disbursed 
based on well-established management practice installation costs and land rental rates. In comparison, credits are awarded based on methods developed for particular species and are often conducted on a case-by-case basis for conservation banking. Habitat exchange developers seek to reduce the administrative burden of conservation banking credit assignment and provide upfront, transparent approaches to credit methods with HQTs (or similar mechanisms) that are applied to all applicants trading on the exchange.

Trading is structured differently between biodiversity conservation mechanisms. USDA PES programs are singleclient transactions, where the USDA is the sole purchaser of all benefits provided by program participants. Conservation banking awards tradable credits to landowners; however, transactions for compensatory mitigation must be approved by the FWS. Habitat exchanges also award tradable credits, but the use of the HQT upfront for all exchange participants allows transactions to occur without additional oversight. Transactions are tracked and credits are retired, but overall this method reduces the transaction costs and administrative burden that occurs in conservation banking.

It is important to note that although the design and structure of biodiversity conservation mechanisms affect participation in the program, other factors also influence participation. Studies highlight the importance of incentives other than payments. Sorice and others (2011) used a survey to discover that payment levels can positively affect a private landowner's willingness to participate in songbird habitat conservation programs, but the effect depends on their attitude towards enrollment as well as their perception of the social pressure to participate. The authors suggest that the promotion of private land conservation may be enhanced by including social networks as well as collaborative processes that reinforce social norms in addition to current incentives. 


\section{Chapter D-Economics of Biodiversity and Habitat Markets}

This circular focuses on market-based mechanisms to promote biodiversity or habitat conservation. There are multiple economic questions to consider when evaluating these mechanisms. Why use market-based approaches? How well do current conservation mechanisms compare to markettype approaches? What is the market size and potential? This chapter reviews the foundations of environmental markets, including the theoretical basis for employing market-based approaches to environmental problems in consideration of these questions. The chapter also explores how well each current, market-based mechanism compares to market theory. Finally, the current size of markets and prices are discussed.

\section{Foundations of Environmental Markets}

Even though environmental protection and conservation can be achieved through prescriptive regulation, economic theory lends itself to the development of approaches that can achieve the same benefits with a more efficient and less costly allocation of resources. To understand how market-based approaches can lead to environmental protection and conservation, the role of the market and how environmental degradation/conservation factors into decisions about resource use must be considered.

Adam Smith introduced the free market theory where "Every individual necessarily labours to render the annual revenue of the society as great as he can. He generally neither intends to promote the public interest, nor knows how much he is promoting it ...He intends only his own gain, and he is in this, as in many other cases, led by an invisible hand to promote an end which was no part of his intention... By pursuing his own interest he frequently promotes that of the society more effectually than when he really intends to promote it. I have never known much good done by those who affected to trade for the public good." (Smith and Cannan, 1904).

This is the treatise of the invisible hand, whereby market forces provide a sufficient supply of goods and services demanded by individuals. The market provides the most efficient distribution of resources, goods, and capital. The most common type of market is defined by perfect competition and has the following specific characteristics: the products of all firms are identical, participants in the market are small and cannot individually affect the product's price, there are no barriers to enter or exit the market, and market participants have perfect knowledge about the products (Mansfield, 1979).
These necessary conditions are theoretical and few markets likely have these exact characteristics. Significant departures from these characteristics can result in market failure. Market failure is a condition in which the market does not efficiently allocate goods. The Pareto Optimal—when no additional gains by one consumer can be made without having a negative effect on another consumer-has not been met. Market failures occur due to externalities, common property, imperfect competition, natural monopolies, public goods provision, and certain kinds of uncertainty (Hartwick, 1986). In resource economics, a market failure often leads to a situation in which prices do not reflect society's preferences. For example, prices of goods do not incorporate societal preferences for biodiversity and too little biodiversity conservation is thus supplied because the price for biodiversity (a non-rival and non-excludable public good) is essentially zero. In the context of biodiversity benefits, one factor leading to market failure is the presence of externalities and another factor is asymmetric knowledge of products and practices.

The concept of externalities is one in which an activity (specifically production) can result in an impact (negative or positive) that is not internal to the accounting of the production activity. Production might entail the manufacture of cars, mineral mining, agriculture, building new housing developments, or any human activity that provides a good or service. The producer's operation is based on an efficient level of production for a particular good, where the marginal cost of the last unit of production equals the price that these goods can earn in the market (based on demand).

The producer's efficient quantity of supply takes into consideration production costs including labor, capital, and materials. The problem is that externalities; in this case biodiversity loss or habitat degradation, or provision as a consequence of production; are not accounted for by the producer, who does not bear the cost nor reap the benefits. The cost of reduced biodiversity or habitat is instead borne by society. If society determined the optimal supply of production, these costs would be included - costs may be to prevent degradation, compensate for damage, or increase biodiversity or habitat-increasing the marginal cost associated with each unit of production and reducing the quantity of production.

A negative externality that affects biodiversity or wildlife habitat is a housing development that clears a forest and displaces the wildlife occupying the land. Another example is the installation of wells and other infrastructure to pump oil, which creates noise, dust, and activity beyond the acceptable 
threshold for wildlife, which are resultantly displaced. Both activities are economic endeavors that provide homes and energy for people, but the negative consequences are rarely considered when estimating the cost of production.

Positive externalities also exist. An example is the planting of vegetation along river banks to provide habitat for species. While this benefits society and individuals (assuming that society and the individual landowner value biodiversity and the co-benefits provided by riparian buffers), there is little economic incentive for an individual to engage in this practice because there is no compensation mechanism for the costs incurred. This leads to an undersupply of biodiversity benefits.

A.C. Pigou first identified the divergence of the producer's and society's interests and argued that the externality could not be mitigated through contractual negotiation within private markets; rather, it would require government intervention via taxes to coerce the offending party to recoup the costs to compensate the injured party (or parties) (Pigou, 1920).

Highlight 16 provides a graphical explanation of producer and society divergence in markets.

Pigou recommended that to correct the inherent market failure, the government must intervene with a tax that should approximate the marginal cost of the externality so that a socially optimal equilibrium could be achieved (Pigou, 1920). The taxes, known as Pigouvian taxes, increase the producer's marginal costs such that they shift the production curve. Under the new market conditions, the government would collect revenues and would theoretically compensate those impacted by the externality. This would result in the social optimum where the externality is reduced and those still harmed by the remaining externality could be compensated by the tax revenue.

Applying tax policy to address an environmental externality can be illustrated by an example relevant to biodiversity. In figure 1, the tan area represents a tract of land. The red areas represent species $\mathrm{X}$ habitat, with larger areas connected by corridors. In this example, a land developer is interested in building houses on the total area of the yellow box.The developer's proposal is based on current land values, building costs, and expectations of purchase price. The green area represents society's preference for development, with the additional yellow space outside of the green preserved to conserve the species' habitat. In command and control, the yellow area may be placed 'off-limits' to producers. Alternatively, a tax on the land in the yellow area could influence the land developer to develop less land (since their costs are now higher).

While taxes are a disincentive to overproduce, Pigou's theorem can be extended to subsidies, which are a positive incentive. The financial assistance or payments for ecosystem services provided by USDA PES programs in this circular are essentially subsidies that yield biodiversity or habitat benefits. The intent of a subsidy is to provide a financial incentive that shifts a producer's supply curve closer to the societal supply curve.

Pigouvian taxes are criticized for imperfectly measuring marginal social costs or benefits (Barthold, 1994). Policymakers must determine the deadweight loss created from an
Externalities in Producer versus Societal Efficient Production

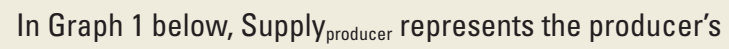
supply curve (costs are lower due to lack of accounting

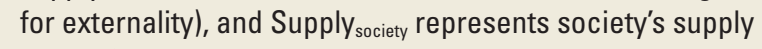
curve. Supply society accounts for the externality, therefore the cost of each unit of production is higher. Demand is based on consumers' willingness to pay for the product, with the demanded quantity decreasing as the price rises. The market equilibrium is the point at which the supply and demand curves intersect. The market equilibrium for society is a lower quantity of products at a higher price with less biodiversity loss. The difference in the supply curves creates dead weight loss. Dead weight loss is the amount by which the social cost outweighs the social benefit.

In Graph 2, the original Supply producer $_{\text {curve shifts to Supply }}$ producer $+\operatorname{tax}$. If the tax is set at the marginal cost of the externality, then the Supply producer + tax will be equal to the Supply society $_{\text {and dead }}$ weight loss will be fully or partially eliminated. The government also collects revenues equal to the area of the gray square.

\section{Producer versus Societal Market Equilibrium}

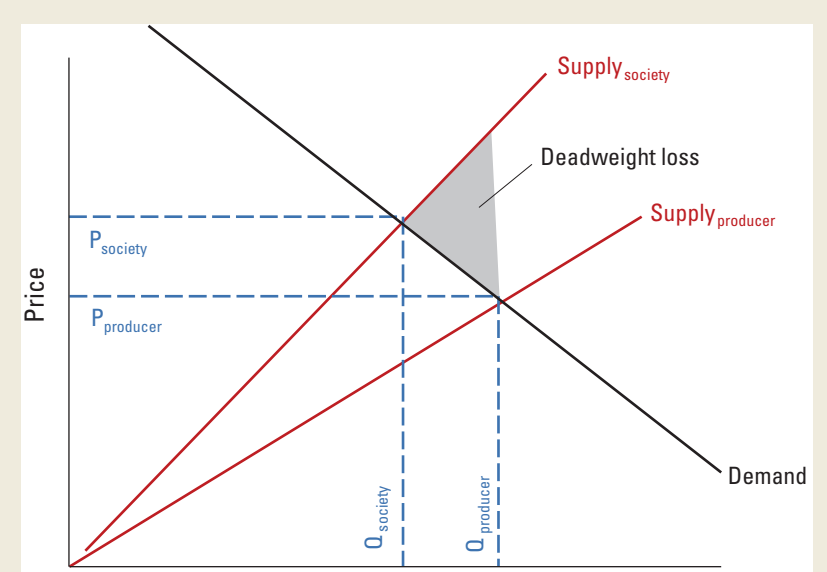

Quantity

\section{Pigouvian Tax Influence on Supply Curve}

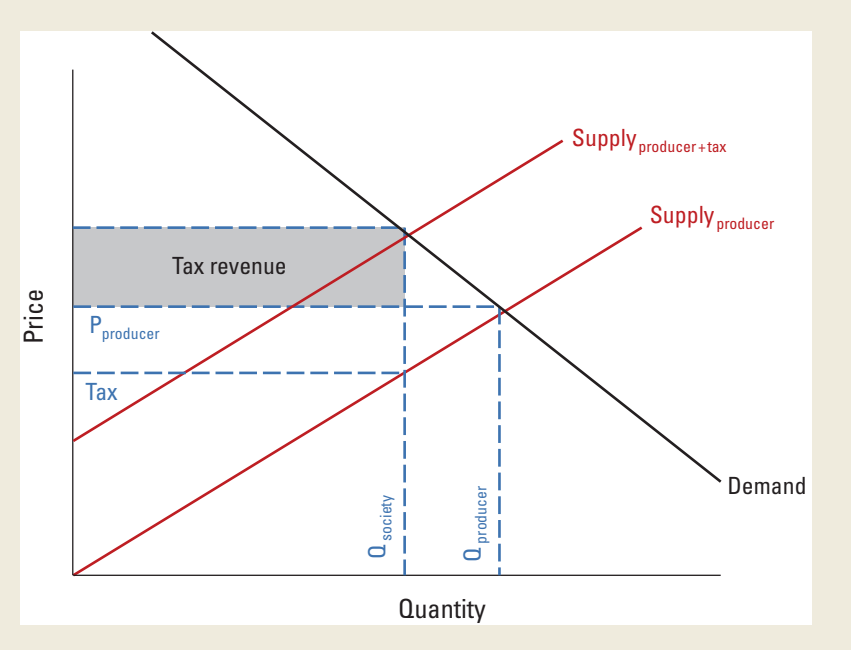




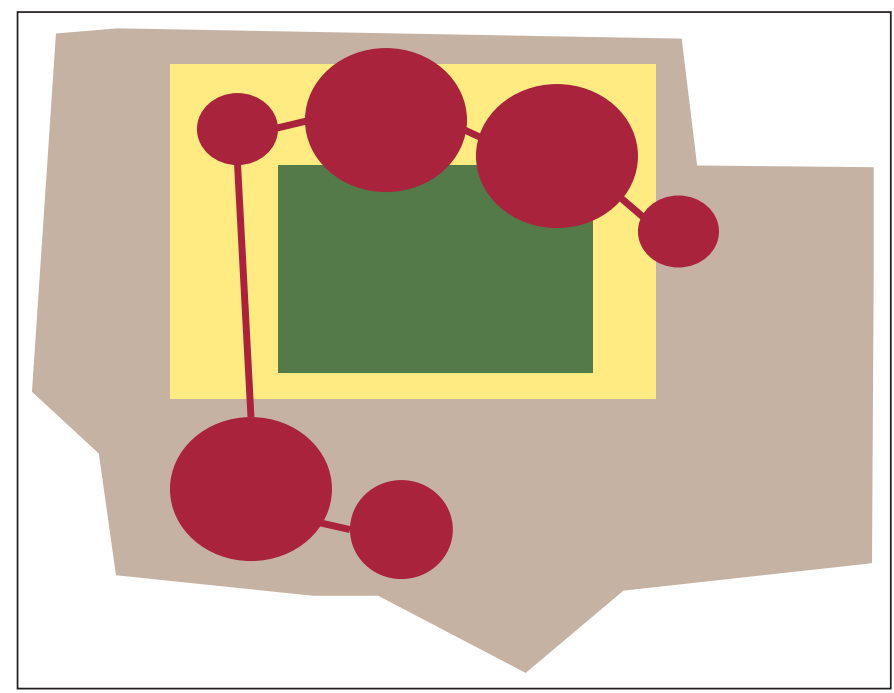

EXPLANATION

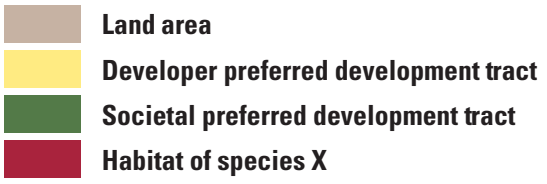

Figure 1. Diagram showing the differences between developer and societal preferences for land use defined graphically. The area in yellow represents the developer's preferred development tract, whereas the area in green is the smaller, societally preferred development tract. Red areas show where species $X$ occupies a considerable part of the developer's preferred tract.

externality and set the tax rate so that it shifts the supply curve in the correct direction and by the necessary amount. In policy implementation this is a challenge, and setting the tax rate to induce a specific reduction in pollution or an increase in ecosystem services may never occur perfectly. For many years, Pigou's theorem dominated economic ideology for pollution abatement, but in 1960, Ronald Coase argued that a Pigouvian tax is not necessary to achieve the social optimum, and in some cases it is detrimental (Coase, 1960).

Coase argued that the market could achieve the optimal level of a produced good that resulted in fewer external impacts through negotiations with private parties under certain conditions. Coase's work relied on two important assumptions: (1) property rights must be well-defined and (2) there are no (or very minimal) transaction costs. If these two assumptions are valid, than the private parties can find the least cost solution to resolve the externality associated with production.

Coase (1960) recommended that the government should strengthen property rights (and make them transferable) and provide ways to reduce transaction costs. Coase's work provided the foundation for cap and trade policy instruments. Fundamentally, cap and trade assigns property rights on environmental degradation (or protection), making individuals liable and allows trading among regulated parties so that they can achieve a specified pollution reduction at the lowest cost.
In policy implementation, the cap and trade mechanism provides an upper biophysical limit on pollution, which provides an assurance that environmental goals will be met. The market leverages the ability of some parties to provide environmental goods, services, or amenities at a lower cost than others. The heterogeneity in the cost of supply provides an opportunity to increase the economic efficiency of achieving an environmental objective. For instance, to protect an endangered species, ranchers may already possess land suitable for the species along with the ability to enhance the habitat in a way that would allow the species to thrive at a relatively low cost, as opposed to a land developer who must mitigate the development impact of building a housing development community on land with a listed species. This heterogeneity in cost allows the buyer - the land developer - to pay the rancher to achieve the biological objective on behalf of the species. This is a win-win-win situation, whereby the species is protected, the rancher is compensated for protecting the species through habitat management or improvement on their land, and the developer has a lower cost.

Early attempts to apply economic theory to obtain environmental benefits occurred in the 1970s. These initial efforts employed market-based Pigouvian tax mechanisms. Largely focused on energy conservation during the period from 1978 to 1986 , Congress established a tax credit for residential energy conservation expenditures to encourage the use of more efficient products through a subsidy (Barthold, 1994). In 1978, Congress enacted a gas guzzler tax aimed at encouraging sales of vehicles with higher fuel economy (Barthold, 1994); similar to the tax credit, this policy was aimed at encouraging consumers to purchase more efficient vehicles by increasing the unit price of less efficient models (via the tax).

In the 1990's there was a shift to cap and trade. The sulfur dioxide trading program initiated under the 1990 Clean Air Act Amendments (United States Government, 1990a) limited sulfur dioxide emissions by electricity generating power plants. The program was instituted using a cap-andtrade mechanism that allowed firms to trade sulfur credits as a way to reduce the overall cost of compliance. This approach capped total emissions while allowing firms with heterogeneous costs to produce more or less emissions and trade credits to achieve cost efficiency (USDA, 2011a).

\section{Biodiversity Specific Market Considerations}

Unlike sulfur dioxide emitted from a stack in a specific region, which has well understood ramifications and relatively simple quantification methods, knowledge about minimum biophysical conditions (acres) to maintain or increase a species, and the impacts of development on a species and the methods used to 'abate' the impact are more complex. The complexity of what constitutes biodiversity, measuring biodiversity benefit outcomes, and establishing markets for trade is challenging. The ecological needs of a species will differ from another necessitating specific land management practices with impacts that may or may not be well understood. 
In addition to the assumptions developed by Coase (1960), it was determined that for successful implementation of market-based mechanisms, marginal environmental benefits across providers should be equal (Jack and others, 2008). However, marginal benefits from an additional unit of biodiversity or habitat protection may not be equal across all providers. Instead, they depend on source, location, size of available habitat, ecological context, and initial conditions of any impact or benefit site. The difficulty associated with quantifying a unit of benefit from biodiversity or habitat conservation - what a credit represents - leads to additional administrative burden in developing metrics that may or may not represent what constitutes a viable unit of improvement. It also adds to the cost of market transactions and reduces the streamlining that could be achieved with standardized metrics.

\section{Payments for Ecosystem Services}

When these market-based mechanisms were first introduced, they were listed from most to least market-like. Payments for ecosystem services (PES) is the least market-like. The incentives the USDA provides serve as subsidies to shift the supply curve in favor of biodiversity benefits. Without these subsidies, most agricultural producers would undersupply biodiversity and habitat because they do not reap society's full benefits from them. Society benefits from biodiversity and habitat conservation and compensates farmers for providing them via the USDA PES programs.

USDA PES program contracts designate the biodiversity benefits on the landscape with property rights. PES uses incentives to obtain results on private land rather than making compulsory regulation (such as command and control). This fact does not mean that PES does not fully meet the criteria of a market as proposed by Coase (1960). The PES mechanism does not create tradable property rights. Rather, the USDA is the single source buyer of biodiversity and habitat benefits.

USDA programs can provide biodiversity benefits up to the statutory limit on either spending or acres; the overall benefits may depend on which site is enrolled in a given year and the quantity and quality of ecological benefits those sites yield. The benefits are unlikely to reflect complete societal preferences for biodiversity conservation. Figure 2 shows the number of acres enrolled in the CRP over the last 20 years (Barbarika, Alex, n.d). The figure shows the number of acres enrolled in the program - the number of acres benefitting from the program largely reflects the expenditures, and yet there is some variance based on differences in land rental rates. It is not possible to extract the amount of biodiversity benefits from this national expenditure and enrollment data alone.

\section{Conservation Banks}

Conservation banks are designed to assign property rights and make them tradable. The program uses the authority of the ESA and an allowance for take to give property rights for species and habitats. Property rights, in this case, are the liability for degradation of species and habitat and the requirement to mitigate. Habitat improvements for listed species can be assigned credits by the FWS, and these are tradable under the ESA authorities. Those activities that lead to an incidental take are required to mitigate, thus stimulating the demand for credits.

Coase's second recommendation is to minimize transaction costs. Given current procedures related to habitat assessment, monitoring, and verification, conservation banking faces important challenges. Transaction costs can be defined as "the resources used to define, establish, maintain, and transfer property rights" (McCann and others, 2005). This definition

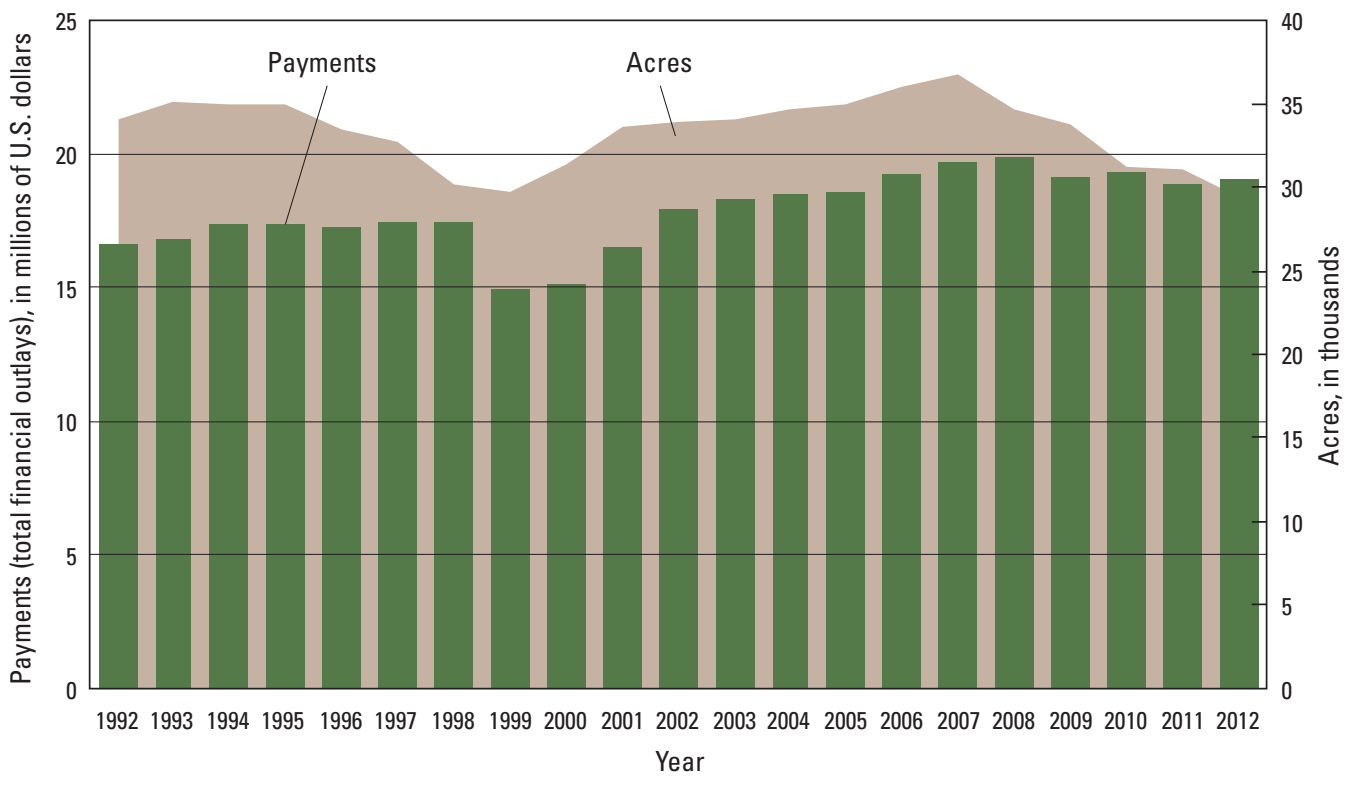

Figure 2. Graph showing the acres of habitat that benefited annually from the Conservation Reserve Program from 1992 through 2012 (area in tan). In comparison, expenditures are depicted by green bars. The graph illustrates that annual payments do not correlate perfectly with the acreage benefited, but there is a clear association. 
includes the administrative costs of a transaction as well as non-monetary costs such as time.

A banker survey conducted by Fox and Nino-Murcia $(2005)^{7}$ revealed that the bureaucracy involved in establishing a banking agreement is a common hurdle. Sixty-seven percent of bankers cited technical and political challenges to State and Federal agencies. This was echoed in interviews conducted by the survey's researchers with a number of individuals involved in setting up banks or in efforts to develop pre-compliance assurances. A snapshot of the prices and profitability of conservation banking is in highlight 17 .

From a biological standpoint, some regulatory agencies believe that conservation banking is good for the species, as it more strategically secures permanently dedicated conservation lands and attracts people with expertise to the industry of creating and managing requisite lands (Ruhl and others, 2005). Professional bankers have an advantage in setting up banks as they have experience with the administrative and financial obligations and can more easily navigate the approval process than individual landowners. Additionally, professional bankers are more likely to have access to the investment capital needed to develop a new bank. Bankers also manage a portfolio of banks, reducing their overall risk if credits are not sold quickly or one bank fails; individual landowners are exposed to higher risk when their efforts are focused on a single project (Randy Wilgis (Environmental Banc and Exchange), written commun., April 15, 2014).

Large tracts of land, and a focus on high quality habitat and connectivity, often increase the ecological effectiveness of conservation banks over alternatives (DOI, 2013b). The alternative approaches, such as permittee-responsible on-site mitigation, are generally less robust than conservation banks. Additionally, mitigation provided by conservation banks occurs in advance of impacts, in contrast to permittee-responsible mitigation, which might reduce the risk of ecological failure (DOI, 2013b). The ecological benefits of conservation banks over their regulated alternatives can also lead to economic efficiencies. In particular, a bank can achieve economies of scale. For the banker, upfront, management, and maintenance costs per unit for a larger area of land are likely to be less than for a smaller parcel. With agencies, approving a single bank to mitigate the impacts of multiple developments rather than approving individual permittee-responsible mitigation sites reduces the overall cost of administration.

A benefit of the market-based approach of conservation banking is the minimum threshold placed on the amount of biodiversity conservation. Rather than using a subsidy that does not dictate the quantity of benefits, the mitigation requirement ensures that there is, theoretically, no net loss of species (although actual outcomes depend on the quality of practices implemented and should be ensured via monitoring and verification). As a pseudo cap and trade mechanism, there

${ }^{7}$ The DOI Office of Policy Analysis is conducting a survey of bankers with results anticipated in 2015-16 (Sarah Cline (DOI PPA), written commun., March 26, 2014).
Conservation Bank Credit Prices and Profitability

Conservation bank credit prices are not transparent: most transactions occur through private trades. The prices vary depending on the species, the location, and the development opportunity. A survey of conservation bankers by Fox and Nino-Murcia (2005) found that credit asking prices ranged from $\$ 3000$ for one acre of San Joaquin kit fox habitat to $\$ 125,000$ for one acre with a breeding pair of Least Bell's Vireo. The survey's findings on asking price do not necessarily equate to the price negotiated between parties, but they do indicate the high prices and range at which credits are traded.

Another finding of the survey was that potential profits were competitive with alternative land uses, including golf courses and residential developments (Fox and Nino-Murcia, 2005). It is notable that this survey occurred before the 2008 real estate bubble burst. Since then, land demand has diminished, influencing demand for mitigation credits and the price of land (Shauna Ginger (FWS), oral commun., April 2, 2014).

A survey by Bunn and others (2013) identified and ranked the barriers to entry in the graph below. Estimating cost and funding site management are both high on the list of concerns. The Department of the Interior is planning to survey conservation bankers in 2015 (Sarah Cline (DOI PPA), written commun., March 26, 2014). This will provide insights into the current state of the market and barriers to adoption.

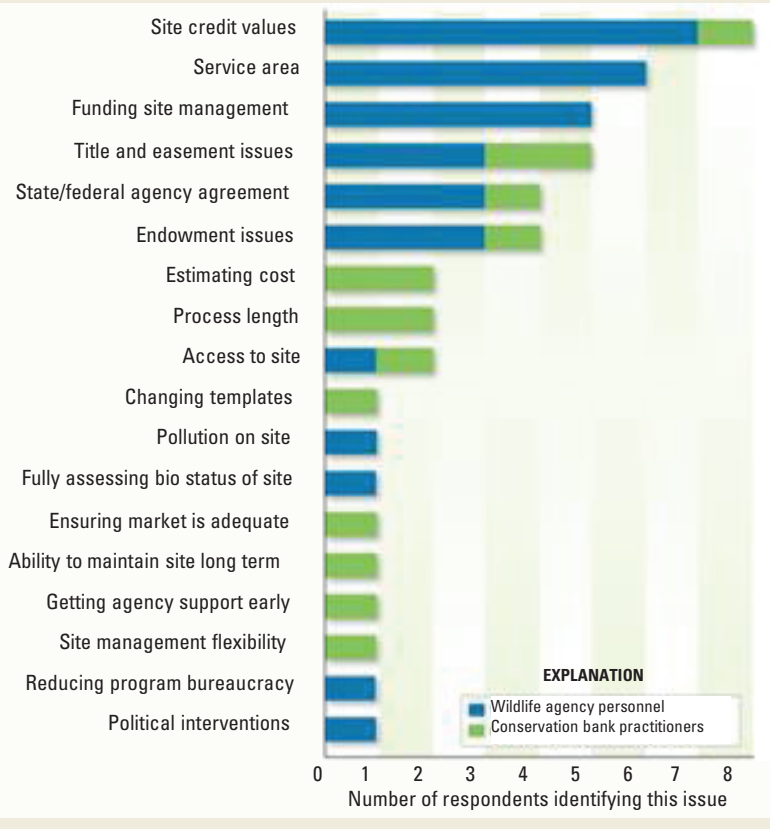


is less uncertainty in the quantity of biodiversity, and the market is leveraged to achieve the requirements at the lowest cost.

The FWS first approved a conservation bank in the early 1990s; today, 105 banks are approved (DOI, 2013b). A total of 74,807 acres were permanently protected by conservation banking easements in 2011. The majority of banks today are sited in California, but growth has begun in other States (and considerable growth has occurred in Oregon, Texas, and Florida).

Most banks, 73 percent, are owned by private, commercial companies as opposed to individual landowners or nonprofit organized banks (DOI, 2013b). There are now conservation banks for 35 different species (DOI, 2013b). One concern is that the majority of the species that do have banks only have a single bank, limiting competition on the supply side. Known as thin markets, markets with too few transactions over a given period of time inhibit efficient price discovery (Anderson and others, 2007). Environmental markets often have limited market activity and private transactions, which makes them prone to be "thin".

Thin markets are subject to a number of issues: prices that don't represent overall supply and demand conditions, price volatility, and the potential for individual transactions affecting price and creating an incentive for price manipulation (Peterson, 2005). All of these issues contribute to the market's reduced ability to efficiently achieve environmental objectives. For conservation banks, a lack of publicly available prices leads to asymmetric information for credit purchasers. Without transparent prices, it reduces the incentive for project proponents to favor purchasing credits from a bank over permittee-responsible mitigation, which may have more clearly defined costs.

\section{Habitat Exchanges}

Habitat exchanges, like conservation banks, assign property rights for outcomes related to biodiversity conservation or improvement and make them tradable in the form of credits. There are multiple exchanges attempting to extend the market approach to candidate species. For exchanges to be successful, property rights must be well established. For pre-compliance mitigation, this requires FWS assurances that if a candidate species is listed the credits will account for mitigation done prior to listing. Without a property right or assurances that liability will be transferable with the purchase of credits, a major challenge to pre-compliance efforts exists.

An issue relevant to all types of biodiversity conservation mechanisms is funding the upfront costs. An example of an approach to overcome the barrier of high upfront costs is described in highlight 18 .

To address transaction costs, the habitat exchange model uses HQTs upfront that will apply to all landowners. Theoretically, this reduces the administrative burden on FWS offices in developing methods to assess credits for landowners and debits for polluters. It also increases transparency in the market so potential bankers can assess the viability of a specific property that would support a listed species.

\section{Innovative Financial Tools}

Conservation often requires high upfront investment. A majority of the upfront expenditures must be committed long before a credit is assigned and can be sold for revenue. This creates a substantial barrier to developing a conservation bank, especially for private landowners. There are also associated risks that are out of the manager's control including: weather variability, invasive species issues, regulator biases, and vegetative success (Randy Wilgis (Environmental Banc and Exchange), written commun., April 15, 2014).

The Alliance for the Chesapeake Bay, a nonprofit organization, works with private forest owners in the Maryland part of the Bay watershed. The State requires mitigation to maintain forest cover via the Forest Conservation Act. Critical areas for Bay recovery are also regulated. The program is administered by local jurisdictions.

To address the barrier to entry associated with capital costs, the Alliance is working to develop innovative financing tools. Similar to small loans offered for homeowner renewable energy investments, the organization hopes to bring investors and landowners together to provide upfront financing that can bridge the gap until credits can be sold (Eric Sprague (Alliance for the Chesapeake Bay), oral commun., August 9 , 2014).

In parts of Maryland, the value of credits were estimated to be from $\$ 16,000$ to $\$ 20,000$ per acre for newly planted forest and from $\$ 6,400$ to $\$ 8,000$ for protecting woodlands, demonstrating the potential value of increasing forest conservation banks (Forests for the Bay, 2015).

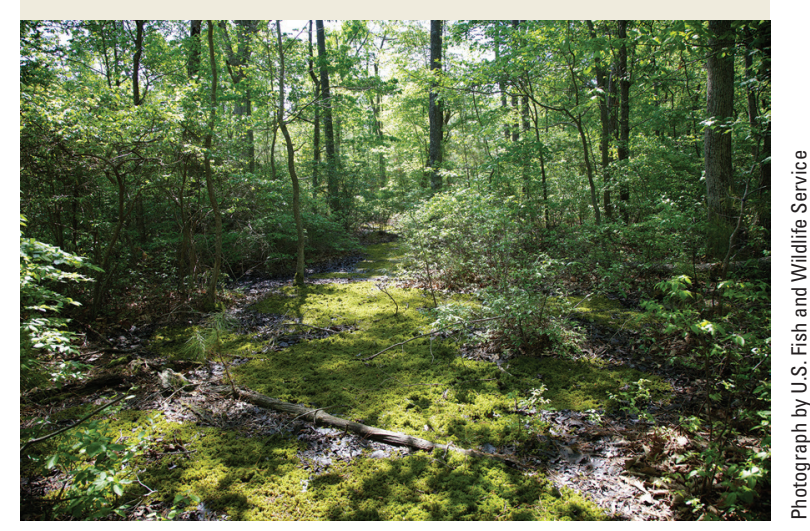


HQTs can also reduce transaction costs associated with trades. In conservation banking, each trade must be approved by FWS, which adds to FWS administrative costs and opportunity costs in the form of time used by bankers and others who need to buy mitigation credits. The HQTs assess projects upfront and remove redundancy in FWS trade approvals. These processes may also increase the number of private developers or public agencies interested in purchasing credits. Use of these tools could improve demand, benefit the market, and provide ecological benefits in the form of large tract banks as opposed to the checkerboard habitats that result from permittee-responsible mitigation.

Contributing to the success of the market, the dynamic permanent mitigation option in habitat exchanges could increase the supply of credits and provide greater competition and pricing. Institutional barriers to this type of approach persist, and it is yet to be proven in a functioning habitat exchange. For example, FWS policies and procedures for approving conservation banks require that banks have easements to protect the land in perpetuity. The dynamic permanent mitigation approach would need to be tested and accepted by FWS within the authority of the ESA.

The ability to avoid pre-approval of trades would allow an exchange to use an auctioning platform. It would also increase market price transparency, which could increase competition and reduce the price of credits.

Similar to conservation banks, habitat exchanges are much like cap and trade whereby there is a minimum habitat area that must be conserved and maintained. The risk that dynamic permanent mitigation credits introduce to this minimum threshold is moderated by the reserve account (see Chapter C: Habitat Exchanges, for more on dynamic permanent mitigation and reserve accounts). By reducing administrative burden on the approval and trading process, habitat exchanges possess the potential to improve the viability of conservation banking for species protection and recovery.

\section{Eco-Labeling}

Eco-labeling differs from the previously discussed environmental markets. Rather than a tax, subsidy, or cap and trade mechanism, eco-labeling uses consumer preferences to differentiate goods produced with an explicit goal of practicing environmental protection or conservation. Eco-labels attempt to address the market failure in which participants do not have perfect knowledge about products. From a biodiversity perspective, there is typically an information asymmetry between consumers and producers where the producer is aware of certain product characteristics, such as production processes that may be detrimental to biodiversity, but the consumer does not have this insight. Environmental certifications and eco-labels provide information about product characteristics that are not derived from its consumption, but may provide environmental benefits (Nunes and Riyanto, 2005). Two examples of eco-labels are described in highlight 19 . Consumers that would like to purchase goods produced in a way that benefits biodiversity or habitat conservation are able to make informed decisions about their purchases with the information that certifications and eco-labels deliver.

\section{Markets for Eco-labeled Products}

Salmon-Safe and Certified Wildlife Friendly are examples of the many eco-labels in the United States. Salmon-Safe is a regional eco-label that certifies farms and urban lands in Oregon, Washington, California, and British Columbia for undertaking land management practices that secure healthy agricultural and urban watersheds so native salmon can spawn and survive. Participants of the Salmon-Safe eco-label include vineyards, farms, corporate and university campuses, large-scale residential developments, and golf courses, collectively covering over 60,000 acres of certified land (Salmon-Safe, 2014).

Similarly, Certified Wildlife Friendly is an international certification program that aims to conserve wildlife through the certification of organizational production practices and enterprise development that allows people and wildlife to coexist. Certified Wildlife Friendly producers conserve over 12 million hectares of land, including wetlands, forests, and grasslands globally (Certified Wildlife Friendly, 2013). In North America, Certified Wildlife Friendly focuses on agricultural farms and ranches. Certified Wildlife Friendly seals are found on a range of products including meats, wool, animal fiber yarn, leather goods, eggs, honey, and soaps.

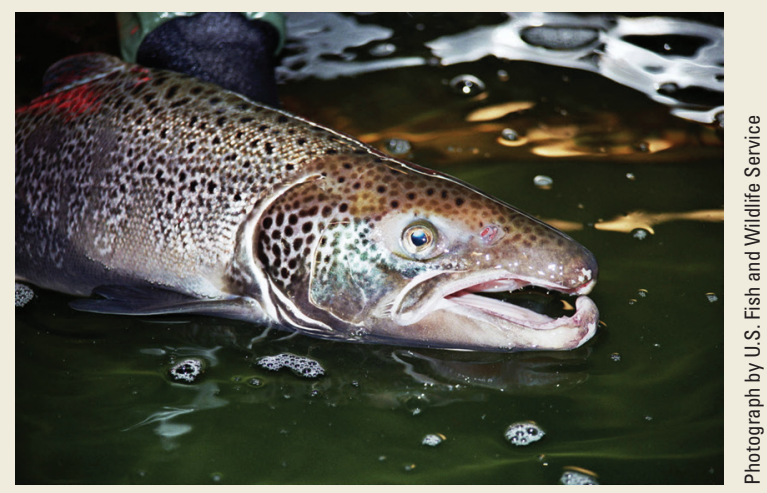


Environmental certifications are often seen as the "ultimate use of a market mechanism" (Clark and Russell, 2003). This is because there is no requirement (regulatory or otherwise) for any market participant to act in a certain way and there is minimal interference from the government. Producers have the option (but are not required) to change their production processes and consumers have the option (but are not required) to purchase the environmentally beneficial products. By simply making information about the environmental benefits of products available to consumers, labeling policies can circumvent the market inefficiencies associated with asymmetric information (Teisl and Roe, 1998).

According to Nunes and Riyanto (2005), the success of certification and eco-labels depends on consumer awareness, firms' incentives to endorse certification and eco-labeling policies, and the sensitivity of consumer demand to production costs. In order for an environmental certification or eco-label program to be efficient, consumers must be aware of biodiversity protection benefits so that they can make an informed choice about whether or not they want to purchase labeled products.

With an increase in voluntary eco-labels, consumers may face information overload (Horne, 2009). Horne reported on a survey of consumers in which 97 percent stated that there "was more stuff to read than I could ever dream of reading," and 92 percent indicated that they felt 'surrounded' by information. Consumers not only face multiple labels, but the meaning and legitimacy of those labels can be difficult for consumers to discern.
A firm's ability and willingness to implement certification and eco-labeling policies depends on changes in production costs necessary to accommodate the new technologies that accompany biodiversity-friendly practices. If these practices increase production costs, then firms may need to increase their prices. In turn, the success of certification and eco-label policies also depends on the sensitivity of consumer demand in the face of higher prices.

Although higher prices can lead to decreased demand, adopting certification and eco-labeling may actually present a great opportunity for some firms. Investment in green technologies and processes can benefit a firm that degrades the environment because it may improve public opinion and allow them to differentiate their product in the market (Amacher and others, 2004). It has been established that some consumers are willing to pay more for differentiated goods labeled as environmentally friendly (Clark and Russell, 2003). Studies that examined this phenomenon include Teisl and others (2002) that shows how the introduction of Dolphin-Safe labeling on canned tuna increased the market share of tuna in the United States after it was introduced; Loureiro and Hine (2002) that found Colorado consumers were willing to pay a higher price premium for locally grown potatoes; and Aguilar and Vlosky (2007) that shows consumers who thought certified wood products can lessen environmental impacts willingly paid a price premium. 


\section{Chapter E-Performance Measurement in Biodiversity and Habitat Markets}

This chapter describes and analyzes selected factors that influence the performance of market-based mechanisms for biodiversity conservation in conservation banking and habitat exchanges. As defined here, performance factors include (1) the type of metric used to represent and measure conservation actions; (2) the type of credit generated by a conservation activity, and the linkage between the level of a credit and the type of metric employed; (3) the choice of a HQT for a given species or habitat type; (4) market support tools such as registries, crediting platforms, and financing mechanisms; and (5) the means by which conservation benefits are monitored and verified. The chapter ends with a discussion of how these performance factors influence the effectiveness and efficiency of market-based mechanisms.

\section{Performance Measures}

Two general types of metrics are used to estimate the impacts of species or habitat conservation mechanisms. The first is referred to as a practice-based metric, whereby an "expected" outcome is achieved by implementing a specific conservation practice. The second general category is a performance-based metric, which measures actual conservation outcomes.

With respect to agricultural lands, USDA conservation programs primarily employ practice-based metrics. The assumption is that successful implementation of a specific conservation practice leads to an environmental goal, whether it is improved wildlife habitat, species conservation, water quality improvement, or carbon sequestration. Approved conservation practices typically undergo extensive validation through research and pilot testing to determine whether they will lead to desired environmental outcomes. In this sense, implementation of a vetted practice is a proxy for performance, although actual outcomes can depend on the biophysical characteristics of a particular farm or ranch.

Habitat conservation programs on agricultural landsas well as in water quality programs - are in the process of transitioning to outcome- or performance-based metrics to determine the success levels of targeted outcomes (Culliney, 2014). Culliney (2014) observed that the 2014 Farm Bill refined conservation programs to allow eventual payment components that reward biophysical outcomes in addition to adopting specific conservation practices. Culliney argues that both practice-based and outcome-based payment mechanisms are necessary and complementary.
Recent efforts through the USDA Conservation Effects Assessment Project (CEAP) have attempted to report on the impacts of habitat conservation practices and whether conservation goals were met (for example, see Briske and others, 2011). Because field-level research addressing the impact of conservation practices on improving habitat and biodiversity has been limited and dispersed geographically, a current focus at the USDA is the development of tools, models, and protocols to measure actual performance and outcomes from the implementation of conservation activities. In several wildlife habitat assessment projects sponsored by CEAP, this work is ongoing (Charles Rewa (USDA NRCS), written commun., September 2014).

Performance-based metrics for measuring biodiversity and wildlife habitat outcomes can be based on three methods: (1) use of validated and reliable habitat or species response models; (2) actual site inspections to verify that a species or habitat is recovering; or (3) area-based metrics that measure satisfactory conservation and stewardship of an ecologically compatible landscape for a particular species or suite of species. Species and habitat models are described later in this chapter. The U.S. Army Corps of Engineers (USACE) is developing an inventory of tools and models to estimate the impacts of conservation actions on various ecosystem services, including wildlife habitats or species (Elizabeth Murray (USACE), oral commun., May 28, 2015).

Area-based metrics reflect the physical level of habitat (as a proxy for species or biodiversity in general), defined as either a simple acre or a functional acre, whereby the area is deemed ecologically viable for the recovery of one or more species. Metrics related to species and simple and functional acres are briefly discussed below. Each of the three metrics can serve as the basis for determining the number of credits a conservation bank can generate and sell.

\section{Species-based Indicators}

One measure of performance in conservation banking is tracking the numbers for a species targeted for restoration. Species can be tracked either by the number of individuals or the number of breeding pairs. One example of a species-based performance measure is a prairie dog conservation bank in Utah. The Least Bell's Vireo is an example of an indicator expressed in terms of breeding pairs (Fox and Nino-Murcia, 2005); a similar approach was proposed for the Florida Scrub 
Jay (Chris Hartley (USDA Office of Environmental Markets), oral commun., April 30, 2014).

Species counts or breeding pair observations are options when the species of concern is on-site and supported by the habitat. These methods provide conservative estimates of the biodiversity benefits at a site. However, field observations can be costly depending on the species and the location. There may also be seasonal and annual influences that impact the presence or absence of a species. This constraint may become more severe in the future with the prospect of increasing climate variability.

\section{Habitat-based Indicators}

Habitat indicators are a second type of performance metric. Similar to practice-based metrics, there are assumptions that restoring or conserving habitat results in species recovery or protection rather than actual observations. As stated above, habitat-based metrics can be based on a simple acre or a functional acre.

A simple acre is exactly that, an acre of habitat restored or conserved to offset a converted acre. This approach does not require a high cost for data collection and analysis of habitat suitability. However, a simple acre is a proxy and may not be a robust indicator that the species exists at a mitigation site. The simple acre metric does not account for habitat quality, type of habitat, risks on the property, connectivity, or landscape features. Mills (2007) finds that retaining habitat alone is a necessary, but not sufficient, condition for species recovery.

A functional acre can have any number of meanings but is generally a unit of measure that accounts for both area and habitat quality, captured by a set of attributes that meet the ecological needs of the species. The criteria used to determine a functional acre vary with a species' needs, but would be standardized within a given habitat exchange platform. These criteria address the ecology of a species and its habitat to determine site suitability and can include vegetation type, water availability, invasive species, habitat connectivity, and risks on or near the property. This information, along with landscape context, helps quantify biodiversity benefits and tradable credits.

The habitat exchanges, as described earlier, are focused on developing tools to quantify functional acres with standardized protocols. These efforts are described alongside other tools used to quantify tradable credits in the next section.

\section{Credit Types and Ratios}

Species or habitat credits represent the unit of exchange that allow trade to take place; the types of credits available can vary from bank to bank. There may also be ratios associated with credits. Ratios are used to account for quality differences between impact and benefit sites (Fox and Nino-Murcia, 2005). The use of ratios is common in conservation banking to ensure mitigation is equivalent to adverse impacts across different sites (FWS, 2003). In other environmental markets, ratios are often used to incorporate uncertainty. For example, in Virginia's water quality trading program, if point sources are to purchase credits from nonpoint sources they must do so at a 2:1 ratio (Virginia Department of Environmental Quality (VDEQ), 2008). Below, the types of species and habitat credits that can be generated, the biophysical basis of those credits, and crediting ratios are described.

\section{Credit Type}

Species or habitat credits are linked to the type of performance metric adopted by the particular bank (species, simple acre, or functional acre), and various types of credits are available depending on the status of the conservation activity undertaken. Table 5 shows various credit types and describes their structure and application. Highlight 20 describes a mixture of credits for a ranch in California.

The six types of credits are not mutually exclusive. A voluntary credit can also be classified as a creation or preservation credit. Similarly, pre-compliance and compensatory

Table 5. Descriptions of credit types.

\begin{tabular}{|c|c|}
\hline Credit type & Description \\
\hline Compensatory & Purchased by regulated parties or by others. These credits meet standards determined by regulating authorities. \\
\hline Restoration & $\begin{array}{l}\text { Applicable to existing habitat that is not otherwise protected and requires practices to restore function for species } \\
\text { of concern. Ongoing management activities required. }\end{array}$ \\
\hline Preservation & Applicable to existing habitat that is not otherwise protected. Ongoing management activities required. \\
\hline
\end{tabular}


Conservation Bank Credit Determination: Van Vleck Ranch Mitigation Bank

The Van Vleck Ranch Mitigation Bank is a plot of 765 acres in Sacramento County, California, that targets vernal pool fairy shrimp and Swainson's hawk. The bank was established between the land owner, VVRR Corporation; the bank owner and operator, Westervelt Ecological Services; the U.S. Army Corps of Engineers, The Environmental Protection Agency, U.S. Fish and Wildlife Services, and the California Department of Fish and Game.

The Van Vleck bank has three types of credit generated through vernal pool preservation and creation, and through grassland preservation. The bank was awarded credits at a 1:1 credit to habitat ratio with 27.10 credits for preservation land management practices conducive to vernal pool fairy shrimp habitat extant in the land plot, 16.24 credits for land management practices that create vernal pool habitat, and 722.11 credits for preservation and land management practices that aid the grassland foraging habitat that benefits Swainson's hawk.

Credits are released and available for sale based on certain milestones and performance events. For vernal pool and Swainson's hawk preservation credits, certain percentages of the overall credits are released at the establishment of the bank and at specific funding milestones for the endowment fund. For vernal pool creation credits, certain percentages of credits are released at the establishment of the bank and at specific land management performance criteria.

\section{Adapted from The Conservation Fund,} $2010 b$.

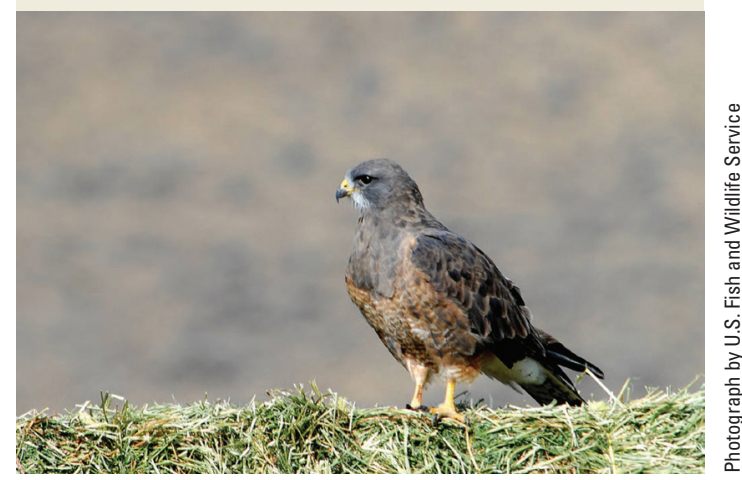

credits can be based on habitat creation or preservation. Depending on the design of the species or habitat banking agreement, the types of conservation activities may result in different numbers of credits awarded.

Pre-compliance credits are a type of credit level envisioned for potential candidate species banking agreements; however, to date there have not been any credits of this type authorized. The FWS has released a draft policy for public comment on pre-compliance credits. Under this policy, all public and private landowners could generate credits that benefit declining wildlife or at-risk species (Barrett, 2014). Credits can be sold or traded, and if the species is listed, the credits can be applied to offset negative impacts from development (Barrett, 2014).

A creation credit is likely to require higher upfront costs for installing 'habitat,' but may also command a higher price in the market than preservation credits. Compensatory credits also have higher costs associated with meeting the conservation standards of the regulatory authority. Demand for these credits is driven by regulation and are likely to command a higher price in the market than a voluntary credit.

\section{Credit Metrics and Ratios}

Credits are associated with a type of performance metric: a simple acre, a functional acre, or the number of species. A simple acre is a quantification of credits that equates one acre of habitat to one credit. A functional acre factors in habitat area and quality in terms of the ecological needs of a species or a habitat of concern. Species credit value quantification is determined for some individual species or breeding pairs.

A sample of conservation banks was examined in the Regulatory In-lieu fee and Bank Information Tracking System (RIBITS) to determine how often different types of credits are used (see USACE, 2015). According to the Department of the Interior Office of Policy Analysis (2013b), the FWS approved 105 conservation banks by 2013 with the majority ( 76 percent) located in California. For the examined sample, eighteen banks were considered to illustrate credit metrics, types of credits, and various credit ratio quantification methods (see table 6). Within the sample, 15 used the simple acre metric, 2 used the functional acre, and only 1 was based on species.

Table 6 illustrates the variety of credit ratio quantification approaches used for different species. For example, with the Giant Garter Snake in Colusa, California, there are three types of credits that can be generated using the simple acre approach: seasonal wetland establishment, wetland enhancement, and habitat creation. Seasonal wetland establishment and habitat creation receive a 1:1 credit ratio (one credit for one established or created acre of habitat), and wetland enhancement receives one-half a credit for each acre enhanced. For the Deadman Creek bank in Merced, California, vernal pools and two separate species are all credited at a 1:1 ratio. Alternatively, certain practices and restrictions on land use can also generate credits, as shown in the case of the Carolina Heelsplitter in South Carolina. For this species, riparian buffers are credited at a 1.3:1 ratio, while restrictions on upland and timber development receive a $0.78: 1$ credit to acre ratio. While different crediting ratios are required given the unique ecological needs of each species, determining credit ratios for each unique species or habitat adds to the overall cost of developing mitigation markets and habitat exchanges. 
Table 6. Sample conservation bank projects from the Army Corps of Engineer's Regulatory In-lieu fee and Bank Information Tracking System (RIBITS).

\begin{tabular}{|c|c|c|c|c|}
\hline Project name & $\begin{array}{l}\text { Location } \\
\text { (county, State) }\end{array}$ & Species & Credit type & Credit quantification methodology \\
\hline Colusa Basin & Colusa, California & $\begin{array}{l}\text { Seasonal Wetlands, Giant } \\
\text { Garter Snake }\end{array}$ & Simple acre & $\begin{array}{l}\text { Seasonal wetland establishment receives } 1: 1 \text { credit ratio, } \\
\text { enhancement } 0.5: 1 \text {, and giant garter snake habitat creation } \\
\text { receives a } 1: 1 \text { credit ratio. }\end{array}$ \\
\hline Deadman Creek & Merced, California & $\begin{array}{l}\text { Vernal pool, CA tiger } \\
\text { salamander, San Joaquin } \\
\text { kit fox }\end{array}$ & Simple acre & All species/habitat credited at 1:1 ratio. \\
\hline Ohlone Preserve & Alameda, California & $\begin{array}{l}\text { CA red-legged frog, } \\
\text { CA tiger salamander, } \\
\text { Alameda whipsnake }\end{array}$ & Simple acre & $\begin{array}{l}\text { Credits for California tiger salamander and Alameda } \\
\text { whipsnake are based on a 1:1 acre to credit ratio. California } \\
\text { red-legged frog credits are based on a 1:1.667 acre-to- } \\
\text { credit ratio. }\end{array}$ \\
\hline Santa Rosa Plain & Sonoma, California & $\begin{array}{l}\text { Sonoma tiger } \\
\text { salamander, Burke's } \\
\text { goldfields, Sonoma } \\
\text { sunshine, Sebastopol } \\
\text { meadowfoam }\end{array}$ & Simple acre & $\begin{array}{l}\text { Credits are generated through habitat preservation and } \\
\text { creation. Credits for the California tiger salamander and } \\
\text { for plants are based on a 1:1 habitat acre-to-credit ratio, } \\
\text { however, USFWS is considering revisions to the plant } \\
\text { credit methodology. }\end{array}$ \\
\hline Van Vleck Ranch & Sacramento, California & $\begin{array}{l}\text { Vernal pool habitat, } \\
\text { Swainson's Hawk }\end{array}$ & Simple acre & $\begin{array}{l}\text { Vernal pool creation, vernal pool preservation, and Swainson's } \\
\text { Hawk habitat acreage are credited at a 1:1 ratio. }\end{array}$ \\
\hline Agua Fria & Merced, California & $\begin{array}{l}\text { San Joaquin kit fox, } \\
\text { Burrowing Owl }\end{array}$ & Simple acre & $\begin{array}{l}\text { One acre equals one credit. Credits are "dual species," which } \\
\text { can be applied to kit fox or burrowing owl but not both. }\end{array}$ \\
\hline Florida Panther & Hendry, Florida & Florida panther & Functional acre & $\begin{array}{l}\text { Dubbed Panther Habitat Units, credits based on a Habitat } \\
\text { Suitability Value depending on habitat type (for example, } \\
\text { basin swamp or mesic hammock). }\end{array}$ \\
\hline Rogue Valley & Agate Desert, Oregon & $\begin{array}{l}\text { Vernal-pool associated } \\
\text { sensitive species }\end{array}$ & Simple acre & $\begin{array}{l}\text { Ratio is } 1 \text { credit per } 1.5 \text { acres of wetted areas and } 1 \text { credit per } \\
10 \text { acres of buffers. Additional credits for listed species } \\
\text { generated through meeting land management criteria. }\end{array}$ \\
\hline $\begin{array}{l}\text { Carolina } \\
\text { Heelsplitter }\end{array}$ & $\begin{array}{l}\text { Lancaster, South } \\
\quad \text { Carolina }\end{array}$ & Carolina heelsplitter & Simple acre & $\begin{array}{l}\text { Riparian buffers receive } 1.3: 1 \text { acre-to-credit ratio and upland } \\
\text { and timber development restrictions receive a } 0.78: 1 \text { credit } \\
\text { to acre ratio. }\end{array}$ \\
\hline $\begin{array}{l}\text { Griffith League } \\
\text { Ranch }\end{array}$ & Bastrop, Texas & Houston toad & Simple acre & $\begin{array}{l}\text { Credits are generated through habitat preservation on a one- } \\
\text { to-one basis. }\end{array}$ \\
\hline $\begin{array}{l}\text { SITLA and Little } \\
\text { Horse Valley }\end{array}$ & Iron, Utah & Utah prairie dog & Species & $\begin{array}{l}\text { SITLA: } 2 \text { credits per prairie dog observed in } 2 \text { most recent } \\
\text { spring counts; additional credits in increments of } 50 \text { for } \\
\text { every additional } 25 \text { prairie dogs sustained for } 2 \text { years. } \\
\text { Maximum credits equal to the number of acres preserved. } \\
\text { Little Horse Valley: } 1: 1 \text { ratio. }\end{array}$ \\
\hline $\begin{array}{l}\text { Blue Heron } \\
\text { Slough }\end{array}$ & $\begin{array}{l}\text { Snohomish, } \\
\text { Washington }\end{array}$ & $\begin{array}{l}\text { Chinook salmon, } \\
\text { Steelhead, and Bull } \\
\text { trout }\end{array}$ & Simple acre & $\begin{array}{l}\text { Credits based on 1:1 ratio. A credit methodology called } \\
\text { Discounted Service Acre-Years (DSAY) is applied to } \\
\text { customers in determining compensation for resource } \\
\text { injuries. }\end{array}$ \\
\hline
\end{tabular}




\section{Tools to Support Biodiversity and Habitat Markets}

Two general classes of tools support the establishment of biodiversity and habitat markets or exchanges: HQTs and market support tools. Habitat Quantification Tools (HQTs) provide protocols and platforms that assess/score the quality of a particular habitat's ability to support wildlife species. These tools and scorecards can establish a baseline that can serve as a standard for calculating the number of credits that a potential conservation site could generate.

HQTs can contain varying levels of complexity. HQTs can be complex models used to assess habitat quality at multiple scales. Scorecards are simple HQTs that use a basic approach to assess quality, providing scores for the fundamental parameters that influence habitat quality. An example of an HQT is provided in highlight 21. Market support tools include facilitation mechanisms like crediting platforms, conservation registries, and financing mechanisms to increase efficiency and effectiveness by lowering transaction costs. Although these mechanisms can lead to costs savings over the long term, initial start-up investments can be high.

\section{Market Facilitation Tools}

Market facilitation tools provide platforms for sharing information about potential buyers and sellers of credits, potential funding mechanisms, registries of projects, and financing mechanisms to encourage market participation. The overall purpose of these tools is to encourage smoother, less costly market exchanges between buyers and sellers of habitat or species credits. Each type of tool is summarized below.

Crediting Platforms/Tracking Tools: Various crediting platforms were developed to ease the transfer of information between regulating authorities, credit developers, credit buyers, and the public. These tools are used to provide one-stop-shopping and reduce the administrative burden and transactions costs associated with setting up conservation banking projects. As indicated before, the U.S. Army Corp of Engineers uses a platform called RIBITS that houses information on all wetland mitigation and conservation banks in the United States. This Web-based portal allows FWS and conservation bank developers to upload information such as draft banking agreements, maps, and other scientific background information to ease the process of bank approval.

RIBITS provides snapshots of all conservation banks, including available credits and contact information. This information allows credit buyers to check for credits and contact banks with greater ease than if they contacted the local FWS office each time they considered making a purchase, and this reduces the burden on FWS offices. Drawbacks to the RIBITS platform include uncited price information and information that may not be regularly uploaded or updated depending on the capacity of the local FWS office.

An all-encompassing platform is the Ecosystem Credit Accounting System (ECAS), which is an information suite replete with protocols, standards, and credit quantification methods (see Willamette Partnership, 2013). The ECAS includes three tools: the Ecosystem Crediting Platform, Credit Calculators, and the Markit Environmental Registry (described below). The ECAS is currently designed for three credit types: aquatic habitat (salmon), upland habitat (sage-grouse, prairie), and water quality. The only place where ECAS is fully operational
An Approach to Landscape-Scale Conservation: Red Cockaded Woodpecker and Gopher Tortoise

Most HQTs take into account indicators of quality and site conditions when determining credits and debits. In addition to quality, there are larger landscape-scale issues that influence population viability including habitat extent and fragmentation.

A recent effort evaluated the influence of landscape factors on the red cockaded woodpecker and the gopher tortoise, species of interest due to their presence on and near military installations in the Southeast. Individual-based, spatially explicit population models were used to estimate credits to capture the influence of landscape dynamics on population viability.

A Decision Analysis approach was developed to examine the influence of model uncertainty on credits associated with landscape change. Decision Analysis was based on two techniques: Pattern Oriented Modeling (POM) and Landscape Equivalency Analysis (LEA). POM evaluates uncertainty in the population model while LEA incorporates abundance and genetic variation into credit and debit quantification.

This approach is designed to minimize habitat fragmentation effects on population viability across the landscape when management shifts habitat locations. The approach has been used to evaluate habitat trading decisions under the Recovery and Sustainment Program for the red-cockaded woodpecker. This type of analysis can potentially improve the recovery of a species by not only considering habitat quality factors that affect individuals, but also changes in reproduction, dispersal, and local extinction that occur across the landscape due to trading.

For a complete description see Bruggeman and Jones, 2014.

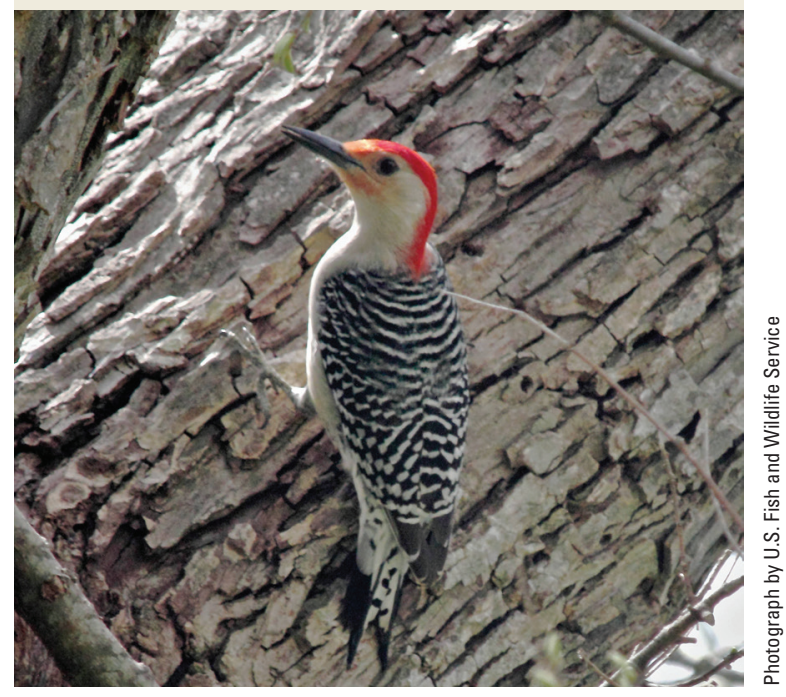


Biodiversity and Habitat Markets: Policy, Economic, and Ecological Implications of Market-Based Conservation

is in Oregon, where it is used for water quality crediting; the habitat-oriented programs are under review by the FWS (Bobby Cochran (Willamette Partnership), oral commun., March 25, 2014).

Credit Registries: Credit registries are databases that track information about credits, typically using a serial number to ensure credits are validated, retired, and not double counted (Bennett and Todd, 2011). Depending on the registry, information about each project can include property descriptions, acreage, practices, agreements, and prices. Often Web-based credit registries increase environmental market transparency for buyers, sellers, and the general public. RIBITS is a registry as well as a credit platform (See USACE, 2015). Markit is another registry, but it lists few conservation banks, reducing its ability to provide information to the public, especially for credit purchasers (Madsen and Percival, 2010). The habitat exchanges now being developed anticipate establishing registries for the sage grouse, lesser prairie chicken, and various species in the Central Valley floodplain. As indicated in one example of a prairie habitat assessment methodology (Willamette Partnership, 2013), there are several steps and components required to register a habitat or species credit. First, credits must be recorded in an FWS-approved database (or registry) with the title of the relevant properties. Additional components are required as well, including storage documents, geographic locations, credit quantities, and credit sales. Information on the general location of the impact and mitigation sites, as well as the quantities of credits being generated and sold, are required. While all of this information helps facilitate smoother market transactions, the absence of any price-per-credit information would tend to increase the negotiation costs of any chosen transaction.

Innovative Finance Mechanisms: A third category of market support tool involves developing innovative finance mechanisms. These mechanisms are designed to address the high cost of entry into conservation banking arrangements for individual landowners. For example, in Maryland, there are State regulations - the Chesapeake Bay Critical Area Protection Act and the Forest Conservation Act (Natural Resources Article 5-1601 - 1613) - that require mitigation for reduced forest cover. These regulations are administered at the county and local levels where crediting and trading are allowed. Residential, commercial, and industrial developers can purchase credits for forest cover from private landowners. Applying for mitigation credits requires a large capital outlay for site surveys and other administrative costs. The Alliance for the Chesapeake Bay - a nonprofit organization focused on Bay protection - is developing a finance mechanism to bring capital from investors to forest landowners. Similar to renewable energy loans, the investors would 'loan' capital to landowners who would pay back administrative expenditures as they sold off credits. While still under development, this approach could increase the supply by individual land owners of forest credits in the region and help provide large tracts of permanently protected forest (Eric Sprague (Alliance for the Chesapeake Bay), oral commun., August 9, 2014).

\section{Habitat Quantification Tools}

With the development of metrics that can assess the potential benefits to a species or of a habitat conservation bank, tools that can provide information on the baseline and improved status of a species or habitat condition, otherwise described as "uplift," are needed. Habitat Quantification Tools (HQTs) use ecological information about species and habitats of concern to identify outcome indicators and potential crediting mechanisms. Most of the tools developed to date require some ecological expertise in field evaluations, vegetation, and geospatial information systems. A significant benefit of establishing a tool for a selected species or habitat is that it provides greater transparency and standardization in the credit and debit quantification process.

Highlight 22 provides a snapshot of the Willamette Partnership's Ecosystem Credit Accounting System, a comprehensive accounting protocol for biodiversity and water assessment. The description includes market support tools and recommended HQTs for use within the accounting system. The system suggests using previously developed tools that support analysis of floodplain, sagebrush/sage-grouse, and oak woodland habitat quality. Although these tools are not explicitly linked to the quantification of credits, they do provide an assessment of baseline habitat conditions that can be used to estimate the number of credits provided for habitat enhancement, restoration, or preservation.

As described earlier, the two habitat exchange efforts under development for the lesser prairie chicken and the sage-grouse are developing standardized HQTs tailored to the particular needs of the species and habitats of concern. The HQT is both a habitat assessment tool and method for developing credits. As described by the Environmental Defense Fund (2014), the lesser prairie chicken and greater sage-grouse HQTs are designed to assess habitat quality on a multi-scale basis. Habitat quality is assessed on four different ecological scales from the site level to the range of the species. Consideration is given to the impacts at each scale in the tool to determine actual biodiversity benefits and the credits to be assigned. The HQT is far more complex than a simple acre crediting scheme but is intended to provide a transparent and standardized process for determining credits and debits.

The HQT uses ecological performance curves and scoring curves based on how ecological attributes impact the lesser prairie chicken. Attributes assessed include habitat acreage, occupancy, species abundance, developed land, tree cover, anthropogenic features, nesting cover, and vegetation height. The Colorado Habitat Exchange HQT design uses the same principals for assessing credits by incorporating habitat quality and measuring effects at a landscape scale tailored to Greater Sagegrouse needs. Both the HQT and its basis as a crediting platform are under development and pending approval by the FWS.

The USDA NRCS has developed an approach to assess the feasibility of supporting Utah prairie dogs on a property the Utah Prairie Dog Habitat Evaluation Model. This model is essentially a scorecard that assigns a value to different 
attributes. The scorecard considers specific attributes: percentage of brush canopy cover, brush height, maximum height of vegetation, distance from existing prairie dog colony, access to moisture-rich vegetation in summer, tree invasion, grass cover in cool- and warm-season, grass species richness in cool- and warm-season, perennial forb cover and species richness, vegetation diversity, irrigation type, and potential for burrow flooding (Toombs, 2007). It is important to note that for scorecards, there may be doubt involved with some of the attribute conditions. For example, in the Utah Prairie Dog Habitat Evaluation Model, there is a degree of uncertainty about the probability of burrow flooding (low, medium, and high). The more objective an HQT (regarding quantitative versus qualitative metrics), the better it provides a standardized, objective assessment of conservation. It is important to note that all HQTs rely on the assessor's ability to conduct field assessments.

\section{Verification and Monitoring of Conservation Benefits}

A critical feature of any conservation bank or habitat exchange activity success is the reality that sellers of habitat credits provide tangible conservation benefits, and credit buyers are confident their purchases have the requisite financial value. Monitoring and verification procedures must be in place to meet the needs of both buyers and sellers. Highlight 23 underscores the types of problems that can occur if effective monitoring and verification are absent. One role that Government can play involves absorbing some of the startup costs, such as the development of monitoring and verification protocols to facilitate market development (Marc Ribaudo (USDA Economic Research Service), written commun., December 31, 2014).

Within the scope of conservation banking, a few steps are required to verify the initial number of credits and ensure that those credits represent viable conservation outcomes. The first step is to determine responsibility for monitoring and verification, and this can vary from bank to bank, but usually includes oversight by FWS-approved third-party verifiers. Third-party verifiers can be consultants, restoration professionals, and others, and they all require accreditation.

The second step is to determine what is to be verified, and this can change over time. At the outset of a project (before any conservation action) a site visit is made and documentation that "confirms site eligibility, estimates of credits, and the adequacy of stewardship/monitoring plans" is reviewed (Willamette Partnership, 2013).

In addition to pre-project monitoring and verification, these activities must also take place on a scheduled, continuous basis. At any conservation bank site, the credit seller handles continued monitoring that documents how performance standards are being met on a timely basis. While performance standards vary according to habitats and species types, the standards represent what is necessary to sustain the habitat functions for which a credit is being sold. Measurable performance standards, and a regular monitoring schedule, are usually based on accepted methods and practices of habitat restoration, data on target species populations, and other important reference conditions (Willamette Partnership, 2013).

As noted at the outset of this chapter, buyer confidence in the robustness of conservation outcomes is essential for conservation bank or future habitat exchange operations. However, a reliable monitoring and verification system that determines and supports the value of a credit can be expensive for the credit supplier. Highlight 23 provides an example of the significance of monitoring and verification. The viability of a market-like approach to biodiversity conservation is determined by whether or not credit values are sufficient to cover monitoring and verification costs (and other transactions costs), and the level of certainty in attaining and maintaining conservation performance standards.

\section{Discussion and Observations}

This chapter discussed five selected factors that can influence the biophysical and economic performance of conservation banking and habitat exchanges in meeting species conservation goals: metrics, banking credit types and ratios, marketing facilitation tools, HQTs, and monitoring and verification requirements. Eco-labeling is not included in this section because of the lack of information about or need for credit types and ratios and HQTs. In recent years, there has been copious research, experimentation, and progress in developing measurement systems, habitat protocols, and banking programs designed to attract both supply and demand for various types of species or habitat credits. One basic trade-off has been the requirement for regulatory and buyer certainty in developing costly metrics and protocols that are viable predictors of credited ecological outcomes. The crafting and integration of market facilitation tools such as crediting platforms, tracking tools, credit registries, and new finance mechanisms have helped mitigate this trade-off between certainty and cost, but they may also entail high market start-up costs in the short term. Regardless, there appear to be enough buyers and sellers to make many of the conservation banking markets viable, which illustrates that the prices of some credits are enough to overcome the costs of bank establishment and management.

With respect to practice-based metrics for biodiversity and wildlife habitat, the current efforts under the CEAP could be expanded and documented to establish a suite of practices with known outcomes and varying levels of certainty, and can be adopted across different landscapes. Although performancebased metrics are more certain than practice-based metrics, they are also more expensive. There is enough experience in performance metric development to warrant an examination of which metrics generate greater predictability. All three types of performance metric categories would be included: models, species counts, and area-based.

The fact that a landowner can supply numerous credit types for a bank site (for example, pre-compliance, creation, 
In 2008, the Willamette Partnership initiated an effort to develop a credit accounting system for ecosystems funded by an NRCS grant. In 2009, twenty-seven State and Federal natural resource management agencies and other important nonprofit stakeholders had agreed to the principals of the system. The Partnership's vision is for a system used for both nongovernmental voluntary efforts and by agencies such as FWS and USDA. While agencies are currently using components of the system, it has not yet been implemented comprehensively.

The outcome of this effort, the Ecosystem Credit Accounting System (ECAS), is a suite of protocols, standards, and quantification methods. The ECAS consists of three tools: a platform to interact with landowners and credit developers, Credit Calculators, and a ledger to track credits and transactions.

The ECAS requires that independent, accredited verifiers confirm project eligibility, baseline and credit calculations,

Salmon Habitat Credit Calculation Method: An excel-based scoring tool, this method scores sites/projects based on six ecological functions that support salmonid species habitat. The biotic support groups and functions considered include cover/refuge, forage, nesting/spawning sites, connectivity, cover/refuge and nesting for insect/invertebrates. Other considerations include habitat formation, temperature regulation, spatial separation, variable velocity, and channel diversity (Willamette Partnership, 2009).

Columbia River Salmon and that project implementation meets quality standards. Once verified, projects are assigned credits. The ECAS uses trading ratios to cover the risks associated with ecological metrics and encourage siting in high priority areas.

Verified projects are required to register credits for public review. This provides a tool that can track and monitor the availability of credits and volume of trade.

The ECAS currently organizes credits into three overarching types: aquatic habitat, upland habitat, and water quality. For biodiversity benefits, the first two are significant. Within aquatic habitat there are three subtypes: floodplain, salmon, and wetland habitat. Upland habitat also has three subtypes: oak woodland, sagebrush/sage-grouse, and upland prairie/fender's blue butterfly habitat. Each of the credit types is associated with a HOT described below; these tools are specified for application in specific United States geographies.

\section{Above text adapted from Willamette Partnership, 2013.}

Prairie Credit Calculation Method: This method is an excel-based scoring tool used to determine functional acres of upland prairie habitat. A score between 0 and 10 is assessed, and that value is divided by 10 and applied to the number of acres to calculate the number of functional acres or credits. For example, a score of 5 would be divided by 10 for .5 and multiplied by number of acres (10) to derive 5 functional acres or credits. Scoring tool criteria include connectivity, vegetation, rare species, and invasive species (Willamette Partnership, 2014).
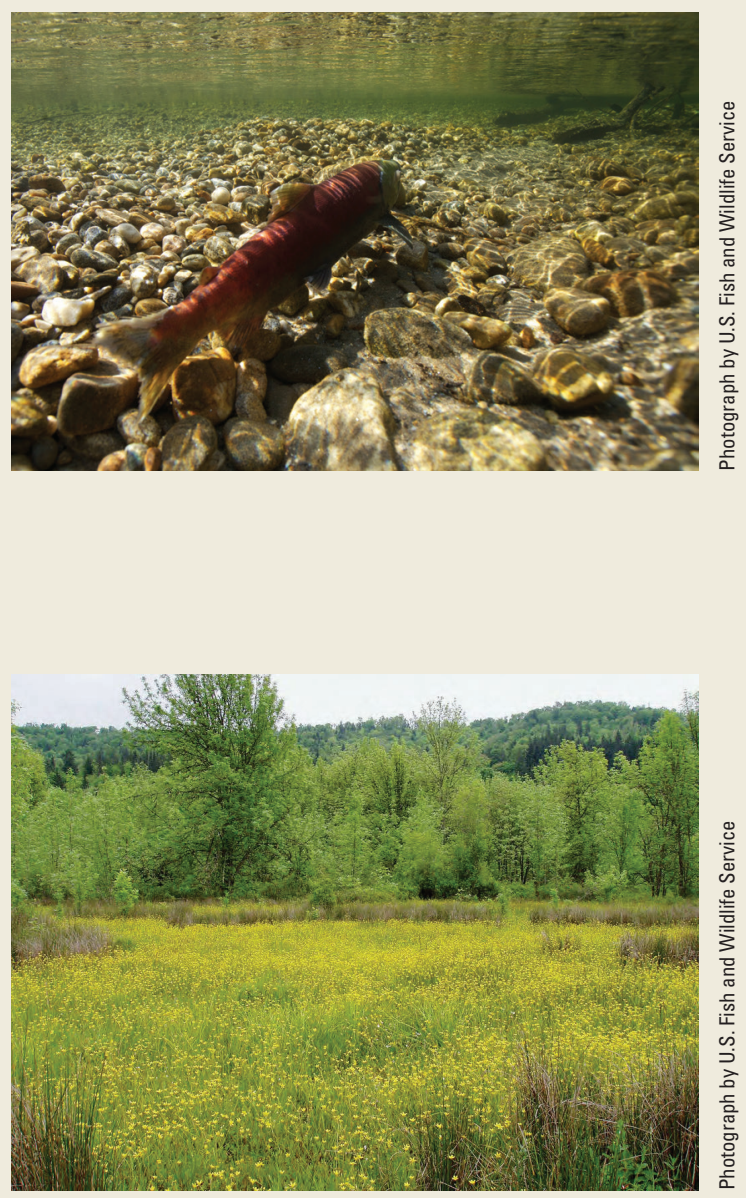


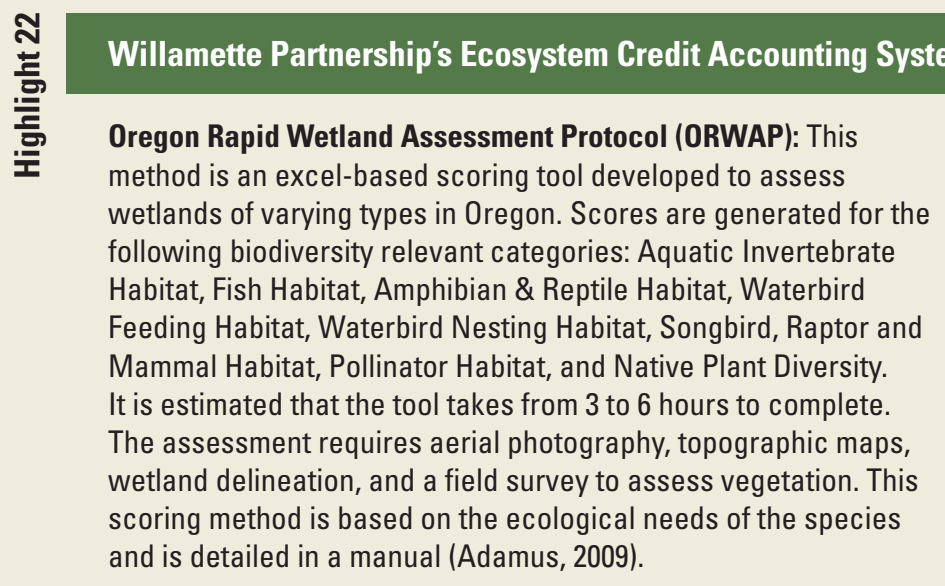

Wetlands

Floodplain Habitat Method: This method generates the Floodplain Habitat Quality Score, which is an assessment of the habitat quality of floodplains. The scoring considers a number of indicators of habitat quality and aggregates these into 6 composite indicators. These indicators are significance-weighted based on expert opinion. Landscape context, flooding regime, and risk/stressors receive a weight of 3 ; vegetation structure and distribution receives a weight of 2; and non-invasive species of vegetation and sensitive/rare species receive a weight of 1 . Details on the metric are provided in a User's Guide (Defenders of Wildlife, 2012a).

Eagle River Floodplain

Sagebrush/Sage Grouse Habitat Method: This method for assessing sagebrush is estimated to take 1 to 2 days including field data collection. Factors considered in the scoring include juniper invasion in the overstory, sagebrush cover, functional vegetative diversity, patch size, distance to sage grouse lek (mating area), proximity to dangers (maintained roads; inhabited human structures; and trees, buildings, or other raptor structures greater than $5^{\prime}$ tall), and distance to persistent water. Metrics are aggregated into a weighted total score (Defenders of Wildlife, 2012c).

Greater Sage Grouse

Oak Woodland Habitat Method: This method for assessing oak woodland habitat is used to calculate functional acres, which are the unit of credit. An excel-based scoring tool is used to assess indicators of habitat quality. The indicators are categorized into 6 weighted composite indicators: landscape context and invasive species of vegetation are weighted at 3; risks/stressors are weighted at 21; and management practices, vegetation structure, and sensitive/rare species are weighted as 1 (Defenders of Wildlife, 2012b).
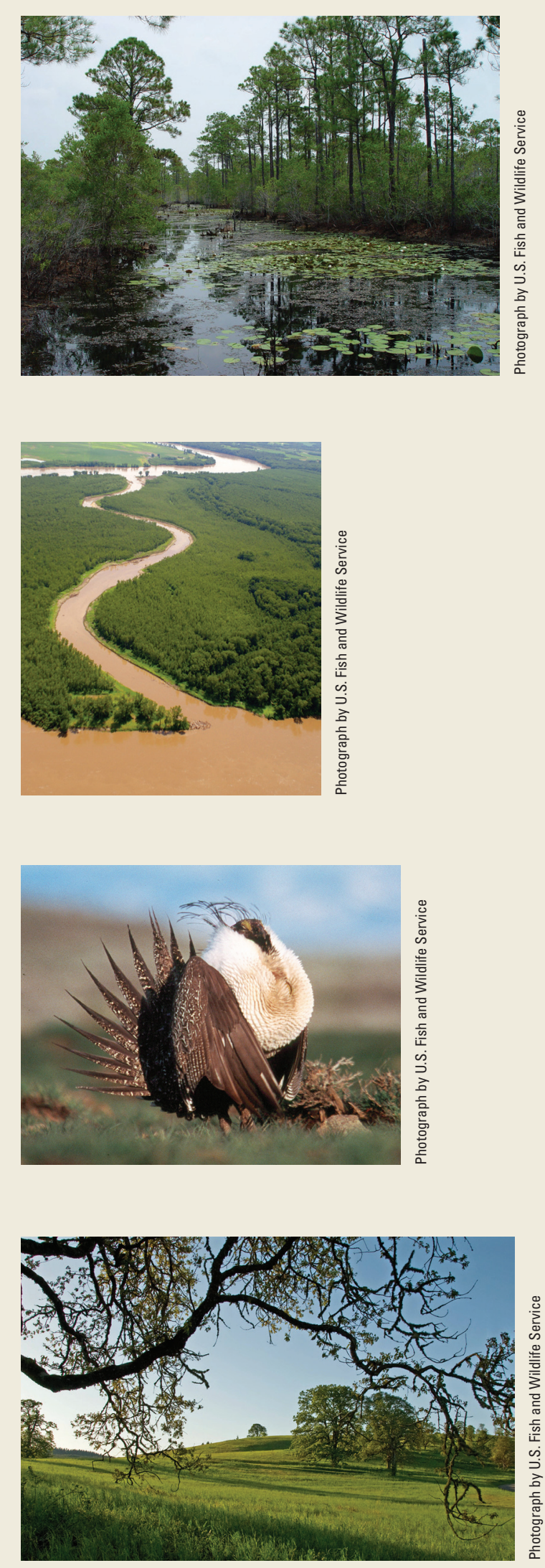
Wetlands provide benefits that are valuable to society and to fish and wildlife. These benefits include water quality improvement, floodwater storage, fish and wildlife habitat, aesthetics, and biological productivity (EPA, 2001). For that reason the government set a national goal for no net-loss of wetlands in the United States in 1989.

Under authority of the Clean Water Act, the USACE requires compensatory mitigation, an action that must be taken to replace a wetland, such as restoring a former wetland, to receive a permit for a project in which wetland loss is inevitable.

In 2005 the U.S. Government Accountability Office (GAO) performed an assessment of the USACE mitigation guidance, the extent to which the USACE oversees mitigation, and enforcement. The GAO found that USACE did not have an effective oversight process to ensure mitigation was actually obtained from permittees. For example, the GAO was able to find evidence for only 24 percent of permit files that required monitoring reports and only 15 percent of total permit files contained evidence that USACE conducted a compliance inspection. The GAO recommended that USACE establish an effective oversight approach that ensures permittees perform required wetland mitigation (GAO, 2005).

In response to the finding, the USACE and the EPA published regulations in 2008 that strengthen and clarify the requirements of monitoring and oversight for mitigation as well as state a preference for mitigation banks over permittee-responsible mitigation (Federal Register, 2008).

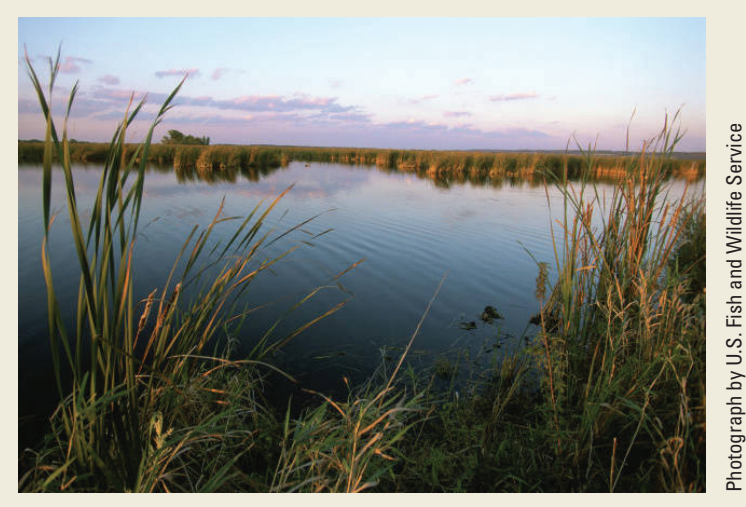

preservation) is a feature that encourages increased participation on the supply side and should be continued. A pilot test of the pre-compliance crediting system currently under public review and comment by the FWS would provide empirical evidence of whether this approach can increase market participation and prevent future listings of species. The strength of the current methods for determining credit/acreage ratios is that they are specific to particular habitats and ecological needs for individual species. However, determining these ratios can be time-consuming and expensive. There may be a possibility to decrease the effort and cost of developing future credit/acreage ratios by exploring a "benefits-transfer" method where previously developed credit/acreage ratios could be applied to a new but similar species.

A lot of progress has been made in developing, deploying, and testing HQTs for various species. Until now, these tools have been fairly site specific. It would be beneficial to standardize a national "conceptual framework" flexible enough to apply to different habitats and species across geographic scales. One multi-species HQT for floodplain ecosystems is being developed and tested by a partnership of conservation organizations (Environmental Defense Fund, Trout Unlimited, Point Blue Conservation Science, Stillwater Sciences and others) for the Central Valley Habitat Exchange.
This tool would account for specific suites of habitat attributes needed by floodplain species within a single framework. Another avenue for further exploration is the application and field testing of an Ecological Integrity Index proposed by Defenders of Wildlife, Nature Serve, The Institute for Natural Resources, and several Federal natural resource management agencies (Vickerman and Kagan, 2014).

Regarding market registries, there are three major constraints. The first is that many, including RIBITS, are resource-constrained, and additional resources could increase its usability for potential buyers and sellers. The second constraint is the lack of price transparency. The third is that there is no comprehensive review of registries; it would be useful to have a separate and more focused review of how registries are working and what characteristics are most valued by buyers, sellers, and (or) regulators.

Finally - and similar to the needs for HQTs - it would be helpful to review monitoring and verification protocols to determine best practices and increase their reliability in measuring biophysical performance. Another goal might be to investigate the practicality of developing standardized monitoring and verification protocols to improve economic performance. 


\section{Chapter F-Future Outlook for Conservation Mechanisms}

In the U.S., there are numerous threats to biodiversity and wildlife habitat. Threats include the transformation of land from habitat to agriculture; residential, commercial, and industrial development; energy and mineral production; and climate change. As a society, biodiversity and habitat are valued as evinced by the Endangered Species Act, National Forest Management Act, and others. However, these values are not inherently translated into the cost of production or the price of goods. This circular evaluates market-based mechanisms designed to address market failures in providing biodiversity benefits. There are ecological and economic trade-offs with each mechanism. This chapter highlights opportunities to improve the success of biodiversity and habitat markets.

Research for this circular uncovered issues that inhibit the wider adoption and success of biodiversity and habitat markets. The most significant are institutional barriers, administrative capacity, alternative mitigation, standardization of metrics, HQTs, and financing. Table 7 provides a high-level summary of the issues, opportunities, and future outlook for overcoming the barriers, followed by additional details in the subsequent sections.

\section{Institutional Barriers}

\section{Issue}

Institutional barriers (as noted throughout this circular); the rigidity of regulations that drive biodiversity and habitat markets (predominantly the Endangered Species Act); and the procedures for implementing those regulations all reduce the market's ability to provide innovative approaches. Specifically, the requirement for conservation banks to provide conservation in perpetuity reduces the supply of landowners willing to participate in programs, reducing the potential market size and quantity of achievable biodiversity benefits.

Another major institutional barrier is that species and habitat are only protected once listed. The ability to sustain and recover species once they are listed as threatened or endangered is diminished. Pre-compliance markets require legal assurances to drive demand. Thus far, efforts to obtain these assurances have been unsuccessful.

\section{Opportunity}

To overcome the disincentive of perpetual conservation, habitat exchange developers suggested a Dynamic Mitigation Credit approach. By aggregating the benefits of multiple landowner conservation efforts over time, the impacts of a permanent land conversion may be mitigated, and a perpetual conservation may not be necessary in all cases. It would require a major institutional change to allow term mitigation for species that could be impacted on a site for a period but might be reintroduced with site reclamation. Under applicable conditions, this could increase species conservation at a much lower cost than permanent mitigation.

A significant detriment to biodiversity and habitat markets is the inability, or lack of confidence in the ability, of the government to provide legal assurances in the pre-listing environment that can persist in the post-listing environment. The opportunity to improve outcomes for species by implementing actions earlier is considerable. The potential that a listing decision could be avoided has multiple positive impacts, including the ecological benefits for conservation as well as the economic impacts avoided due to regulation. There is demand from polluters for pre-compliance credits as evidenced by the gopher tortoise effort, the Colorado Habitat Exchange, and similar efforts to develop pre-listing markets.

To institute acceptance of pre-listing credits in a postlisting environment, the FWS could take a bottom-up or top-down approach. FWS field offices could develop candidate conservation assurances for species that are candidates for listing. In some instances this has led to legal problems-a voluntary market for the dunes sagebrush lizard in Texas has led to environmental nonprofits suing the FWS — but individual offices continuing to try may find better acceptance of this approach. Alternatively, a new FWS rule for the addition of pre-listing species in the impending conservation banking guidance may realize greater success.

\section{Outlook}

It is difficult to predict whether or not these specific institutional barriers will be overcome. Over the past two decades, efforts to develop pre-listing markets were attempted but this 
Table 7. Summary of biodiversity and habitat market issues, opportunities, and future outlook.

[HQT, habitat quantification tool]

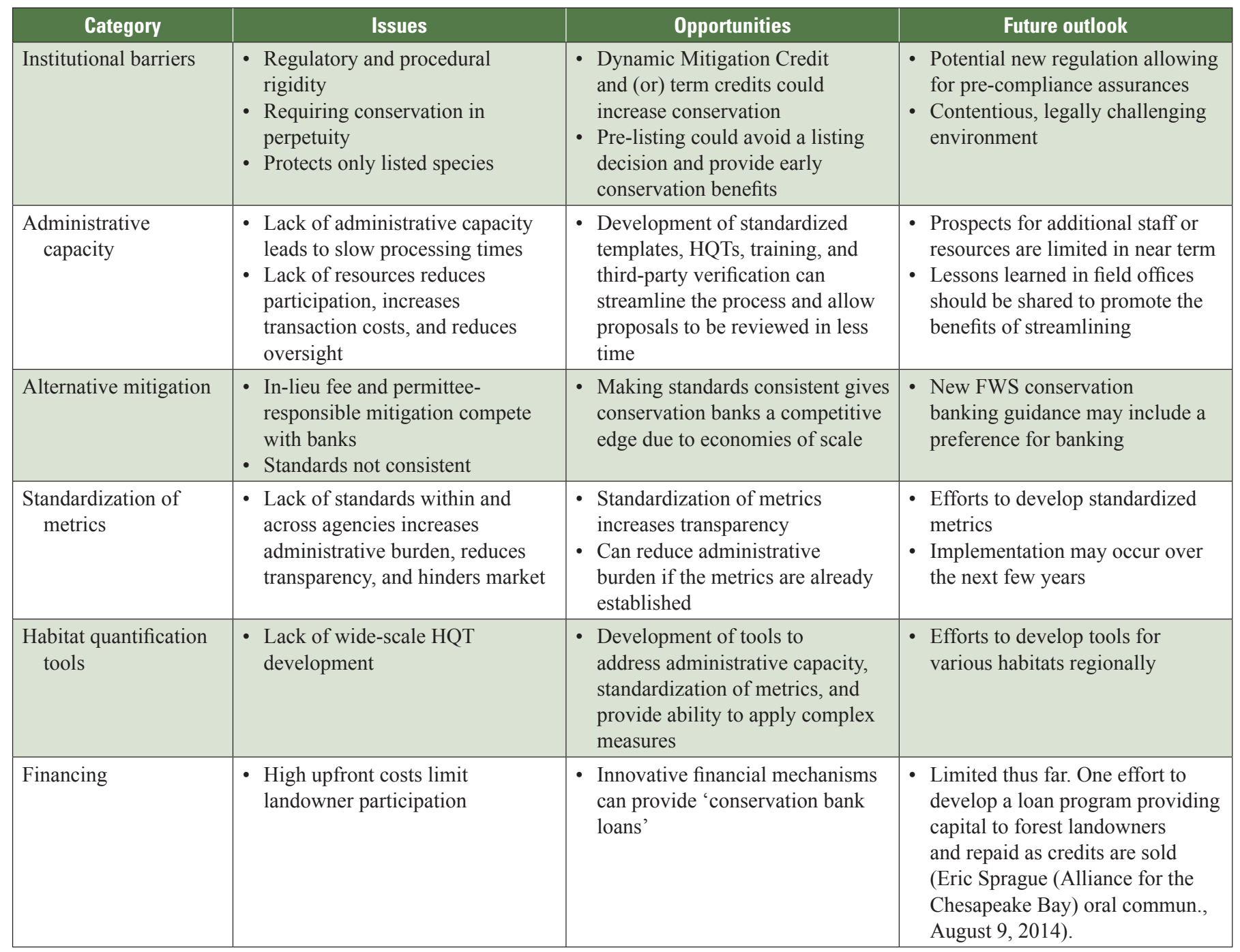

has been met with caution on the part of FWS. The contentious legal environment in which the FWS has been sued for not listing species, sued for avoiding listing due to State programs (such as for the dunes sagebrush lizard), and sued for listing species (such as the lesser prairie chicken) reduces the likelihood that the FWS will be able to make institutional changes.

\section{Administrative Capacity}

\section{Issue}

The DOI PPA survey of FWS employees (2013a) and a survey of conservation bankers by Fox and Nino-Murcia (2005) both highlighted issues associated with FWS offices not having the capacity to process applications for conservation banks. Administrative capacity is a function of staff and resources and is a problem for both FWS and USDA administered PES programs. The surveys indicate that limited administrative capacity led to slow processing times, delays in banking document approval, and delays in solicitor approval. Lengthy banking documents also impede participation. The ability to review and approve documents is not only an upfront issue in the development of a bank or acceptance of a farm in a PES program. Agencies also need to approve trades for conservation banks and monitor and verify practices to ensure conservation is being achieved on the landscape. A lack of resources can lead to fewer landowners participating and increase transaction costs (in terms of time); lack of oversight might also reduce ecological outcomes.

\section{Opportunity}

Many opportunities exist for reducing the administrative burden on FWS and USDA offices while simultaneously improving their capacity to manage conservation bank and 
PES programs. Standardized templates, HQTs, training, and third-party verification can streamline the process and allow proposals to be reviewed in less time.

\section{Outlook}

The prospect of additional staffing or resources for agencies is limited in the near term. Opportunities do exist for improving efficiency through the use of templates, tools, and third party verifiers. Lessons learned in field offices can be shared to promote the benefits of these approaches. For example, the State of California instituted a template for conservation bank applicants (FWS, 2010); reporting on its effectiveness in reducing processing time would provide valuable information for other field offices.

\section{Alternative Mitigation}

\section{Issue}

Specific to conservation banks, the allowance for alternative mitigation including in-lieu fee programs and permitteeresponsible mitigation, serve as competition for banks and reduce bank viability. In itself, competition effectively reduces costs and provides efficient allocation of resources. However, these alternative approaches to conservation banking hold unfair competitive advantages over banking and often lack equivalent conservation benefits. For example, permitteeresponsible mitigation does not require polluters to provide financial assurances that conservation will remain in perpetuity. At the same time, the small plots of mitigation likely to be provided by permittee-responsible mitigation deliver less conservation than the large tracts provided by conservation banks. Alternative mitigation, therefore, may have a lower upfront cost, minimizing conservation banking's role as a competitive option.

\section{Opportunity}

More stringently setting standards on alternative approaches so they fall in-line with conservation banking could improve the competitive edge of conservation banks, which could in turn attain economies of scale in contrast to small-scale permittee efforts. A preference for conservation banks can also be achieved by programmatic statement or by field offices giving higher ratios for conservation bank credits than permittee-responsible mitigation to account for differences in conservation yield.

\section{Outlook}

The FWS conservation banking guidance expected in 2015 may include a preference for banking based on the ecological superiority of large tracts of land for species recovery.

\section{Standardization of Metrics}

Issue

Different field offices may use different metrics for the evaluation of credits and debits for a species. A lack of standard metrics to quantify biodiversity and habitat benefits within and across agencies increases administrative burden, reduces transparency, and hinders the market. Additionally, the current tendency towards practice- versus performance-based metrics reduces opportunities for innovative conservation approaches. For example, the emphasis on the installation of specific practices in most PES programs calculates cost-share for all acreage on the same basis rather than incentivizing better practices or better land participation for higher rewards.

\section{Opportunity}

The standardization of metrics can provide the opportunity for a more transparent process for credit and debit assignment. Standardization could reduce the administrative burden on agencies if the metrics are already established. A move towards performance-based metrics encourages the development of innovative approaches to increase conservation and participation by landowners with high biodiversity value land.

\section{Outlook}

Nonprofit environmental organizations have efforts in place to develop, and encourage the development of, performance-based and standardized metrics. In coordination with other organizations and government agencies, the implementation of these metrics could occur over the next few years. A presaging of this transition is the establishment of the CSP in 2002, which resembles a performance-based PES program.

\section{Habitat Quantification Tools}

\section{Issue}

As mentioned earlier, there is a need for Habitat Quantification Tools (HQTs). The development of HQTs is necessary to measure complex, landscape-scale metrics that measure biodiversity benefits more accurately than simple acre proxies. There are limited, regional efforts to develop HQTs, but widescale development, deployment, and testing of more tools could greatly benefit biodiversity and habitat markets.

\section{Opportunity}

The development of HQTs has clear benefits. It addresses issues of administrative capacity and standardization of metrics and provides the ability to apply complex measures to the assignment of credits and debits. If valid HQTs are available, 


\section{Biodiversity and Habitat Markets: Policy, Economic, and Ecological Implications of Market-Based Conservation}

the upfront evaluation of conservation banks and PES applicants can be streamlined. The availability of these tools allows landowners to assess their property and encourages additional market participation. A HQT can reduce the subjectivity of credit and debit assignment and supports standardized metrics. Tools can theoretically reduce the need for approval of credit exchanges, which would reduce the transaction costs associated with conservation banks, allow for the auctioning of credits, and support a more robust market.

\section{Outlook}

There are extant efforts to develop HQTs for conservation efforts across the Nation. In particular, HQTs are central to habitat exchange efforts. Thus far, the wide-scale development and application of HQTs is underdeveloped, because it is an expensive, complex task to develop these tools and may require reprioritization from agencies (including FWS, USACE, and EPA) to institutionalize the development and use of HQTs.

\section{Financing}

\section{Issue}

The adoption of conservation banking by individual landowners is limited by the high upfront costs associated with applying and implementing the practices necessary to achieve conservation goals. PES programs provide annual payments during the period when practices are first installed, encouraging individual landowners to participate. However, for conservation banking many costs are incurred prior to credit assignment and the purchase of credits may not be immediate. The financial risks for individual landowners are also substantial.

\section{Opportunity}

Innovative financial mechanisms can provide 'conservation bank loans' that bridge the gap from when capital is first needed to when revenue from credits can be recouped. This structure is being evaluated in Maryland for forest landowners with assistance from the Chesapeake Bay Alliance. Simple loans may increase landowner participation and provide value for environmental investors.

\section{Outlook}

While one financing effort is cited, mechanisms to help bolster biodiversity and habitat markets have not received a lot of attention. It is possible that as the markets continue to grow, the investment community will recognize the opportunities and improve the financial mechanisms that support landowner entrance into these markets.

\section{Conclusions}

Some challenges face the growth and performance of biodiversity and habitat markets. These challenges include institutional barriers, administrative capacity, alternative mitigation, standardization of metrics, Habitat Quantification Tools, and financing. Each of these challenges presents an opportunity for increased adoption and success of biodiversity and habitat markets.

It is important to acknowledge the growing use of market-based mechanisms over the last few decades. This growth was achieved through the efforts of individuals in the U.S. Fish and Wildlife Service and the U.S. Department of Agriculture. From a nascent market in California, conservation banking has spread to States across the country with a documented record of delivering conservation benefits to many species. Attributable to the success of the program, is the fact that there are efforts to expand and employ similar tools for as yet unlisted species.

Payment for Ecosystem Services programs have a long history, but the move towards targeting high yield land, employing habitat quality metrics, and even employing performance-based metrics suggests the potential for these programs to adapt and meet the growing needs of society for biodiversity and habitat. Addressing the challenges and opportunities present to promote and grow biodiversity and habitat markets can help protect the Nation's remarkable expanse of wildlife. 


\section{References}

Adamus, Paul, Morlan, Janet, and Verble, Kathy, 2009, Manual for the Oregon rapid wetland assessment protocol (ORWAP) (version 2.0): Salem, Oreg., Oregon Department of State Lands, accessed July 30, 2015, at http://willamettepartnership.org/wp-content/uploads/2014/09/orwap_manual_v2.pdf.

Agarwala, Meghna; Kumar, Satish; Treves, Adrian; and Naughton-Treves, Lisa, 2010, Paying for wolves in Slapur, India and Wisconsin, USA: Comparing compensation rules and practice to understand the goals and politics of wolf conservation: Biological Conservation, v. 143, no. 12, p. 2945-2955. [Also available at http://dx.doi.org/10.1016/j. biocon.2010.05.003.]

Aguilar, F.X., and Vlosky, R.P., 2007, Consumer willingness to pay price premiums for environmentally certified wood products in the U.S.: Forest Policy and Economics, v. 9, no. 8, p. 1100-1112. [Also available at http://dx.doi. org/10.1016/j.forpol.2006.12.001.]

Amacher, G.S., Koskela, Erkki, and Ollikainen, Markku, 2004, Environmental quality competition and eco-labeling: Journal of Environmental Economics and Management, v. 47, no. 2, p. 284-306. [Also available at http://dx.doi. org/10.1016/s0095-0696(03)00078-0.]

American Farmland Trust, 2014, Regional Conservation Partnership Program - A Guide for developing project proposals: Washington, D.C., American Farmland Trust, 24 p., accessed July 30, 2015, at http://162.242.222.244/programs/ federal/documents/RCPP_Proposal_Guide_Master.pdf.

Anderson, John, Hudson, Darren, Harri, Ardian, and Turner, Steve, 2007, A New taxonomy of thin markets in Southern Agricultural Economics Association Annual Meeting, February 4-7, 2007, Mobile, Alabama: Southern Agricultural Economics Association Annual Meeting, Mobile, Alabama, 2007; 17 p., accessed July 30, 2015, at http://ageconsearch. umn.edu/bitstream/34826/1/sp07an01.pdf.

Barbarika, Alex, [n.d.], Conservation reserve programAnnual summary and enrollment statistics FY 2012: Washington, D.C., Farm Service Agency, U.S. Department of Agriculture, 45 p., accessed July 30, 2015, at http://www. fsa.usda.gov/Internet/FSA_File/summary12.pdf.
Barrett, Kelli, 2014, Should landowners earn biodiversity offsets for conserving species habitat before it becomes endangered?: Ecosystem Marketplace-A Forest Trends Initiative Web page, accessed July 30, 2015, at http://www. ecosystemmarketplace.com/pages/dynamic/article.page. php?page_id $=10490 \&$ section $=$ news_articles\&eod $=1$.

Barthold, Thomas, 1994, Issues in the design of environmental excise taxes: The Journal of Economic Perspectives, v. 8 , no. 1 , p. 133-151. [Also available at http://dx.doi. org/10.1257/jep.8.1.133.]

Bennett, Karen and Todd, Al, 2011, A registry for environmental credits: Chesapeake Bay Environmental Markets Team white paper (draft): Washington, D.C., Office of Environmental Markets, U.S. Department of Agriculture, 8 p., accessed July 30, 2015, at http://www.chesapeakebay.net/ channel_files/17872/(post-meeting_doc)_white_paper_verification_of_environmental_credits.pdf.

Briske, D.D., Derner, J.D., Milchunas, D.G., and Tate, K.W., 2011, An evidence-based assessment of prescribed grazing Practices, chap. 1 in Briske, D.D., ed., Conservation benefits of rangeland practices-Assessment, recommendations, and knowledge gaps: Washington, DC, Natural Resources Conservation Service, U.S. Department of Agriculture, $p$. 21-74. [Also available at http://www.nrcs.usda.gov/Internet/ FSE_DOCUMENTS/stelprdb1045796.pdf.]

Bruggeman, Douglas and Jones, Mike, 2014 Development of adaptive management tools to guide habitat allocations for at-risk species: East Lansing, Michigan, Department of Fisheries and Wildlife, Michigan State University, SERDP project RC-1656, accessed July 30, 2015, at https://www. serdp-estcp.org/content/download/24286/251895/file/RC1656-FR.pdf.

Bunn, David, Lubell, Mark, and Johnson, C.K., 2013, Reforms could boost conservation banking by landowners: California Agriculture, v. 67, no. 2, p. 86-95. [Also available at http:// dx.doi.org/10.3733/ca.v067n02p86.]

California Department of Fish and Game, 1996, Supplemental policy regarding conservation banks within the NCCP area of Southern California: Sacramento, Calif., California Department of Fish and Game, accessed July 30, 2015, at https:// nrm.dfg.ca.gov/FileHandler.ashx?DocumentID=80890. 
California Department of Fish and Wildlife, 2015, Conservation and mitigation banking laws and policies: California Department of Fish and Wildlife Web page, accessed July 30, 2015, at https://www.wildlife.ca.gov/Conservation/Planning/Banking/Laws-and-Policies.

Caro, Tim, 2010, Conservation by proxy-Indicator, umbrella, keystone, flagship, and other surrogate species ( $2 \mathrm{~d}$ ed.): Washington, D.C., Island Press, 374 p.

Casey, Frank, Vickerman, Sara, Hummon, Cheryl and Taylor, Bruce, 2006, Incentives for biodiversity conservation-An ecological and economic assessment: Washington, D.C., Defenders of Wildlife, $92 \mathrm{p}$. [Also available at http://www. defenders.org/publications/incentives_for_biodiversity_conservation.pdf.]

Certified Wildlife Friendly, 2013, Certified Wildlife Friendly production standards for North America (version 1.0): Wildlife Friendly Enterprise Network Web page, accessed July 30, 2015, at http://wfen.files.wordpress.com/2013/02/ certified-wildlife-friendly-standards-final-2013-v1-0.pdf.

Cheatum, Molly, Casey, Frank, Alvarez, Pelayo, and Parkhurst, Ben, 2011, Payments for ecosystem services-A California rancher perspective-Conservation Economics and Finance Program white paper: Washington, D.C., Defenders of Wildlife, 64 p. [Also available at http://www. live.defenders.org/publications/payments_for_ecosystem_ services_a_california_rancher_perspective.pdf.]

Chen, Xiaoxuan and Ando, A.W., 2006, Optimal contract length for voluntary land conservation programs: Champaign, Ill., Department of agricultural and consumer economics, University of Illinois at Urbana-Champaign, 32 p., accessed July 30, 2015, at http:/www.webmeets.com/files/ papers/ERE/WC3/461/ContractLengthWorldCongress.pdf.

Claassen, Roger, Cattaneo, Andrea, and Johansson, Robert, 2008, Cost-effective design of agri-environmental payment programs-U.S. experience in theory and practice: Ecological Economics, v. 65, no. 4, p. 737-752. [Also available at http://dx.doi.org/10.1016/j.ecolecon.2007.07.032.]

Clark, C.D., and Russell C.S., 2003, Ecolabels and economic efficiency - Some preliminary results in American Agricultural Economics Association, 2004 Annual Meeting, August 1-4, Denver, Colorado: American Agricultural Economics Association annual meeting, Denver, Colo., 2004; 20 p. [Also available at http://ageconsearch.umn.edu/ bitstream/20338/1/sp04cl01.pdf.]

Coase, Ronald, 1960, The problem of social cost: Journal of Law and Economics, v. 3, Oct., p. 1-44. [Also available at http://dx.doi.org/10.1086/466560.]

Culliney, Susan, 2014, Payments for wildlife and biodiversity outcomes under Farm Bill programs: Washington, D.C.,
Defenders of Wildlife, 26 p. [Also available at http://www. defenders.org/sites/default/files/publications/paymentsfor-wildlife-and-biodiversity-outcomes-under-farm-billprograms.pdf.]

Davis, F.W., Scott, J.M., and Goble, D.D., 2006, The Endangered Species Act at thirty-Conserving biodiversity in human-dominated landscapes, volume 2: Washington, D.C., Island Press., 376 p.

Defenders of Wildlife, 1997, Defenders makes grizzly compensation payments on Blackfeet Reservation-Press release: Defenders of Wildlife Web page, accessed July 30, 2015, at http://www.defenders.org/press-release/defenders-makesgrizzly-compensation-payments-blackfeet-reservation.

Defenders of Wildlife, 2012a, Floodplain habitat metric user's guide: Washington, D.C., Defenders of Wildlife, 38 p., accessed July 30, 2015, at: http://willamettepartnership.org/ wp-content/uploads/2014/09/Floodplain-user-guide.pdf.

Defenders of Wildlife, 2012b, Oak habitat metric user's guide: Washington, D.C., Defenders of Wildlife, 32 p., accessed July 30, 2015, at http://willamettepartnership.org/wp-content/uploads/2014/09/Oak-habitat-user-guide.pdf.

Defenders of Wildlife, 2012c, Sagebrush / sage grouse habitat metric user's guide: Washington, D.C., Defenders of Wildlife, 37 p., accessed July 30, 2015, at https://ir.library. oregonstate.edu/xmlui/bitstream/handle/1957/53630/Sagebrush_Users\%20guide_email.pdf?sequence $=1$.

Donlan, C.J., Gartner, Todd, Male, Timothy, and Li, Y.-W., 2013, National affairs - USA - Species conservation incentives: Environmental Policy and Law, v. 43, no. 3, p. 162-166.

Environmental Defense Fund (EDF), 2013, Colorado habitat exchange: New York, Environmental Defense Fund, 2 p., accessed July 30, 2015, at http://sagebrusheco.nv.gov/ uploadedFiles/sagebrusheconvgov/content/Meetings/EIRESOLVE-ColoradoHabitatExchangeOverview.pdf.

Environmental Defense Fund (EDF), 2014, Lesser Prairie Chicken Habitat Quantification Tool: New York, Environmental Defense Fund, accessed July 30, 2015, at http:// www.habitatexchanges.org/files/2014/02/Habitat_Quantification_Tool_LEPC_Feb-2014.pdf.

Food and Agriculture Organization of the United Nations (FAO), 2010, Forest biological diversity, chap. 3 in Global forest resources assessment 2010_Main report: Rome, Food and Agriculture Organization of the United Nations, 49 p., accessed July 30, 2015, at http:/www.fao.org/ docrep/013/i1757e/i1757e03.pdf.

Forests for the Bay, 2015, Ecosystem services markets for MD forestland, accessed July 30, 2015, at https://www.forestsforthebay.org/ecosystem_services_markets.cfm?sid=MD. 
Fox, Jessica and Nino-Murcia, Anamaria, 2005, Status of species conservation banking in the United States (review): Conservation Biology, v. 19, no. 4, p. 996-1007. [Also available at http://dx.doi.org/10.1111/j.15231739.2005.00231.x.]

Gartner, Todd and Josh Donlan, 2011, Insights from the field: forests for species and habitat: World Resource Institute Issues Series Brief, Southern Forests for the Future Incentives Series, Issue Brief 10. [Also available at http://pdf.wri. org/forests_for_species_and_habitats.pdf.]

Gosnell, Hannah, Burright, Harmony, Nielsen-Pincus, Max, Ellison, Autumn, and Moseley, Cassandra, 2013, Barriers and preferences for landowner participation in conservation programs in the interior northwest (briefing paper): Eugene, Oreg., Ecosystem Workforce Program, University of Oregon, no. 49, accessed July 30, 2015, at http://ewp. uoregon.edu/sites/ewp.uoregon.edu/files/BP_49.pdf.

Gotelli, Nicholas and Colwell, Robert, 2001, Quantifying Biodiversity-Procedures and pitfalls in the measurement and comparison of species richness: Ecology Letters, v. 4, no. 4, p. 379-391. [Also available at http://dx.doi.org/10.1046/ j.1461-0248.2001.00230.x.]

Hartwick, John, and Olewiler, N.D., 1986, The economics of natural resource use (1st ed.): New York, Harper and Row, $530 \mathrm{p}$.

Horne, R.E., 2009, Limits to labels-The role of eco-labels in the assessment of product sustainability and routes to sustainable consumption: International Journal of Consumer Studies, v. 33, no. 2, p. 175-182. [Also available at http:// dx.doi.org/10.1111/j.1470-6431.2009.00752.x.]

International Union for the Conservation of Nature (IUCN), 2014, IUCN red list of threatened species (version 2014.2) — Table 6A-Red list category summary country totals (Animals) - (updated 24 July 2014): International Union for the Conservation of Nature Web page, accessed July 30, 2015, at http://cmsdocs.s3.amazonaws. com/summarystats/2014_2_Summary_StatsPage_Documents/2014_2_RL_Stats_Table6a.pdf.

Jack, B.K., Kousky, Carolyn, and Sims, K.R.E., 2008, Designing payments for ecosystem services-Lessons from previous experience with incentive-based mechanisms: Proceedings of the National Academy of Sciences of the United States of America, v. 105, no. 28, p. 9465-9470. [Also available at http://dx.doi.org/10.1073/pnas.0705503104.]

Jain, Siddarth, comp., 2013, Conserving bobolinks in Rhode Island, USA: The Economics of Ecosystems and Biodiversity Web page, accessed July 30, 2015, at http://doc. teebweb.org/wp-content/uploads/2013/04/Conserving-Bobolinks-in-Rhode-Island-USA.pdf.
Kemp, Loni, 2009, Farmer's guide to the Conservation Stewardship Program-Rewarding farmers for how they grow what they grow: Washington, D.C., National Sustainable Agriculture Coalition, 27 p., accessed July 30, 2015, at http://sustainableagriculture.net/wp-content/ uploads/2011/09/NSAC-Farmers-Guide-to-CSP-2011.pdf.

Leopold Center, 2013, Bear Creek Riparian Buffer Project (funding impact brief): Ames, Iowa, Leopold Center for Sustainable Agriculture, no. 5, accessed July 30, 2015, at http://www.leopold.iastate.edu/sites/default/files/pubs-andpapers/2013-06-funding-impact-brief-bear-creek-riparianbuffer-project.pdf.

Loureiro, M.L. and Hine, S.E., 2002, Discovering niche markets: A comparison of consumer willingness to pay for local (Colorado grown), organic, and GMO-free products: Journal of Agricultural and Applied Economics, v. 34, no. 3, p. 477-488. [Also available at http://ageconsearch.umn.edu/ bitstream/15073/1/34030477.pdf.]

Madsen, Becca and Alain Percival, 2010, New pilot registry helps users track conservation credits: Ecosystem Marketplace Web page, accessed August 11, 2015, at http://www. ecosystemmarketplace.com/pages/dynamic/article.page. php?page_id=7546.

Madsen, Becca, Carroll, Nathaniel, and Moore Brands, Kelly, 2010, State of biodiversity markets - Offset and compensation programs worldwide: Washington, D.C., Ecosystem Marketplace, accessed July 30, 2015, at http:/www.foresttrends.org/documents/files/doc_2388.pdf.

Madsen, Becca, Carroll, Nathaniel, Daniel, Kandy, and Bennett, Genevieve, 2011, State of biodiversity markets-Offset and compensation programs worldwide 2011 update: Washington, D.C., Ecosystem Marketplace, accessed July 30, 2015, at http://www.ecosystemmarketplace.com/ reports/2011_update_sbdm.

Mansfield, Edwin, 1979, Price and output under perfect competition in Microeconomics - Theory and applications (reprint, 3rd ed.): New York, Norton. 248-250 p.

Martin, Steve, and Mead, Deblyn, 2014, Role of in-lieu fee programs and conservation banking, presented at the Conservation Banking Training Course, National Conservation Training Center, April 14-18, 2014: Conservation Banking Training Course, Shepherdstown, W. Va., 2014, accessed August, 3, 2015, at http://www.fws.gov/endangered/landowners/conservation-banking.html.

McCann, Laura, Colby, Bonnie, Easter, K.W., Kasterine, Alexander, and Kuperan, K.V., 2005, Transaction cost measurement for evaluating environmental policies: Ecological Economics, v. 52, no. 4, p. 527-542. [Also available at http://dx.doi.org/10.1016/j.ecolecon.2004.08.002.] 
Mercer, D.E., Cooley, David, and Hamilton, Katherine, 2011, Taking stock-Payments for forest ecosystem services in the United States: Washington, D.C., Forest Trends, 49 p., accessed July 30, 2015, at http://www.forest-trends.org/ documents/files/doc_2673.pdf.

Mills, L.S., 2007, Bridging applied population and ecosystem ecology with focal species concepts, chap. 13 in Conservation of wildlife populations-Demography, genetics, and management: Malden, Mass., Blackwell, p. 276-285.

National Wildlife Federation (NWF), 2014, 2014 Farm Bill conference report analysis: National Wildlife Federation Web page, accessed July 30, 2015, at http://www.nwf.org/ / media/PDFs/wildlife/farm\%20\%20bill/NWF-2014-FarmBill-Analysis_final.pdf.

NatureServe, 2013, NatureServe Explorer-An online encyclopedia of life [Web application] (version 7.1) — Vulpes macrotis mutica-Infraspecific taxon record: NatureServe Explorer Web page, accessed July 30, 2015, at http:// explorer.natureserve.org/servlet/NatureServe? searchName= Vulpes + macrotis + mutica.

Nunes, Paulo and Riyanto, Yohanes, 2005, Information as a regulatory instrument to price biodiversity benefits - Certification and ecolabeling policy practices: Biodiversity and Conservation, v. 14 no. 8, p. 2009-2027. [Also available at http://dx.doi.org/10.1007/s10531-004-2529-3.]

Peterson, Hikaru Hanawa, 2005, Trading behavior in a marginal organized market: Journal of Agricultural and Resource Economics v. 30, no. 3, p. 449-468, accessed July 30, 2015, at: http://ageconsearch.umn.edu/bitstream/30981/1/30030449.pdf.

Pigou, A.C., 1920, The economics of welfare: London, Macmillan, $976 \mathrm{p}$.

Prokopy, L.S., Floress, Kristin, Klotthor-Weinkauf, Denise, and Baumgart-Getz, Adam, 2008, Determinants of agricultural best management practice adoption-Evidence from the literature: Journal of Soil and Water Conservation, v. 63 , no. 5, p. 300-311. [Also available at http://dx.doi. org/10.2489/63.5.300.]

Ribaudo, Marc, Hansen, LeRoy, Hellerstein, Daniel, and Greene, Catherine, 2008, The use of markets to increase private investment in environmental stewardship: Economic Research Service Report (ERR), no. 64; 77 p., accessed July 30, 2015, at http://www.ers.usda.gov/publications/erreconomic-research-report/err64.aspx.

Ruhl, J.B., Glen, Alan, and Hartman, David, 2005, A practical guide to habitat conservation banking law and policy: Natural Resources \& Environment, v. 20, no. 1, p. 26-30, accessed July 30, 2015, at http://www.jstor.org/ stable/40924630.
Sage and Columbian Sharp-tailed Grouse Technical Committee, 2009, Prescribed fire as a management tool in Xeric sagebrush ecosystems-Is it worth the risk to sage-grouse?: Wyoming Game and Fish Department Web page, accessed July 30, 2015, at https://wgfd.wyo.gov/WGFD/media/ content/PDF/Habitat/Sage\%20Grouse/SG_PRESCRIBEDBURNING.pdf.

Salmon-Safe, Inc., 2005, Salmon-Safe farm management certification program-Field assessor's guidelines 4.2: Portland, Oreg., Salmon-Safe, accessed July 30, 2015, at http://www. salmonsafe.org/sites/default/files/file/salmonsafe-farmstandards42.pdf.

Salmon-Safe, Inc., 2014, About-Salmon-Safe: Salmon-Safe Web page, accessed July 30, 2015, at https://www.salmonsafe.org/about.

Scarlett, Lynn and Boyd, James, 2011, Ecosystem services - Quantification, policy applications, and current Federal capabilities (discussion paper): Washington, D.C., Resources for the Future, accessed July 30, 2015, at http:// www.rff.org/RFF/Documents/RFF-DP-11-13.pdf.

Smith, Adam, and Cannan, Edwin, ed., 1904, An inquiry into the nature and causes of the wealth of nations: London, Methuen \& Co., 2 v.

Sorice, M.G., Haider, Wolfgang, Conner, Richard, and Ditton, R.B., 2011, Incentive structure of and private landowner participation in an endangered species conservation program: Conservation Biology, v. 25, no. 3, p. 587-596. [Also available at http://dx.doi.org/10.1111/j.1523-1739.2011.01673.x.]

Sorice, M.G., Chi-Ok Oh, Granter, Todd, Snieckus, Mary, Johnson, Rhett, and Donlan, C.J., 2013, Increasing participation in incentive programs for biodiversity conservation: Ecological Applications, v. 23, no. 5, p. 1146-1155. [Also available at http://dx.doi.org/10.1890/12-1878.1.]

Stavins, R.N., 2001, Experience with market-based environmental policy instruments: Washington, D.C., Resources for the future, 88 p., accessed July 30, 2015, at http://www.rff. org/documents/rff-dp-01-58.pdf.

Sullivan, Patrick, Hellerstein, Daniel, Hansen, LeRoy, Johansson, Robert, Koenig, Steven, Lubowski, R.N., McBride, W.D., McGranahan, D.A., Roberts, M.J., Vogel, S.J., and Bucholz, Shawn, 2004, The conservation reserve programEconomic implications for rural America: Washington, D.C., Economic Research Service, U.S. Department of Agriculture, Agricultural Economic Report, no. 834, accessed July 30, 2015, http://dx.doi.org/10.2139/ssrn.614511.

Teisl, M.F. and Roe, Brian, 1998, The economics of labeling: An overview of issues for health and environmental disclosure: Agricultural and Resource Economics Review, v. 27, no. 2, p. 140-150. [Also available at http://ageconsearch. umn.edu/bitstream/31535/1/27020140.pdf.] 
Teisl, M.F., Roe, Brian, and Hicks, R.L., 2002, Can eco-labels tune a market? Evidence from Dolphin-Safe labeling: Journal of Environmental Economics and Management, v. 43, no. 3, p. 339-359. [Also available at http://dx.doi. org/10.1006/jeem.2000.1186.]

The Conservation Fund, 2010a, Case study series-The Orchard Creek conservation bank, The Conservation Fund Web page, accessed July 30, 2015, at http://www.conservationfund.org/images/programs/files/Orchard_Creek.pdf.

The Conservation Fund, 2010b, Case Study Series-The Van Vleck Ranch Mitigation bank, The Conservation Fund Web page, accessed July 30, 2015, at http://www.conservationfund.org/images/programs/files/Van_Vleck_Mitigation_Bank.pdf.

The Natural Resources Agency, 2015, State and federally listed endangered and threatened animals of California: California Department of Fish and Wildlife Web page, accessed July 30, 2015, at http://www.dfg.ca.gov/biogeodata/cnddb/ pdfs/TEAnimals.pdf.

Thurston County Resource Stewardship Department, 2013, Thurston County - Prairie habitat assessment methodology-Protocol (part 1 of 3)—Draft version 1.00: Olympia, Wash., Thurston County Resource Stewardship Department, 33 p. [Also available at http://willamettepartnership.org/ wp-content/uploads/2014/09/Prairie-Habitat-AssessmentMethodology.pdf.]

Tjaden, Bob, Martinez-Cruz, Adán, Wechsler, Seth, and Pritzlaff, Richard, 2013, Ecosystem services on forest and agricultural and of Maryland-A survey of Maryland tree farmers and agricultural landowners: College Park, Md., University of Maryland, accessed July 30, 2015, at http:// www.enst.umd.edu/sites/default/files/_images/uploaded/ Ecosystem_Services_on_Forest_and_Agricultural_Lands_ of_MD_Final_Report.pdf.

Toombs, T.P., 2007, Utah prairie dog habitat evaluation guide: New York, Environmental Defense Fund, 14 p., accessed July 30, 2015, at http://www.nrcs.usda.gov/Internet/FSE_ DOCUMENTS/nrcs141p2_032763.pdf.

U.S. Army Corps of Engineers (USACE), U.S. Environmental Protection Agency, U.S. Natural Resources Conservation Service, U.S. Fish and Wildlife Service and U.S. National Marine Fisheries Service, 1995, Federal guidance for the establishment, use and operation of mitigation banks: Federal Register, v. 60, no. 43, p. 12286-12293. [Also available at http://www.gpo.gov/fdsys/pkg/FR-1995-03-06/pdf/955280.pdf.]

U.S. Army Corps of Engineers (USACE) and U.S. Environmental Protection Agency (U.S. EPA), 2008, Compensatory mitigation for losses of aquatic resources: Federal Register, v. 73, no. 70, p. 19594-19705. [Also available at http:// www.gpo.gov/fdsys/pkg/FR-2008-04-10/pdf/E8-6918.pdf.]
U.S. Army Corp of Engineers (USACE), 2014, Regulatory in-lieu fee and bank information tracking system (RIBITS) Deadman Creek conservation bank profile: U.S. Army Corps of Engineers Web page, accessed July 30, 2015, at https://ribits.usace.army.mil/ribits_apex/ $\mathrm{f} ? \mathrm{p}=107: 10: 16285644158503::$ NO::P10_BANK_ID:2074.

U.S. Army Corp of Engineers (USACE), 2015, Regulatory in-lieu fee and bank information tracking system (RIBITS): U.S. Army Corps of Engineers Web page. [Also available at: https://ribits.usace.army.mil.]

U.S. Department of Agriculture (USDA), 1997, Riparian forest buffer-Conservation practice job sheet: Washington, D.C., Natural Resources Conservation Center, U.S. Department of Agriculture, 4 p., accessed July 30, 2015, at ftp:// ftp.wcc.nrcs.usda.gov/wntsc/strmRest/buffers/RiprarianForestBufferJobSheet.pdf.

U.S. Department of Agriculture (USDA), 2007, Sustainable agriculture-Definitions and terms: National Agricultural Library Web page, accessed July 30, 2015, at http://www. nal.usda.gov/afsic/pubs/terms/srb9902terms.shtml\#term4.

U.S. Department of Agriculture (USDA), 2011a, Natural resources credit trading reference: Washington, D.C., Natural Resources Conservation Service, U.S. Department of Agriculture, 79 p., accessed July 30, 2015, at http:// www.nrcs.usda.gov/Internet/FSE_DOCUMENTS/stelprdb1045650.pdf.

U.S. Department of Agriculture, (USDA) 2011b, USDA issues conservation reserve program rental payments to help safeguard soil and water on 417,000 farms (news release): U.S. Department of Agriculture's Farm Service Agency Web page, accessed July 30, 2015, at http://www.fsa.usda. gov/FSA/newsReleases?area=newsroom\&subject=land ing\&topic $=$ ner\&newstype $=$ newsrel $\&$ type $=$ detail\&item $=$ nr_20111006_rel_0134.html.

U.S. Department of Agriculture (USDA), 2012a, Farm Service Agency, Conservation Reserve Program-Soil rental rates [Farm Service Agency response to audit attached]: Washington, D.C., Office of Inspector General, U.S. Department of Agriculture, [variously paged]accessed July 30, 2015, at http://www.usda.gov/oig/webdocs/03601-0051-Te.pdf.

U.S. Department of Agriculture (USDA), 2012b, Working lands for wildlife questions and answers: Natural Resource Conservation Service, U.S. Department of Agriculture Web page, accessed July 30, 2015, at http://www.nrcs.usda.gov/ Internet/FSE_DOCUMENTS/stelprdb1048825.pdf.

U.S. Department of Agriculture (USDA), 2013a, Conservation reserve program: Farm Service Agency, U.S. Department of Agriculture Fact Sheet (Feb. 2013), accessed July 30, 2015, at https://www.fsa.usda.gov/Internet/FSA_File/crpfactsheet0213.pdf. 
U.S. Department of Agriculture (USDA), 2013b, Sage-Grouse Initiative-Conservation beyond boundaries SGI-2012 Progress report: Washington, D.C., Natural Resources Conservation Service, U.S. Department of Agriculture, 4 p., accessed July 30, 2015, at http://www.nrcs.usda.gov/Internet/FSE_DOCUMENTS/stelprdb1167827.pdf.

U.S. Department of Agriculture (USDA), 2014a, ACEPAgricultural conservation easement program: Natural Resource Conservation Service, U.S. Department of Agriculture Web page, accessed July 30, 2015, at http://www. nrcs.usda.gov/wps/portal/nrcs/main/national/programs/easements/acep/.

U.S. Department of Agriculture (USDA), 2014b, Animal enhancement activity-ANM33-Riparian buffer, terrestrial and aquatic wildlife habitat (2014 ranking period 1): Natural Resource Conservation Service, U.S. Department of Agriculture, accessed July 30, 2015, at http://www.nrcs.usda. gov/Internet/FSE_DOCUMENTS/stelprdb1240368.pdf.

U.S. Department of Agriculture (USDA), 2014c, CSP—Conservation Stewardship Program: Natural Resources Conservation Service, U.S. Department of Agriculture Web page, accessed July 30, 2015, at http://www.nrcs.usda.gov/wps/ portal/nrcs/main/national/programs/financial/csp/.

U.S. Department of Agriculture (USDA), 2014d, 2014 Farm Bill-Environmental quality incentives program-EQIP: Natural Resources Conservation Service, U.S. Department of Agriculture Web page, accessed July 30, 2015, at http:// www.nrcs.usda.gov/wps/portal/nrcs/detail/national/programs/financial/eqip/?cid=stelprdb1242633.

U.S. Department of Agriculture (USDA), 2014e, Strengthening conservation with Regional Partnership: Natural Resources Conservation Service, U.S. Department of Agriculture Web page, accessed July 30, 2015, at http://www. nrcs.usda.gov/wps/PA_NRCSConsumption/download?cid=s telprdb1252536\&ext=pdf.

U.S. Department of Agriculture (USDA), [n.d.], Environmental quality incentives program: Catalog of Federal domestic assistance Web page, accessed July 30, 2015, at https:// www.cfda.gov/index?s=program \&mode $=$ form $\&$ tab $=$ core $\& \mathrm{i}$ $d=d 3 b 37 b 7$ fea938aa4995886019b69ff32.

U.S. Department of the Interior, (DOI) 2013a, A preliminary analysis of the conservation banking program and results from a survey of the USFWS staff: Washington D.C., Office of Policy Analysis, U.S. Department of the Interior, (Sept.), $66 \mathrm{p}$. [Also available at http://www.fws.gov/endangered/ landowners/pdf/CB\%20Report\%20DOI_Final_Sept2013. pdf.]

U.S. Department of the Interior, (DOI) 2013b, Conservation banking overview and suggested areas for future analysis: Washington D.C., Office of Policy Analysis, U.S. Department of the Interior, (Sept.), 16 p. [Also available at http://
www.fws.gov/endangered/landowners/pdf/Conservation\%20Banking\%20Overview\%20DOI-Sept2013.pdf.]

U.S. Endowment for Forestry and Communities, 2008, Forest conservation easements-Who's keeping track?: Greenville, S.C., U.S. Endowment for Forestry and Communities, 12 p., accessed July 30, 2015, at http://www.usendowment.org/ images/Forest_Conservation_Easements_2_.pdf.

U.S. Environmental Protection Agency (EPA), 2001, Functions and values of wetlands: Washington, D.C., Office of Wetlands, Oceans and Watersheds, 2 p., accessed July 30, 2015, at http://water.epa.gov/type/wetlands/outreach/ upload/fun_val_pr.pdf.

U.S. Environmental Protection Agency (EPA), 2010, Guidelines for preparing economic analysis (May 2014 update): Washington, D.C., 300 p., accessed July 30, 2015, at http:// yosemite.epa.gov/ee/epa/eerm.nsf/vwAN/EE-0568-50. pdf/\$file/EE-0568-50.pdf.

U.S. Fish and Wildlife Service (FWS) and National Oceanic and Atmospheric Administration (NOAA), 1999, Announcement of final Safe Harbor policy: Federal Register, v. 64, no. 116, p. 32717-32726. [Also available at http:// www.gpo.gov/fdsys/pkg/FR-1999-06-17/pdf/99-15256.pdf.]

U.S. Fish and Wildlife Service (FWS), 2003, Guidance for the establishment, use, and operation of conservation banks: Washington, D.C., U.S. Fish and Wildlife Service, 18 p., accessed July 30, 2015, at http://www.fws.gov/endangered/ esa-library/pdf/Conservation_Banking_Guidance.pdf.

U.S. Fish and Wildlife Service (FWS), 2005a, Why save endangered species?: Arlington, Va., Endangered Species Program, U.S. Fish and Wildlife Service, accessed July 30, 2015, at http://www.fws.gov/nativeamerican/pdf/why-saveendangered-species.pdf.

U.S. Fish and Wildlife Service(FWS), 2005b, Working together-Tools for helping imperiled wildlife on private lands: Washington, D.C., U.S. Fish and Wildlife Service, accessed July 30, 2015, at http://www.fws.gov/endangered/ esa-library/pdf/ImperiledWildlifeFinalDec2005.pdf.

U.S. Fish and Wildlife Service (FWS), 2006, Draft recovery plan for listed species of the Rogue Valley Vernal Pool and Illinois Valley Wet Meadow ecosystems: Portland, Oreg., Region 1 -U.S. Fish and Wildlife Service, 152 p. [Also available at https://www.fws.gov/oregonfwo/FieldOffices/Roseburg/VernalPools/Documents/DraftRecoveryPlanForRogueValleyVPAndIllinoisValleyWetMeadowEcosyststems.pdf.]

U.S. Fish and Wildlife Service (FWS), 2007, Vernal pool fairy shrimp (Branchinecta lynchi) 5-year review-Summary and evaluation: Sacramento, Calif., Sacramento Fish and Wildlife Office, U.S. Fish and Wildlife Service, 74 p. [Also available at http://www.fws.gov/cno/es/images/Graphics/VPFS_5yr\%20review\%20CNO\%20FINAL\%2027Sept07.pdf.] 
U.S. Fish and Wildlife Service (FWS), 2010, Mitigation banking proposal procedures with a section on Instructions for bank sponsors (checklists draft prospectus - draft BEI) (Sept. 2010) [Microsoft Word Document]: Sacramento Fish and Wildlife Office Web page, accessed July 30, 2015, at https://www.fws.gov/sacramento/es/Conservation-Banking/ Home/es_conse-banking.htm.

U.S. Fish and Wildlife Service (FWS), 2011a, Partners for Fish and Wildlife Program-Program history: U.S. Fish and Wildlife Service Web page, accessed July 30, 2015, at http://www.fws.gov/partners/programHistory.html.

U.S. Fish and Wildlife Service (FWS), 2011b, Safe Harbor agreements for private landowners: Arlington, Va., Endangered Species Program, U.S. Fish and Wildlife Service, accessed July 30, 2015, at http://www.fws.gov/endangered/ esa-library/pdf/harborqa.pdf.

U.S. Fish and Wildlife Service (FWS), 2013, Endangered species-Glossary: U.S. Fish and Wildlife Services Web page, accessed July 30, 2015, at http://www.fws.gov/Midwest/ Endangered/glossary/index.html.

U.S. Fish and Wildlife Service (FWS), 2014, Environmental conservation online system-Summary of listed species listed populations and recovery plans as of Thu, $10 \mathrm{Jul}$ 2014 [time] 17-41-40 GMT: U.S. Fish and Wildlife Service Web page, accessed July 10, 2014, at http://ecos.fws.gov/ tess_public/pub/boxScore.jsp.

U.S. Fish and Wildlife Service (FWS), 2014, Draft agreement habitat exchange agreement for the lesser prairie-chicken (draft): Washington, D.C., U.S. Fish and Wildlife Service, 46 p., accessed July 30, 2015, at http://www.thehabitatexchange.org/files/2014/05/Habitat-Exchange-Agreement May-2014.pdf.

U.S. Fish and Wildlife Service (FWS), [n.d.], Little known but important features of the Endangered Species Act: Pacific Region U.S. Fish and Wildlife Service Web page, accessed July 30, 2015, at http://www.fws.gov/pacific/news/grizzly/ esafacts.htm.

U.S. Forest Service (USFS), 2003, Forest legacy program implementation guidelines: Washington, D.C., Forest Service, U.S. Department of Agriculture, 44 p., accessed July 30, 2015, at http://www.fs.fed.us/spf/coop/library/fpl_guidelines.pdf.

U.S. Forest Service (USFS), 2013, Forest legacy programProtecting private forest lands from conversion to nonforest uses: Forest Service, U.S. Department of Agriculture Web page, accessed July 30, 2015, at http://www.fs.fed.us/ spf/coop/programs/loa/aboutflp.shtml.

U.S. Forest Service (USFS), 2014, Managing wildland firesPrescribed fire-Fire and Aviation Management Program: Forest Service, U.S. Department of Agriculture Web page, accessed July 30, 2015, at http://www.fs.fed.us/fire/management/rx.html.

U.S. Government Accountability Office (GAO), 2005, Wetlands protection-Corps of Engineers does not have an effective oversight approach to ensure that compensatory mitigation is occurring-Report to the ranking Democratic member, Committee on Transportation and Infrastructure, House of Representatives: Washington, D.C., U.S. Government Accountability Office, no. GAO-05-898. [Also available at http://www.gao.gov/assets/250/247675.pdf.]

Vickerman, Sara and Kagan J.S., 2014, Assessing ecological integrity across jurisdictions and scales: Washington, D.C., Defenders of Wildlife, 38 p. [Also available at http://www. defenders.org/sites/default/files/publications/assessing-ecological-integrity-across-jurisdictions-and-scales.pdf.]

Virginia Department of Environmental Quality (VDEQ), 2008, Trading nutrient reductions from nonpoint source best management practices in the Chesapeake Bay WatershedGuidance for agricultural landowners and your potential trading partners: Richmond, Va., Virginia Department of Environmental Quality, accessed July 30, 2015, at http:// www.deq.virginia.gov/Portals/0/DEQ/Water/PollutionDischargeElimination/VANPSTradingManual_2-5-08.pdf.

Wagner, K.K., Schmidt, R.H., and Conover M.R., 1997, Compensation programs for wildlife damage in North America: Wildlife Society Bulletin, v. 25, no. 2, p. 312-319. [Also available at http://digitalcommons.unl.edu/cgi/viewcontent. cgi?article $=1826 \&$ context $=$ icwdm_usdanwrc.]

Wade, D.D., and Lundsford, James, 1986, Fire as a forest management tool-Prescribed burning in the southern United States: Woodland Steward Series Web page, accessed July 30, 2015, at http://www.woodlandstewardseries.com/ landowner-information-for-managing-woodland/documents/ Fireasaforestrytool.pdf.

Wheeler, D.P., and Strock, J.M., 1996, Official policy on conservation banks (modified 2007): Sacramento, Calif., California Resources Agency, accessed July 30, 2015, at http:// www.californiawetlands.net/static/documents/1995\%20 Policy\%20on\%20Conservation\%20Banks.pdf.

Wildlands, Inc., 2008, Deadman Creek conservation bank greement-Wildlands, Inc., agreement with Sacramento, CA, Fish and Wildlife Service field office: Markit Group Limited Web page, accessed July 30, 2015, at https://products.markit.com/br-reg/PublicReport.action?getDocumentB yId=true\&document_id=100000000006693.

Willamette Partnership, 2009, Ecosystem credit accountingPilot general crediting protocol-Willamette Basin version 1.1: Portland, Oreg., Willamette Partnership, 39 p., accessed July 30, 2015, at http://willamettepartnership.ecosystemcredits.org/docs/General_Crediting_Protocol_1.1.pdf. 
Willamette Partnership, 2011, Measuring up-Synchronizing biodiversity measurement systems for markets and other incentive programs-Sponsored by the USDA Office of Environmental Markets: Portland, Oreg., Willamette Partnership, [variously paged]. [Also available at http:// willamettepartnership.org/wp-content/uploads/2015/04/ Measuring-Up-w-appendices-final.pdf.]

Willamette Partnership, 2013, Willamette Partnership ecosystem credit accounting system-General crediting protocol version 2.0-November 1, 2013: Portland, Oreg., Willamette Partnership, 87 p., accessed July 30, 2015, at http://willamettepartnership.org/wp-
content/uploads/2014/06/General-Crediting-Protocolv2.0_2013-11-01_Final.pdf.

Willamette Partnership, 2014, Prairie habitat quality calculator V2.0 user guide: Portland, Oreg., Willamette Partnership, 14 p., accessed July 30, 2015, at http://willamettepartnership. org/wp-content/uploads/2015/02/Upland-Prairie-HabitatQuality-Calculator-v2.0_USER-GUIDE.pdf.

Wunder, Sven, 2007, The Efficiency of payments for environmental services in tropical conservation: Conservation Biology, v. 21, no. 1, p. 48-58. [Also available at http://dx.doi. $\operatorname{org} / 10.1111 / \mathrm{j} .1523-1739.2006 .00559 . x$. 
For more information concerning this publication, contact:
Emily Pindilli, Economist
Science and Decisions Center
U.S. Geological Survey
913 National Center
12201 Sunrise Valley Drive
Reston, VA 20192
epindilli@usgs.gov
http://www.usgs.gov/sdc/

Publishing support provided by the USGS Science Publishing Network Publishing Service Centers (PSC)

Editing by Stokely Klasovsky, Raleigh PSC

Illustrations and layout by Jeannette M. Foltz, Reston PSC

Illustrations by Caryl Wipperfurth, Raleigh PSC

Web support by Angela E. Hall, Reston PSC 
